\title{
Secretome Proteins as Candidate Biomarkers for Aggressive Thyroid Carcinomas
}

by

\author{
Seham Chaker
}

A thesis submitted in conformity with the requirements for the degree of Master of Science

Institute of Medical Science

University of Toronto

(C) Copyright by Seham Chaker (2012) 


\title{
Secretome Proteins as Candidate Biomarkers for Aggressive Thyroid Carcinomas
}

\author{
Seham Chaker \\ Master of Science \\ Institute of Medical Science \\ University of Toronto
}

2012

\section{Abstract}

Using secretome proteomics and bioinformatics, analyses of non-aggressive and aggressive thyroid carcinoma (TC) cell lines revealed nine proteins as potential biomarkers for detection of aggressive TCs. Of these, APP, APLP2, AXL, PKM2, 14-3-3 zeta and SET were detected in patients' sera by western blotting and showed significant differences in subcellular expression in benign and malignant tissues using immunohistochemistry (IHC). Membrane and cytoplasmic ALCAM expression was reduced in patients with poorly/undifferentiated (aggressive) TC compared to well-differentiated (non-aggressive) TC $(p<0.001, \mathrm{AUC}=0.865$, sensitivity $=82 \%$, specificity $=74 \%$ ) as analyzed by IHC in $158 \mathrm{TCs}$ and 45 benign nodules Kaplan-Meier survival analysis revealed reduced disease-free survival for TC patients with lower ALCAM expression (median survival 7.3 years compared to 13.5 years for patients with higher expression, $\mathrm{p}=0.002)$. ALCAM sera levels were elevated in aggressive versus nonaggressive TC patients ( $\mathrm{p}=0.04)$, as measured by ELISA. ALCAM may potentially serve as a useful diagnostic and prognostic marker for aggressive TC. 


\section{Acknowledgments/Contributions}

I would like to give special thanks to my supervisor Dr. Paul G. Walfish for giving me this wonderful opportunity to participate in thyroid cancer research. This experience has been truly rewarding and enriched with his great support and expertise in the field. I would also like to thank my program advisory committee for sharing their expertise and advise for the successful completion of the project. I am very grateful for the mentorship and guidance I have received from Dr. Ranju Ralhan and for the countless hours spent co-supervising my work. I would like to extend my gratitude to Dr. Christina MacMillan for teaching me thyroid pathology and for reviewing patient tissues used for experimentation. I would also like to thank Dr. Ian Witterick and Dr. Jonathan Irish for advising and helping me to ensure the project meets its goals.

I would also like to acknowledge the contributions of my fellow lab members and researchers. Many thanks to Lawrence Kashat for carrying out the cell culturing work used in this study and for his contributions that have allowed us to reach our goals. I would like to thank Dr. K.W. Michael Siu and Dr. Sebastien Voisin of York University for conducting the mass spectrometry analysis. I appreciate Dr. Ipshita Kak's efforts in creating all of the clinical databases necessary for the completion of this project and for co-scoring immunostained slides. I would like to thank Dr. Hilmi Ozcelik for helping with the bioinformatics network analysis and also Marianne of Special Histology, Mount Sinai Hospital for allowing me to use Visiopharm imaging system for microscopy. I am truly grateful for the kind support and friendship I have received from Dr. Jatinder Kaur, Dr. Helen He, Dr. Tada Kunavisarut, Dr. Jasmeet Assi, Dr. Ajay Matta, and Dr. Gunjan Srivastava. 
The financial support of this work is gratefully acknowledged from Mount Sinai Foundation of Toronto, Da Vinci Gala Fundraiser, Ontario Graduate Scholarship, Alex and Simona Shnaider Chair in Thyroid Cancer, The Joseph and Mildred Sonshine Family Centre for Head and Neck Disease at Mount Sinai Hospital, George Knudson Oakdale Pro-Am Charity Golf Tournament, and the Mount Sinai Hospital Department of Medicine Research Fund. 


\section{Table of Contents}

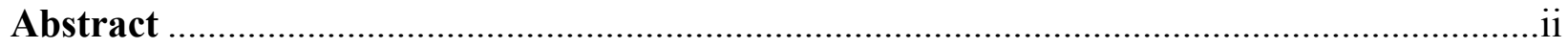

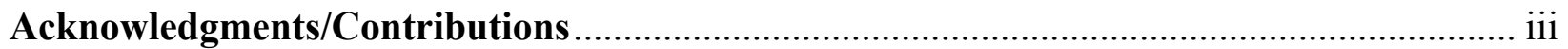

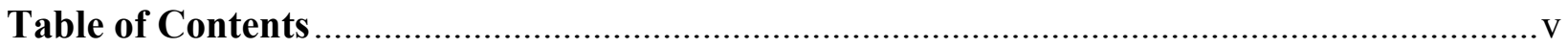

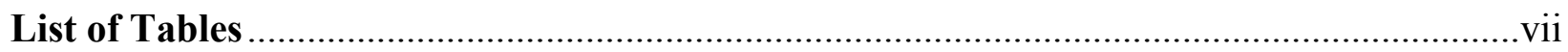

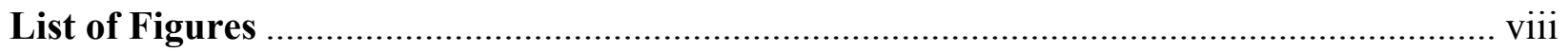

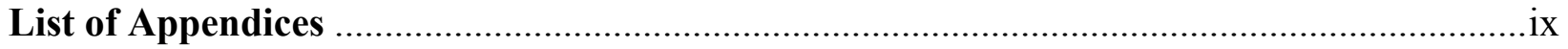

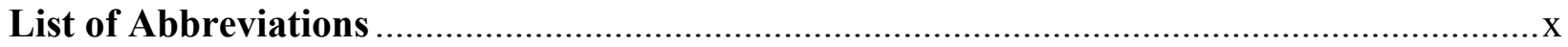

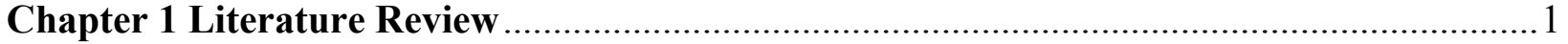



1.1 Thyroid Carcinoma - Overview ….................................................................. 1

1.2 Subtypes of Thyroid Carcinoma ..............................................................................

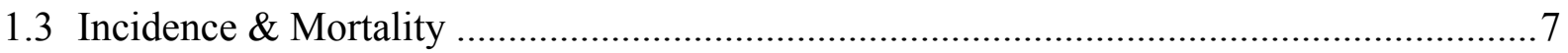

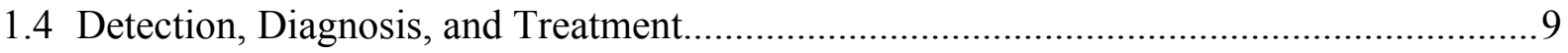

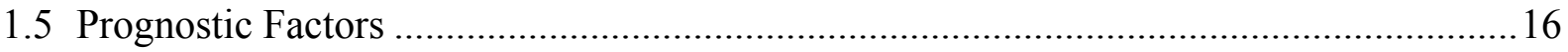

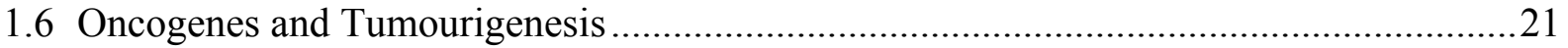



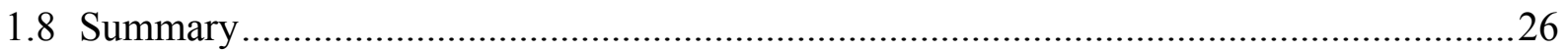

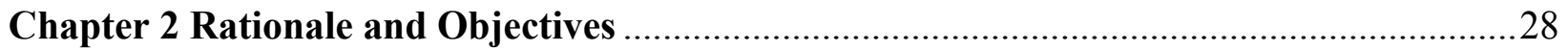

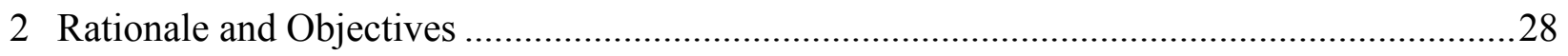

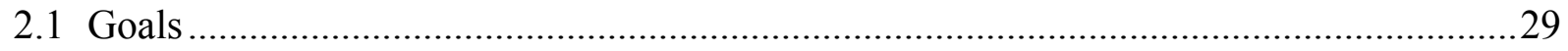

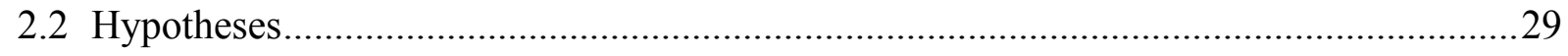

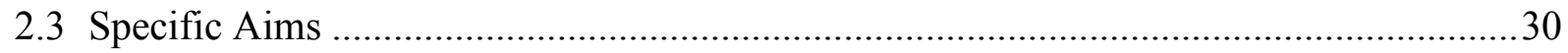


Chapter 3 Methods

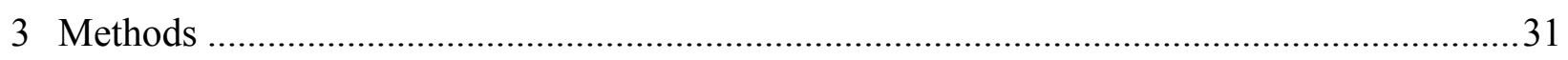

3.1 General Schematic ....................................................................................................





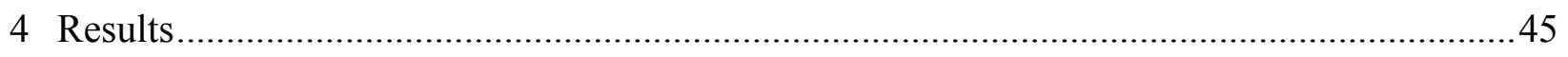



4.2 Detection of Secretome Proteins in Human Sera by Western Blots....................................49

4.3 Immunohistochemical Analysis of Identified Proteins in Human Thyroid Tissues..........51

4.4 Comparison of Serum ALCAM and AXL levels Between Benign, Non-Aggressive,

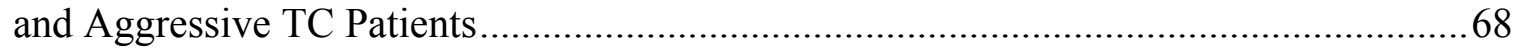

Chapter 5 Discussion, Conclusions, Future Directions ……………………………..............

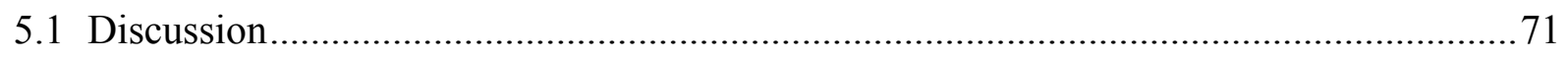

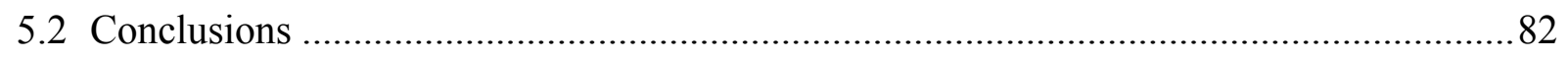

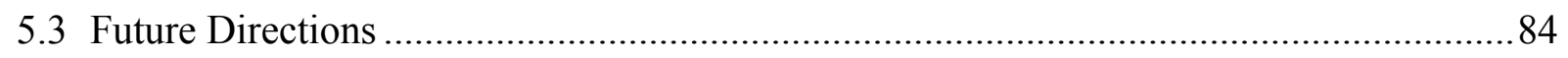

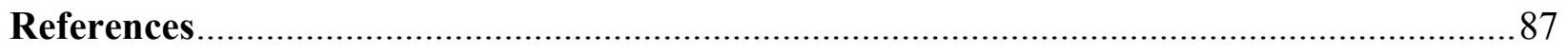

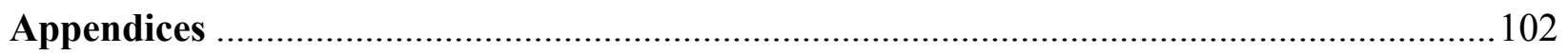




\section{List of Tables}

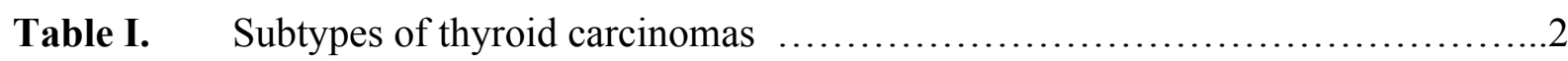

Table II. Thyroid cancer incidence and mortality by age in the United States............8

Table III. AJCC thyroid cancer TNM staging system.............................. 12

Table IV. Clinical trial agents for thyroid cancer patients...........................25

Table V. Immunohistochemical analysis of secretome proteins in benign versus

malignant thyroid tissues.........................................57

Table VI. Analysis of ALCAM expression with clinical and pathological characteristics...................................................59

Table VII. Receiver operating curve analysis of ALCAM expression in association with



Table VIII. Correlation of ALCAM and AXL sera levels with clinico-pathological characteristics. 


\section{List of Figures}

Figure 1. Schematic of experimental workflow......................................... 32

Figure 2. Ingenuity Pathway Analysis reveals several important protein-protein interactions of identified secretome proteins.

Figure 3. Identified secretome proteins are detected in benign and thyroid cancer patients' sera using western blot analysis 50

Figure 4. Immunostaining of proteins in human benign and thyroid cancer tissues shows differences in subcellular localization.

Figure 5. Scatterplot analysis for immunohistochemical (IHC) scores of proteins in thyroid tissues.

Figure 6. Immunostaining of ALCAM shows different expression between benign, non-aggressive, and aggressive human thyroid cancer tissues.

Figure 7. ALCAM expression is decreased in poorly/undifferentiated thyroid cancer tissues

Figure 8. Decreased ALCAM expression is associated with reduced patient diseasefree survival

Figure 9. ALCAM and AXL expression in thyroid cancer patient sera using enzymelinked immunosorbent assay. 


\section{List of Appendices}

Appendix I. Summary of high-confidence proteins in BCPAP, C643, and SW1736 thyroid cancer cell lines identified by mass spectrometry at York University

Appendix II. MS/MS spectra of the identified peptides at York University ..............103

Appendix III. Representative control Ponceau S stained immunoblot.....................123

Appendix IV. Outline of patient clinical information for tissues used for immunohistochemistry

Appendix V. Receiver operating curve analyses of protein expression in benign versus malignant thyroid tissues.

Appendix VI. Detailed analyses of protein expression in benign versus malignant thyroid tissues.

Appendix VII. Combined ALCAM and AXL sera expression in relation to clinico-pathological parameters using ELISA 


\section{List of Abbreviations}

ADAM - a disintegrin and metalloproteinase

ALCAM - activated leukocyte cell adhesion molecule

APP - amyloid beta A4 protein

APLP2 - amyloid-like protein 2

ATCC - American Type Culture Collection

AJCC - American Joint Committee on Cancer

ATC - anaplastic thyroid carcinoma

ATP - adenosine triphosphate

AUC - area-under-curve

AXL - tyrosine protein kinase receptor UFO

BRAF - B-raf proto-oncogene

CI - confidence interval

$\mathrm{CM}$ - conditioned media

CCS - Canadian Cancer Statistics

DSMZ - German Collection of Microorganisms and Cell Culture

DTC - differentiated thyroid carcinoma

ELISA - enzyme-linked immunosorbent assay

EGFR - epidermal growth factor receptor

EMT - epithelial-mesenchymal transition

FFPE - formalin-fixed paraffin-embedded

FNAB - fine needle aspiration biopsy

FTC - follicular thyroid carcinoma

FVPTC - follicular variant papillary thyroid carcinoma

hnRNP K - heterogeneous nuclear ribonucleoprotein K

HR - hazard ratio

IPA - Ingenuity Pathway Analysis

LC-MS/MS - liquid chromatography-tandem mass spectrometry

L1CAM - L1 cell adhesion molecule

MAPK - mitogen-activated protein kinase

MLNR - metastatic lymph node ratio

MNG - multinodular goiter

MSH - Mount Sinai Hospital

MTC - medullary thyroid carcinoma

NCI - National Cancer Institute

NFGR - nerve growth factor receptor

NIS - sodium-iodide symporter

NPV - negative predictive value

OR - odds ratio

PDPTC - poorly-differentiated papillary thyroid carcinoma

PGK1 - phosphoglycerate kinase 1

PI3K - phosphatidylinositol 3'-kinase

PKM2 - pyruvate kinase muscle isozyme M2

PTC - papillary thyroid carcinoma 
RAI $\left(I^{131}\right)$ - radioactive iodine

RAS - rat sarcoma viral oncogene

REB - Research Ethics Board

RECIST - Response Evaluation Criteria in Solid Tumors

rhTSH - recombinant human thyroid stimulating hormone

RRA - radioactive remnant ablation

ROC - receiver operating characteristic

SEER - Surveillance Epidemiology and End Results

SET - phosphatase 2A inhibitor

SD - standard deviation

$\mathrm{T}_{3}$ - triiodothyronine

TACE - tumour necrosis factor $\alpha$ converting enzyme

TC - thyroid carcinoma

$\mathrm{Tg}$ - thyroglobulin

TGF- $\beta$ - transforming growth factor $\beta$

TNM - tumour, lymph nodes, metastasis

TSH - thyroid stimulating hormone

VEGF - vascular endothelial growth factor

VEGFR - vascular endothelial growth factor receptor 


\section{Chapter 1 Literature Review}

\section{Introduction \\ 1.1 Thyroid Carcinoma - Overview}

Thyroid carcinoma (TC) is the most prevalent malignancy of the endocrine system (1, 2). The estimated new TC cases and deaths in the United States in 2012 are 56,460 and 1,780, respectively (National Cancer Institute statistics 2012; http://www.cancer.gov/statistics). 80\% $85 \%$ of all TCs are well-differentiated papillary thyroid carcinoma (PTC), with overall 10-year survival rates more than $95 \%$, even with the presence of lymph node metastasis $(1,3) .10 \%$ $15 \%$ of patients with differentiated thyroid carcinoma (DTC) present with or will develop distant metastases (4). In this set of patients, the 10-year survival rate drops to approximately $40 \%(3,5)$. However, anaplastic thyroid carcinoma (ATC) is among the most aggressive and deadly cancers known, with a median survival of less than 6 months, although it accounts for only $2 \%$ of all thyroid tumours $(6,7)$. Thus, even though TCs generally have an impressive survival rate, there exists a subset of aggressive and poorly or undifferentiated thyroid tumours that account for the majority of the deaths attributed to this malignancy (3). Follicular thyroid carcinoma (FTC), ATC, PTC, and Hürthle cell carcinomas (an FTC variant) consist of tumours originating from thyroid follicular cells, whereas medullary thyroid carcinoma (MTC), a calcitonin-secreting tumour, originates from thyroid C cells. Although there are some common forms of treatment between TC subgroups, there lie critical differences in therapeutic intervention according to the tumour type. The differentiation between aggressive and non- 
aggressive tumours, therefore, becomes vitally important for long-term management of TC patients and presents an unanswered question for translational cancer research.

\subsection{Subtypes of Thyroid Carcinoma}

Different subtypes of TC include papillary, follicular, medullary, and anaplastic TC. The percentage distribution of TC tumour types, 10-year survival, and deaths according to a study of 53, 856 patients are listed in Table I (2). There are 15 histological variants of PTC, some of which will be described in more detail.

\section{TABLE I}

Subtypes of thyroid carcinomas

\begin{tabular}{lccc}
\hline Tumour Type & $\begin{array}{c}\text { \% Of all } \\
\text { TC }\end{array}$ & $\begin{array}{c}\text { 10-year relative } \\
\text { survival (\%) }\end{array}$ & $\begin{array}{c}\text { Deaths by } \\
\text { Tumour Type } \\
\text { (\%) }\end{array}$ \\
\hline Papillary $^{1}$ & 79 & 93 & 53 \\
Follicular & 13 & 85 & 18 \\
Hürthle (FTC variant) & 2 & 76 & 7 \\
Medullary & 4 & 75 & 9 \\
Anaplastic & 2 & 14 & 14 \\
\hline
\end{tabular}

Table adapted from Sipos et al. (2)

1 - Papillary TC variants include: follicular, macrofollicular, tall cell, columnar cell, clear cell, oncocytic (Hürthle) cell, diffuse sclerosing, cribriform, solid, PTC with insular pattern, PTC with mucoepidermoid carcinoma, PTC with focal anaplastic spindle and giant cell carcinoma, PTC with medullary carcinoma, and PTC with fasciitis or fibromatosis-like stroma (8).

\section{Papillary Thyroid Carcinoma}

PTC often presents as a thyroid nodule ranging in size from 1 centimeter or less (microcarcinoma) to several centimeters in diameter, and often may be in the background of a 
multinodular goiter (MNG) (9). The primary tumour can be a combination of solid and cystic, or just solid, but rarely completely cystic. The diagnosis of PTC is based on the nuclear characteristics of the tumour, such as having an irregular "raisin-like" nuclear membrane that is usually oval, not round (9). As well, PTCs appear to have powdery to clear chromatin (“Orphan Annie eye nuclei"), nuclear overlapping, small nucleoli, nuclear grooves and sometimes nuclear pseudoinclusions (9). The papillary structures of the classic PTC are complex and typically appear as "finger-like" projections. There are several histological variants of PTC, some of which have been described as being biologically more aggressive than classic PTC, such as the tall cell variant, diffuse sclerosing variant, columnar cell variant, and the follicular variant.

\section{Follicular Variant PTC}

The follicular variant PTC (FVPTC) is the most common variant of PTC, following classic PTC. FVPTC has the same characteristic nuclear features of classic PTC but has a follicular rather than papillary architecture $(9,10)$. FVPTCs are often difficult to diagnose because of the cytological similarity to follicular adenomas (11). FVPTCs were believed to behave in a similar clinical manner as classic PTC, however, recent studies have suggested otherwise (10-12). Gupta et al. reported that it is important to understand the differences in the subtypes of FVPTC because they have clinical and genotypic differences that could account for the more aggressive behaviour of the tumour (11). They report that diffuse FVPTC has a higher rate of central lymph node metastasis and B-raf proto-oncogene (BRAF) mutation than the encapsulated and non-encapsulated FVPTC (11). Oncogenes are discussed in section 1.6. 


\section{Tall Cell Variant PTC}

This variant is associated with higher recurrence rates and poorer prognosis, and usually presents in older males (9). The histology of these tumours is characterized by at least $50 \%$ cells with granular eosinophilic cytoplasm and a height twice that of the width $(9,13,14)$. This tumour is often accompanied by vascular and extrathyroidal extension (9). A study showed that regardless of tumour size, age, sex, and confinement of the tumour to the thyroid, this variant shows a higher rate of lymph node and distant metastasis compared to classic PTC (14). The presence of BRAF mutation in tall cell variants could account for this increase in tumour aggressiveness (13).

\section{Oncocytic (Hürthle cell) Variant PTC}

The oncocytic (Hürthle cell, or oxyphilic) variant of PTC is comprised of large polygonal cells, nuclear features characteristic of PTC with prominent central nucleoli, and granular eosinophilic cytoplasm (9). The abundant mitochondria within the cytoplasm give an eosinophilic granularity (9). The clinical behaviour of this variant is believed to be similar to that of classic PTC. This variant should not be confused with the Hürthle cell carcinoma, which is a type of FTC that shows focal papillary architecture and presents with a more aggressive clinical course (15).

\section{Diffuse Sclerosing Variant PTC}

The diffuse sclerosing variant of PTC is described as having diffuse involvement of both thyroid lobes without the formation of a localized mass, though, in about $50 \%$ of the cases, a dominant nodule is present in one of the thyroid lobes (15). The tumour often arises in 
the background of lymphocytic thyroiditis and is characterized as having abundant psammoma bodies, diffuse stromal fibrosis, dense lymphoid infiltration, extensive squamous metaplasia, and nuclei similar to classic PTC $(9,15)$. Most patients are young adult females, though there are also cases reported in young children and adolescents (15). These tumours show a more aggressive behaviour compared to classic PTC; they have higher lymph node and pulmonary metastases, however, there is no increase in mortality for this group $(9,15)$.

\section{Columnar Cell Variant PTC}

The columnar cell variant is an infrequent variant of PTC that demonstrates more aggressive behaviour involving extrathyroidal extension (9). The majority of this type of tumour consists of pseudostratified columnar cells with elongated hyperchromatic nuclei, as well as supra- and subnuclear cytoplasmic vacuoles, while the nuclear features of classic PTC are less apparent in this variant (9). The encapsulated form does not metastasize, or shows low metastatic potential; however, the unencapsulated form of this variant displays the more aggressive behaviour (15).

\section{Papillary Carcinoma with Insular Pattern}

The histological appearance of PTC with insular pattern consists of the presence of well-defined nests of tumour cells with scant cytoplasm and dark, round, monomorphic nuclei, cytologic uniformity, hypercellularity, and scant colloid (16). These tumours are typically greater than four centimeters in size and have a high nuclear to cytoplasmic ratio with the absence of nuclear grooves and intranuclear inclusions that are generally seen in classic PTC (16). This variant is a more aggressive variant of PTC, often debated whether they should be 
labelled as a poorly-differentiated form of PTC because they can still uptake radioactive iodine (RAI, $\mathrm{I}^{131}$ ), a process that does not occur in poorly or undifferentiated TCs. A study by Rufini et al. studied two groups of this insular variant, one group being predominantly insular $(>50 \%$ of tumour), while the other a focal insular variant ( $<50 \%$ of tumour), and they showed that only 4 of 9 (44\%) of the former group had the ability for I ${ }^{131}$ uptake, while 1 of 2 in the second group could uptake $I^{131}(17)$. As well, they showed that the predominantly insular group was associated with aggressive features such as extrathyroidal extension, lymph node metastasis, distant metastasis, and a poor prognosis (17). Therefore, their histological and biological behaviour deem them to be in the middle of PTC and ATC in aggressiveness and require more aggressive treatment.

\section{Anaplastic Thyroid Carcinoma (ATC)}

In ATC, there are no features of differentiated tissue, but rather the tumour is extensively infiltrative and is characterized by atypical cells, either spindle, epithelioid, squamoid, giant, or osteoclast-like giant cells with abundant atypical mitotic figures, and multinucleated cells $(1,18)$. The spindle cell variants are sometimes arranged in fascicles to resemble sarcoma, while at other times are arranged to resemble fibrous histiocytoma (6). The giant cell variant is more pleomorphic and has numerous tumour giant cells, whereas the squamoid type is characterized as having irregular configuration and abundant cytoplasm (6). These variants are described as having tan white fleshy large tumours with large areas of hemorrhage, high mitotic activity, necrosis, marked invasiveness, and a low rate of apoptosis (19). It is suggested that well-differentiated TCs may progress towards ATC through dedifferentiation of insular variants of PTC or FTC and altered expression of p53 (6). This is 
further supported by a finding that differentiated TC regions co-exist in up to $90 \%$ of ATCs (6).

Although ATC is rare with an age-adjusted annual incidence of 2 per million/year (20), its lethality is highlighted by the finding that of approximately 1,200 thyroid carcinoma deaths in the USA in 2006 , over $50 \%$ were due to ATC despite accounting for only $2 \%$ of all thyroid carcinomas (18). Histologic appearance of ATC predicts poor prognosis; the mean survival of ATC patients after diagnosis is only 6 months, making this cancer one of the most aggressive types (1). Furthermore, distant metastatic sites include $80 \%$ lung, 6-15\% bone, and 5-13\% brain (21-24). Favourable prognostic factors for ATC patients include: younger age $(<45$ years), female sex, small foci of ATC, no evidence of metastatic disease, and surgery for locoregional disease (25). The overall 5-year survival rates for stage IVA, IVB, and IVC ATC are $22.9 \%, 10.1 \%$, and $0 \%$ respectively, according to the AJCC. Due to the lack of evidences of various therapeutic approaches, there is currently no consensus on the management of ATC patients. A combination of surgery, radiation therapy, and chemotherapy may improve ATC patient survival (25).

\subsection{Incidence \& Mortality}

The estimated number of new TC cases in Canada for 2011 was 5,700 (1,200 males and 4,500 females) (Canadian Cancer Statistics 2011, CCS). According to the United States National Cancer Institute's Surveillance Epidemiology and End Results (SEER) database, as of January 1, 2009, there were approximately 496,901 people alive in the United States who had a history of thyroid malignancy (National Cancer Institute statistics 2012). Also, it is estimated 
that 56,460 people (13,250 men and 43,210 women) will be diagnosed with and 1,780 men and women will die of TC in 2012 (SEER). Based on rates from 2007-2009, 1.03\% of men and women born today will be diagnosed with TC sometime during their lifetime (SEER).

\section{TABLE II}

Thyroid cancer incidence and mortality by age in the United States

\begin{tabular}{ccc}
\hline Age (y) & Incidence (\%) & Mortality (\%) \\
\hline$<20$ & 1.8 & 0.1 \\
$20-34$ & 15.5 & 0.8 \\
$35-44$ & 20.4 & 2.2 \\
$45-54$ & 24.3 & 8.3 \\
$55-64$ & 19.0 & 16.9 \\
$65-74$ & 11.7 & 24.7 \\
$74-85$ & 5.9 & 29.8 \\
$85+$ & 1.4 & 17.3 \\
\hline
\end{tabular}

Data summarized from NCI SEER Database for data from years 2005-2009.

The median age for TC diagnosis is 50 years and the median age for death is 73 years (SEER). The trend in SEER cancer incidence for cancer of the thyroid between 1997-2009 for all races and genders showed a significant increase of 6.6 , which clearly demonstrates that the incidence of thyroid malignancy is at an all-time high. A similar increase in incidence is found among the Canadian population with a $6.8 \%$ increase in incidence for males and $8.8 \%$ for females (CCS). The widespread increase in TC incidence over several decades and the cause of this increase is still controversial. Some studies suspected that the increase was due to increased patient exposure to diagnostic X-rays (26), especially among children (13). Another study suggested that the increased incidence is due to improved diagnostics that has been increasing the detection of small subclinical tumours, such as with the use of ultrasound-guided fine needle aspiration biopsies (FNAB) (27). Other factors that have been suggested to have an 
influence on the increased incidence of thyroid carcinomas are radiation exposure (28) and increased body mass index (29). A 2006 study by Davies and Welch investigated TC cases in the US from 1973 to 2002 and found that the increase in incidence was attributed to detection of small PTC and subclinical disease with no significant increase in FTC and MTC, nor in true recurrence of cancer (30). Contrary to this belief, a study from the SEER database by Enewold et al. for TC cases diagnosed from 1980 to 2005 of 48, 403 patients, they found that incidence varied by gender, ethnicity, and histological type, and that increased incidence was only found in PTC and consistently among all racial/ethnic groups (31). Of 39, 706 PTC cases further analyzed, it was found that rates increased most rapidly for females. Also, between 1992-1995 and 2003-2005, rates increased almost 100\% among White non-Hispanics and Black females, whereas only $20-50 \%$ among White Hispanics, Black males, and Asian/Pacific Islanders. They concluded that this data reveals that increased sensitivity in diagnostic procedures and medical surveillance cannot alone account for these increasing thyroid cancer trends, especially considering that tumours of all sizes are increasing at an equal rate.

\subsection{Detection, Diagnosis, and Treatment}

In the early stages of thyroid cancer, symptoms are usually absent. As the cancer progresses, some symptoms patients may present with are hoarseness of the voice, a lump in the front of the neck, swollen lymph nodes in the neck, trouble swallowing or breathing, and/or consistent pain in the throat or neck. However, most often these symptoms are not due to cancer, but rather either benign goiters/nodules, or infection. Benign or malignant nodules are often incidentally detected when a patient is seen for other conditions, whereby ultrasound, CT 
scan, MRI, or other forms of medical surveillance are used. Blood tests are performed to measure the levels of TSH (thyroid stimulating hormone), which acts on the thyroid gland to stimulate the production of thyroid hormone thyroxine $\left(\mathrm{T}_{4}\right)$, as well as thyroid hormones $\left(\mathrm{T}_{3}\right.$ triiodothyronine, and $\mathrm{T}_{4}$ ) to determine how well the thyroid is functioning and to rule out any non-cancerous diseases such as hyper- or hypothyroidism.

\section{Fine-Needle Aspiration Biopsy}

Thyroid nodules are detected by ultrasound scans of the neck. FNAB is then performed to determine if the nodule is benign or malignant, and if possible, the type of malignancy. The accuracy of this procedure has increased through the use of ultrasound guided FNA. In this technique, a fine needle ( 22 to 27 gauge) is inserted into the thyroid and an aspirate is obtained, upon which cytological smears are made to assess if malignancy is present $(32,33)$.

The Bethesda system is currently used to classify and report thyroid cytopathology assessments obtained through the use of FNA (34). The six diagnostic categories of this system are (a) inadequate or non-diagnostic, (b) benign or hyperplastic, (c) atypia of undetermined significance/follicular lesion of undetermined significance, (d) follicular or Hürthle cell neoplasm, (e) suspicious for malignancy, and (f) malignant $(32,34)$. Approximately 60-70\% of all thyroid FNAs have benign cytology (32). Seven to $10 \%$ of FNAB are non-diagnostic, and contributing factors to this rate are nodule composition, FNA technique, and on-site assessment of specimen adequacy (32). Three to $6 \%$ of FNAB diagnoses are atypia of undetermined significance, and this rate can be attributed by poor specimen preparation or by the presence of

minimal atypical features in a predominantly benign appearing sample $(34,35)$. FNAs are often repeated for these reports. Follicular or Hürthle cell neoplasm on FNA represent 6-12\% 
of diagnoses (36-39), and carry a 15-30\% risk for malignancy (35). Therefore, surgical assessment for vascular and/or capsular invasion, often by hemithyroidectomy, is required to distinguish a follicular cancer from a benign follicular adenoma (40-42). Although most turn out to be benign follicular adenomas, those that do have a carcinoma require a second surgery to completely remove the thyroid (32). Mutational analyses for a panel of genes including BRAF, rat sarcoma viral oncogene (RAS), RET/PTC, and PAX8/PPAR $\gamma$ is reported to have a sensitivity ranging from $38-85 \%$, with a $>95 \%$ specificity for detection of malignancy (36-38, $43,44)$. Specimens that are suspicious for malignancy on cytology account for 3-5\% of FNA cases, and this is due to the presence of some but not all the nuclear features of the cancer, and these features are not accounted for in the majority of the sample $(32,34,45)$. The risk of malignancy is $60-70 \%$ for this group, therefore surgery is often recommended (32). Lastly, 3$7 \%$ of FNAs have a diagnosis of malignancy with conclusive features of $\mathrm{TC}$, and a total thyroidectomy is often performed, unless there is the presence of metastatic disease, lymphoma, and PDPTC, whereby surgery may not necessarily be performed (32).

\section{Tumour Stage Classification}

Criteria for TC tumour staging according to the American Joint Committee on Cancer (AJCC) guidelines include patient age, tumour type, tumour size, presence and location of lymph node metastases, and presence of distant metastases (AJCC Cancer Staging Manual, $6^{\text {th }}$ Ed. 2002). The following table lists the TNM (tumour, lymph nodes, metastasis) classification system for TC (Table III). All ATCs (undifferentiated TC) are stage IV, while no PTCs or FTCs are stage III or IV for patients under the age of 45 years. 


\section{TABLE III}

AJCC thyroid cancer TNM staging system

\begin{tabular}{|c|c|c|c|c|}
\hline \multirow[t]{2}{*}{ Stage } & \multicolumn{2}{|c|}{ Papillary or Follicular } & \multirow{2}{*}{$\begin{array}{l}\text { Medullary } \\
\text { Any age }\end{array}$} & \multirow{2}{*}{$\begin{array}{c}\text { Anaplastic } \\
\text { Any age }\end{array}$} \\
\hline & Patient age $<45 y$ & Patient age $\geq 45 y$ & & \\
\hline $\mathbf{I}$ & any $\mathrm{T}$, any $\mathrm{N}, \mathrm{M} 0$ & $\mathrm{~T} 1, \mathrm{~N} 0, \mathrm{M} 0$ & $\mathrm{~T} 1, \mathrm{~N} 0, \mathrm{M} 0$ & \\
\hline II & any $\mathrm{T}$, any $\mathrm{N}, \mathrm{M} 1$ & $\mathrm{~T} 2, \mathrm{~N} 0, \mathrm{M} 0$ & $\mathrm{~T} 2, \mathrm{~N} 0, \mathrm{M} 0$ & \\
\hline \multirow[t]{4}{*}{ III } & & T3, N0, M0 & T3, N0, M0 & \\
\hline & & $\mathrm{T} 1, \mathrm{~N} 1_{\mathrm{a}}, \mathrm{M} 0$ & $\mathrm{~T} 1, \mathrm{~N} 1_{\mathrm{a}}, \mathrm{M} 0$ & \\
\hline & & $\mathrm{T} 2, \mathrm{~N} 1_{\mathrm{a}}, \mathrm{M} 0$ & $\mathrm{~T} 2, \mathrm{~N} 1_{\mathrm{a}}, \mathrm{M} 0$ & \\
\hline & & $\mathrm{T} 3, \mathrm{~N} 1_{\mathrm{a}}, \mathrm{M} 0$ & $\mathrm{~T} 3, \mathrm{~N} 1_{\mathrm{a}}, \mathrm{M} 0$ & \\
\hline \multirow[t]{6}{*}{ IVA } & & T4 $a$, N0, M0 & T4 $a$, N0, M0 & $\mathrm{T} 4_{\mathrm{a}}$, any $\mathrm{N}, \mathrm{M} 0$ \\
\hline & & $\mathrm{T} 4_{\mathrm{a}}, \mathrm{N} 1_{\mathrm{a}}, \mathrm{M} 0$ & $\mathrm{~T}_{\mathrm{a}}, \mathrm{N} 1_{\mathrm{a}}, \mathrm{M} 0$ & \\
\hline & & $\mathrm{T} 1, \mathrm{~N} 1_{\mathrm{b}}, \mathrm{M} 0$ & $\mathrm{~T} 1, \mathrm{~N} 1_{\mathrm{b}}, \mathrm{M} 0$ & \\
\hline & & $\mathrm{T} 2, \mathrm{~N} 1_{\mathrm{b}}, \mathrm{M} 0$ & $\mathrm{~T} 2, \mathrm{~N}_{\mathrm{b}}, \mathrm{M} 0$ & \\
\hline & & $\mathrm{T} 3, \mathrm{~N} 1_{\mathrm{b}}, \mathrm{M} 0$ & $\mathrm{~T} 3, \mathrm{~N} 1_{\mathrm{b}}, \mathrm{M} 0$ & \\
\hline & & $\mathrm{T} 4_{\mathrm{a}}, \mathrm{N} 1_{\mathrm{b}}, \mathrm{M} 0$ & $\mathrm{~T} 4_{\mathrm{a}}, \mathrm{N} 1_{\mathrm{b}}, \mathrm{M} 0$ & \\
\hline IVB & & $\mathrm{T} 4 \mathrm{~b}$, any $\mathrm{N}, \mathrm{M} 0$ & $\mathrm{~T}_{\mathrm{b}}$, any $\mathrm{N}, \mathrm{M} 0$ & $\mathrm{~T} 4_{b}$, any $\mathrm{N}, \mathrm{M} 0$ \\
\hline IVC & & any $\mathrm{T}$, any $\mathrm{N}, \mathrm{M} 1$ & any $\mathrm{T}$, any $\mathrm{N}, \mathrm{M} 1$ & any $\mathrm{T}$, any $\mathrm{N}, \mathrm{M} 1$ \\
\hline
\end{tabular}

Table adapted from AJCC Cancer Staging Manual, Sixth Edition and Cooper et al. 2009 (46)

$\mathrm{T} 1$ - Primary tumour diameter $\leq 2 \mathrm{~cm}$ and is limited to the thyroid

T2 - Primary tumour diameter between 2 and $4 \mathrm{~cm}$ and is limited to the thyroid

T3 - Primary tumour diameter $\geq 4 \mathrm{~cm}$ and is limited to the thyroid or with minimal extrathyroidal extension

$\mathrm{T} 4_{\mathrm{a}}$ - Any size tumour extending beyond the thyroid capsule to invade subcutaneous soft tissues, larynx, trachea, esophagus, or recurrent laryngeal nerve (For ATC, T4 ${ }_{\mathrm{a}}$ defines an intrathyroidal ATC - surgically resectable)

$\mathrm{T} 4_{\mathrm{b}}$ - Any size tumour invading prevertebral fascia or encasing the carotid artery or mediastinal vessels

(For ATC, T4 ${ }_{\mathrm{b}}$ defines an extrathyroidal ATC - surgically unresectable)

$\mathrm{N}_{\mathrm{a}}$ - Metastasis to level VI nodes (pretracheal, paratracheal, and prelaryngeal/Delphian)

$\mathrm{N} 1_{\mathrm{b}}$ - Metastasis to unilateral, bilateral, contralateral cervical, or superior mediastinal nodes

M0 - There is no distant metastasis

M1 - There is distant metastasis 


\section{Radioactive Iodine Therapy and Thyroglobulin}

After surgical removal of the thyroid for patients with DTC, $\mathrm{I}^{131}$ is administered to destroy any remaining thyroid tissue, and also allows for subsequent RAI scans to detect locoregional and/or metastatic disease (47). Efficacy of this treatment is assessed by serum thyroglobulin (Tg) levels. Tg is used as a marker for DTC management and detection of residual/recurrent disease. $\mathrm{Tg}$ is a prohormone of $\mathrm{T}_{4}$ and $\mathrm{T}_{3}$ and is synthesized by follicular cells of the thyroid and released into the serum. Therefore, residual $\mathrm{Tg}$ after $\mathrm{I}^{131}$ therapy is indicative of malignancy (47). Determinants of serum Tg concentrations are (a) mass of thyroid tissue present (b) presence of thyroid injury due to either post-FNA, thyroidectomy or RAI therapy, or during thyroiditis (c) and amount of TSH receptor stimulation (i.e. endogenous TSH, recombinant human TSH (rhTSH), serum human chorionic gonadotropin, TSH receptor antibodies associated with autoimmune thyroid disease) (48). Anti-Tg antibodies may also alter the detected level of serum $\mathrm{Tg}$ and may result in false low levels, thereby presenting a limitation in this assay especially for patients with autoimmune diseases where levels of anti$\mathrm{Tg}$ antibodies may be higher than normal (49). Approximately $10 \%$ of the general population has anti-Tg anitbodies compared to $20 \%$ for DTC patients (50). Serum Tg levels prior to surgery are not a reliable indicator of TC because both normal and malignant thyroid cells release Tg. Since serum Tg is cleared with a half-life of 30 hours, it is expected that it be undetectable if the patient is cured after total thyroidectomy and RAI ablation (51). However, it may take up to one year or longer for the levels to fall below detection (52). The sensitivity of most serum Tg assays is $0.9 \mathrm{ng} / \mathrm{mL}$, however, the sensitivity has increased to $0.1 \mathrm{ng} / \mathrm{mL}$ or lower with recent available assays $(53,54)$. The sensitivity of this assay is increased when $\mathrm{Tg}$ 
levels are measured after TSH stimulation, which includes thyroid hormone withdrawal or administration of rhTSH.

Serum $\mathrm{Tg}$ is emerging as an important indicator for the requirement of radioactive remnant ablation (RRA) therapy post total thyroidectomy for patients with well-differentiated PTC. The need for RRA therapy post total thyroidectomy is highly debated. The American Thyroid Association, European Thyroid Association, British Thyroid Association, and the Mayo Clinic set different guidelines as to which PTC patients should receive RRA therapy based on posed risk for recurrent disease. Some factors considered include TNM stage, presence of lymph node metastasis, extrathyroidal extension, and vascular invasion (55). A study led by Dr. Walfish at Mount Sinai Hospital introduced the application of post-surgical stimulated Tg for RRA selection in low risk PTC (55). Patients with Tg levels $<1 \mathrm{ng} / \mathrm{mL}$ were not administered RRA whereas patients with Tg levels $>5 \mathrm{ng} / \mathrm{mL}$ received RRA (55). Patients with Tg levels 1-5 ng/mL were selected for RRA based on certain histology, nodes, gender, neck ultrasound, and patient's choice (55). Of 104 patients, 59 had undetectable stimulated-Tg after thyroidectomy, 35 patients had $\mathrm{Tg}$ values of $1-5 \mathrm{ng} / \mathrm{mL}$, and 10 patients had stimulated$\operatorname{Tg}$ levels $>5 \mathrm{ng} / \mathrm{mL}$. RRA was administered to only 1 patient with $\mathrm{Tg}<1 \mathrm{ng} / \mathrm{mL}, 6$ patients with Tg between 1 and $5 \mathrm{ng} / \mathrm{mL}$, and 9 patients with $\mathrm{Tg}>5 \mathrm{ng} / \mathrm{mL}$. Three year follow-up of patients who had not received RRA based on these Tg levels showed no disease recurrence, as assessed by ultrasound scans and serum Tg levels. In comparison to current guidelines set by the thyroid associations that would have suggested $67-85 \%$ of patients receive RRA, this study suggested RRA for only $15.4 \%$ of patients, an $82 \%$ reduction in the use of RRA. Therefore, they conclude that stimulated-Tg measurement performed after total thyroidectomy is an objective parameter that can assist in RRA decision-making for patients with low risk DTC. Patients included in the study did not have detectable interfering serum anti-Tg antibodies, a necessary 
selection criterion to avoid misleading serum Tg levels. Patients not receiving RRA therapy are spared from potential side effects such as sialadenitis, lacrimal gland/duct injury, and infertility $(56-58)$.

\section{Detection and Treatment of Anaplastic Thyroid Carcinoma (ATC)}

ATCs are usually identified as rapidly growing masses, often $>5 \mathrm{~cm}$ as either a single nodule or multiple nodules upon initial presentation (6). This mass is associated with pressure symptoms and hoarseness (6). The diagnosis of ATC is confirmed with the use of FNAB, which is shown to be $90 \%$ accurate (22). Failure of FNAB to diagnose ATC may be due to sampling an area that consists of well-differentiated TC foci or sampling areas with abundant

presence of necrosis, fibrosis, or hemorrhage (6). ATC can also be incidentally found in patients who have undergone surgery with a known diagnosis of well-differentiated TC (6). The majority of patients with ATC do not undergo surgery due to the tumour being beyond the bounds of any meaningful resection (6). In a subset of patients where the disease is localized, complete resection of the disease without affecting surrounding vital structures may lead to prolonged patient survival (6). Most ATC patients die from uncontrolled local symptoms. Sometimes surgery followed by chemoradiation is performed on ATC patients with nonlocalized disease as a palliative measure to prevent death by asphyxiation and possibly increase survival by a few months (6). Radiotherapy alone is also sometimes used as a palliative measure to increase local control and short-term patient survival (59). A study reported that for 51 ATC patients treated with radiotherapy for local control, the median survival was found to be 7.5 months, versus 1.6 months for patients without local control (59). However, some 
issues pertaining to radiotherapy include timing of the therapy, dose administered, and pattern of delivery (6).

Because many ATC patients present with metastases, chemotherapy becomes important in the multimodal management of ATC. However, whether using monotherapy (doxorubicin) or combination therapy (i.e. cisplatin, bleomycin, melphalan, paclitaxel), disappointing response rates have been reported (6). Most studies report only a few patients with improvements, but no patients with a complete response, often due to the chemoresistance of ATC cells (6).

For multimodal treatment of ATC, controversy still remains regarding the timing of the different modes of treatment. One study suggests chemoradiation to be given before surgery (24), while another study suggests chemoradiation after surgery (60).

\subsection{Prognostic Factors}

\section{Histology}

Patient outcome is strongly influenced by tumour histology. As stated in detail above, there are aggressive TCs as well as aggressive variants of PTC. ATC is known to have the worst prognosis, followed by insular carcinoma/PDPTC, and medullary thyroid carcinoma (MTC). The aggressive variants of PTC include the tall cell, follicular, columnar cell, and diffuse sclerosing variant. Despite there being 15 variants of PTC with different characteristic histological features, many have similar clinical behaviour (2). 


\section{Tumour Size}

The size of the tumour correlates with prognosis for patients with PTC, and the larger the tumour size, the more likely the presence of locoregional and distant metastases (61). Also, the risk of recurrent disease and cancer-specific mortality is increased linearly with tumour size (61) . A study my Mazzaferri et al. reported that tumours $<1.5 \mathrm{~cm}$ in size had a $0.4 \% 30$-year cancer-specific mortality rate as compared to $22 \%$ for tumours $>4.5 \mathrm{~cm}(61)$.

\section{Age}

Age at the onset of this disease is a critical predictor of patient outcome. An age cut-off of 45 years is currently used by TC staging guidelines of the AJCC. Patients under this cut-off are considered stage I if there is no distant metastasis, and are considered stage II with distant metastasis, therefore, no patient in this group can be stage III or IV. Conversely, patients above this age cut-off have stage III disease if their tumour is larger than $4 \mathrm{~cm}$, has minimal extrathyroidal extension, or has regional lymph node metastasis. Stage IV category includes patients with greater extrathyroidal extension, lateral lymph node metastasis, distant metastasis, or having an ATC. Studies have concluded that patients younger than 45 years have a survival advantage compared to their older counterparts $(62,63)$. Other studies have suggested different age cut-offs, ranging from 50 to 60 years $(64,65)$. However, a recent study by Oyer $e t$ al. aimed to elucidate the relationship between age and prognosis for DTCs, such as PTC and FTC, by investigating a total of 42, 209 DTC cases (66) . Patients 45 years and older had significantly worse survival than younger patients, and that a significant decrease in diseasespecific survival was first seen in patients aged $\geq 35$ years and this survival steadily decreased with each additional decade of age (66). They concluded that patients $\geq 35$ years were 14 
times more likely to die from DTC than patients who were younger, and that increasing age represented by a continuum starting at 35 years is associated with poorer survival (66) .

\section{Gender}

Mortality rates and recurrence rates are higher among men than women $(2,61)$. Furthermore, men have higher rates of extrathyroidal invasion than women (51\% vs. 39\%), higher rate of locoregional lymph node involvement (40\% vs. 32\%), and over twice the rate of distant metastases ( $9 \%$ vs. 4\%) (2). A recent study evaluating the disease-specific survival of women and men of different age groups concluded that women had improved survival compared to men when diagnosed under the age of 55, however this survival became similar to men for women diagnosed at 55-69 years of age and above 70 years (67). They hypothesized that older age influences the effect of gender on survival outcomes due to hormonal alterations caused by menopause in women (67) .

\section{Lymph node Metastasis}

Prior to the use of ultrasonography, approximately $15-30 \%$ of patients had locoregional lymph node involvement at presentation, however, with the widespread use of ultrasonography and the ability to identify small nodes, these rates have increased $(68,69)$. There has been much controversy regarding the clinical importance of lymph node metastasis, and while some studies have found no difference in survival for patients with or without lymph node metastasis $(70,71)$, others report an increased risk of recurrence $(61,72)$ and reduced survival $(73)$. However, a study of the SEER database concluded that patient age was an important factor for survival for patients with lymph node metastasis, whereby patients aged $<45$ years had no 
effect on survival as compared to $46 \%$ increased risk of death for patients $\geq 45$ years $(\mathrm{p}<0.001)$ (74) . The AJCC includes nodal status as a parameter for TNM staging for PTC; however, it only takes into account the presence/absence and location of lymph node metastasis but not the extent of involvement (46). A recent study by some in our group has shown that the metastatic lymph node ratio (MLNR; ratio between number of metastatic nodes and total number of lymph nodes resected) is an independent predictor of PTC recurrence and enhances the predictive value of TNM nodal classification (75). For 35 patients with recurrent disease of a total of 253 patients analyzed, TNM nodal classification with total MLNR had greater accuracy in predicting recurrence than the TNM nodal classification alone (75). Other studies have shown that elevated MLNR reduces survival in well-differentiated TC (76) and MTC (77) . Therefore, the MLNR may be a more reliable means for identifying risk of recurrence than the current staging system alone.

\section{Extrathyroidal Extension}

Approximately $30 \%$ of patients with PTC have extrathyroidal extension (61) . Gross extension of the cancer into surrounding musculature, esophagus, or trachea is associated with high risk of recurrence (78) . These patients require aggressive surgical debridement $(79,80)$ and may also benefit from external beam radiotherapy (81) . Microscopic thyroid extension is also associated with an increased risk for recurrent disease (82), as well as higher risk of lymph node metastasis (83) and a higher mortality rate than patients without this spread (61). 


\section{Distant Metastases}

Although only $5-10 \%$ of patients initially present with distant metastases, it is the main cause of death for PTC patients $(5,84)$. An additional $2.5-5 \%$ of patients will develop them after initial radioiodine ablation (85) . Mortality is high for these patients; one study stated a $50 \%$ survival at 3.5 years, however, survival is improved in younger patients (86), patients with microscopic disease(5), and patients with iodine-avid tumours $(5,86)$. Fifty percent of patients with distant metastasis develop it in the lungs, $25 \%$ have only metastasis to the bone, $20 \%$ have both lung and bone metastases, and about 5\% develop distant metastases to other sites $(5,85)$.

\section{Risk of Recurrence}

The AJCC staging criteria was developed to aid in prognostication of TC patients, predict risk of death, and to aid in making decisions on postoperative therapy. For risk of recurrence, patients are stratified into three categories depending on certain features that account for increased risk. Low-risk patients have (i) no local or distant metastases; (ii) fully resected macroscopic tumours; (iii) no tumour invasion of locoregional tissues or structures; (iv) no aggressive histology (i.e. tall cell or insular variant) or vascular invasion or; no I ${ }^{131}$ uptake outside the thyroid bed $(46,87)$. Intermediate-risk patients have (i) microscopic invasion of tumour into the perithyroidal soft tissues at initial surgery; (ii) cervical lymph node metastases or $\mathrm{I}^{131}$ uptake outside the thyroid bed (88) ; (iii) tumour with aggressive histology or vascular invasion (46). High-risk patients have macroscopic tumour invasion, incomplete tumour resection, and distant metastases (46). Depending on patient risk, the primary aim of the first dose of RAI after total thyroidectomy may be 1) remnant ablation - destroys residual 
thyroid tissue and facilitates detection of recurrent disease and initial staging, 2) adjuvant therapy - decreases risk of recurrence and mortality by destroying suspected metastatic disease, or 3) RAI therapy - treats known persistent disease (46).

\subsection{Oncogenes and Tumourigenesis}

It is estimated that $3.2 \%$ to $6.2 \%$ of TCs can be explained by familial factors. Most of the familial TCs are PTC, and a 4 to 10 fold increase in the incidence of PTC is reported in relatives of PTC patients (89). Familial PTC cases are known to have an early onset of disease and a more aggressive phenotype (90). There have been several oncogenes studied and associated with particular subtypes of TC, which has led researchers to a better understanding of this disease. The mitogen-activated protein kinase (MAPK) signalling pathway is a key pathway that is constitutively activated in the presence of some mutations, and this pathway includes important cell surface receptors such as RET, guanosine triphosphate-binding Gproteins such as RAS and intracellular kinases such as RAF (91). MAPK pathway plays a critical role in cell proliferation, differentiation, and apoptosis $(1,92)$.

\section{B-raf Proto-Oncogene (BRAF) Mutation}

The most extensively studied mutation in TC is the BRAF mutation, and it is associated with $29 \%$ to $83 \%$ of PTC tumours $(1,93,94), 10 \%$ of poorly-differentiated, and $15 \%$ of undifferentiated tumours (1). This mutation is the most potent isoform in stimulating the MAPK pathway (95). The BRAF mutation results in a 500 fold increase in activation of the MAPK pathway and is associated with the silencing of many thyroid-specific iodine- 
metabolizing genes (96). Although the MAPK pathway is affected by many genetic alterations in PTC, the histological phenotype and expression profile is not necessarily the same among all, therefore, suggesting that other pathways may be involved (91). The exact clinical implications of this mutation are debated. Some studies have found this mutation to be associated with persistent disease and death, extrathyroidal extension, multifocality, presence of nodal metastases, advanced-stage disease, poor iodine uptake, and older age at initial presentation $(91,97-99)$. Other studies have shown an absence of significant relationships between clinical outcome and BRAF mutation $(93,97,100)$. Since the BRAF mutation is exclusive to PTC, or ATC originating from PTC, it can be used to aid in the diagnoses of PTC patients (101). One study showed that the mutation was present in $72 \%$ of tumour samples and that examination of this mutation in $16 \%$ of the indeterminate FNA biopsies resulted in a diagnosis (102). In another study, a diagnosis was established for 5 of 15 indeterminate FNA samples using this mutation analysis (2). Since poorly-differentiated and anaplastic TC harbour the BRAF mutation, but not RET/PTC, it is believed that the BRAF mutation may predispose PTCs to de-differentiation (103). A study by Knauf et al. showed that targeted expression of BRAF in transgenic mice results in de-differentiation of PTC (104).

\section{RET/PTC, RAS, and PAX8/PPAR $\gamma$ Mutations}

Another mutation associated with $\mathrm{TC}$ is the RET/PTC mutation. This mutation is present in $20 \%$ of classic PTCs (91). The BRAF and RET/PTC mutations are mutually exclusive; therefore they do not occur in the same tumour (91). The RAS mutation is present in $20-40 \%$ of benign nodules (follicular adenomas), $40-50 \%$ of FTC, and $10-20 \%$ of follicular 
variant PTC, and is associated with less lymph node and more distant metastases (91), while the PAX8/PPAR $\gamma$ mutation is present in $2-10 \%$ of follicular adenomas and $35 \%$ of FTC (91) .

p53

The p53 gene is a tumour suppressor gene that plays an important role in its nuclear transcription factor production and cell cycle regulation, DNA repair, and apoptosis. p53 is mutated or absent in approximately $50 \%$ of all human cancers and $52 \%$ of ATC (105). Mutations in this gene result in angiogenesis, growth, and dedifferentiation (18). Interestingly, reintroduction of the wild type p53 in ATC cell lines resulted in the redifferentiation of ATC (106) .

\section{PI3K/Akt Pathway}

Aberrant activation of the phosphatidylinositol 3'-kinase (PI3K) /Akt pathway has also been shown to play a role in thyroid tumourigenesis and promotes the progression of a thyroid adenoma to FTC and to ATC (18). This pathway has many key roles, including cell survival and proliferation. Hou et al. report genetic alterations in 31\% of benign thyroid adenomas, $55 \%$ of FTC, $24 \%$ of PTC, and $58 \%$ of ATC (107).

\section{EGFR and VEGF}

Epidermal growth factor receptor (EGFR) is a cell membrane receptor that plays a major role in tumourigenesis and cancer progression (18). Induction of EGFR by stimulation with its ligands or activating mutations of its tyrosine kinase domains leads to a cascade of responses including cell growth, proliferation, invasion, cell survival, and angiogenesis (108). 
Overexpression of EGFR has been associated with advanced tumour stage, metastasis, and poor clinical outcome in several human cancer such as breast, cervical, lung, bladder, and head and neck cancers (18). At least one-third of all ATCs demonstrate EGFR overexpression (109). Many kinds of EGFR-targeted therapies are being investigated including anti-receptor monoclonal antibodies, anti-ligand monoclonal antibodies, ligand-toxin conjugates, and tyrosine kinase inhibitors (18).

Vascular endothelial growth factor (VEGF) functions in the tumourigenic process by binding to the tyrosine kinase receptor VEGFR, thereby activating downstream signalling pathways involved in angiogenesis (18). Therefore, VEGF is implicated in accelerated growth, local invasion, and metastasis (18). Current therapeutic approaches involve targeting both the EGFR and VEGF signalling pathways in combination.

\subsection{New Therapies for Thyroid Cancer}

Recently, new therapies have entered clinical trials using multi-targeted kinase inhibitors for patients with advanced or progressing metastatic thyroid cancers. Agents tested commonly target growth factor receptor pathways and have similar drug toxicities. Since a common feature of TC is increased vascularization with elevated expression of VEGF compared to normal tissue, many drugs are chosen for their targeting of its receptor (VEGFR) (110). Several clinical trials using different tyrosine kinase inhibitors that have been conducted and/or are ongoing are listed in Table IV (111-117). Patient response to treatment is determined as per the Response Evaluation Criteria in Solid Tumors (RECIST) (118). A lack in drug response through targeted inhibition could be attributed by compensatory signalling pathways that can rescue tumour growth (110). 


\section{TABLE IV}

Clinical trial agents for thyroid cancer patients

\begin{tabular}{|c|c|c|c|c|}
\hline Drug & $\begin{array}{l}\text { Pathway } \\
\text { Targeted }\end{array}$ & ТС Туре & Patient Response & $\begin{array}{c}\text { Author \& Year } \\
\text { of Study }\end{array}$ \\
\hline Sorafenib & $\begin{array}{l}\text { RAF, RET, } \\
\text { VEGFR }\end{array}$ & 30 DTC & $\begin{array}{l}23 \% \text { - partial response } \\
53 \% \text { - stable disease }\end{array}$ & $\begin{array}{c}\text { Gupta- } \\
\text { Abramson et al. } \\
2008\end{array}$ \\
\hline Sorfenib & $\begin{array}{l}\text { RAF, RET, } \\
\text { VEGFR }\end{array}$ & $\begin{array}{l}41 \mathrm{PTC} \\
11 \mathrm{FTC} \\
4 \mathrm{ATC} \\
\end{array}$ & $\begin{array}{l}15 \% \text { - partial response } \\
56 \% \text { (PTC) - stable disease } \\
\text { No response for FTC and ATC }\end{array}$ & Kloos et al. 2009 \\
\hline Sorfenib & $\begin{array}{l}\text { RAF, RET, } \\
\text { VEGFR }\end{array}$ & $32 \mathrm{DTC}$ & $\begin{array}{l}25 \% \text { - partial response } \\
34 \% \text { - stable disease }\end{array}$ & $\begin{array}{c}\text { Hoftijzer et al. } \\
2009\end{array}$ \\
\hline Sunitinib & VEGFR & $\begin{array}{l}37 \mathrm{DTC} \\
6 \mathrm{MTC}\end{array}$ & $\begin{array}{l}\text { 11\% (DTC) - partial response } \\
57 \% \text { (DTC) - stable disease } \\
33 \% \text { (MTC) - stable disease }\end{array}$ & $\begin{array}{c}\text { Cohen et al. } \\
2008\end{array}$ \\
\hline Sunitinib & VEGFR & $\begin{array}{l}28 \mathrm{DTC} \\
7 \mathrm{MTC}\end{array}$ & $\begin{array}{l}3 \% \text { - complete response } \\
29 \% \text { - partial response } \\
46 \% \text { - stable disease }\end{array}$ & Carr et al. 2010 \\
\hline Axitinib & $\begin{array}{l}\text { VEGFR, c-Kit, } \\
\text { PDGFR }\end{array}$ & $\begin{array}{c}60 \text { of many } \\
\text { types }\end{array}$ & $\begin{array}{l}30 \% \text { - partial response } \\
28 \% \text { - stable disease }\end{array}$ & $\begin{array}{c}\text { Cohen et al. } \\
2008\end{array}$ \\
\hline Pazopanib & $\begin{array}{l}\text { VEGFR, } \\
\text { PDGFR }\end{array}$ & $\begin{array}{c}39 \text { de- } \\
\text { differentiated } \\
\text { DTC }\end{array}$ & $46 \%$ - partial response & Bible et al. 2010 \\
\hline Gefitinib & EGFR & $\begin{array}{c}27 \text { of many } \\
\text { types }\end{array}$ & No response & $\begin{array}{c}\text { Pennel et al. } \\
2008\end{array}$ \\
\hline
\end{tabular}

Table adapted from Antonelli et al. 2011 (110)

c-Kit : a protein receptor that binds to stem cell factors

PDGFR : platelet-derived growth factor receptor

In vitro tests are shown to be $60 \%$ effective in predicting chemosensitivity in vivo (119), while negative chemosensitivity tests in vitro are associated with $90 \%$ treatment ineffectiveness in vivo (120), therefore in vitro studies are an important preliminary measure for the selection of clinical trial drugs. These in vivo studies allow researchers to avoid administration of ineffective chemotherapeutics (110) .

Several other drug groups and targets are currently being tested in vitro or in clinical trials, many of which are tailored to the treatment of ATC. Combretastatin A4 phosphate is a 
vascular disrupting agent that inhibits tumour blood flow through already existing vessels (105). AZD2171 is another tyrosine-kinase inhibitor of VEGFR, and it has been shown to block tumour growth and extend the survival of ATC-bearing mice (121). Histone deacetylase inhibitors show promise for TC treatment as well. Through hyperacetylation, these agents are able to induce cell differentiation, cell cycle arrest, apoptosis, and they also have the potential to enhance drug cytotoxicity (105).

The sodium-iodide symporter (NIS) is an intrinsic plasma membrane protein that mediates follicular thyroid cells to actively transport iodide into the thyroid gland (18) . Subsequent iodide accumulation through this mediation allows for effective therapeutic application of RAI and diagnostic thyroid scintigraphy (18). This function is lost in ATCs due to decreased expression of NIS resulting in a loss of iodide accumulation (18). Transfection of human NIS into ATC-bearing mice tumours effectively inhibited tumour growth when a therapeutic dose of $\mathrm{I}^{131}$ was administered to the mice (122). Furthermore, gene therapy targeting of transcription factors TTF-1 and PAX8, which cooperate in the transcriptional activation of thyroid-specific genes such as Tg and NIS, can lead to the re-activation of these genes and improve the ability of ATC cells to uptake radioiodine (18) .

\subsection{Summary}

There are many subtypes of TC and each subtype presents not only different histological characteristics, but also different clinical outcomes. There are limitations in preoperative diagnoses of TC, and there are currently no biochemical markers that could aid in identifying aggressive subtypes of TC, nor to aid in prognostication. Although serum Tg is an 
important marker for management of TC patients, it is limited to differentiated carcinomas and absence of anti-Tg antibody interference. Also, there is much controversy regarding the extent of treatment to be given to TC patients, such as whether total thyroidectomy or lobectomy is required, or which patients require RAI ablation. Therefore, new therapeutic strategies and targets are required for time and cost-effective management of TC patients. 


\section{Chapter 2 \\ Rationale and Objectives}

\section{Rationale and Objectives}

Currently there are no molecular markers that can identify and predict aggressive TC cases, particularly those that may result in distant metastases and reduced survival (123). Although ultrasound-guided FNAB is the most accurate technique for pre-operative diagnosis of TC patients, about $20-40 \%$ of all cytological reports are limited by indeterminate, suspicious, or atypical findings (124). This often results in many patients undergoing unnecessary total thyroidectomies, as many of the suspected nodules turn out to be benign (91, 125). Despite the plethora of criteria to differentiate aggressive TCs from non-aggressive cases, lack of universal consensus and controversy generating ongoing debates resulted in only a select few being considered in the currently recommended TNM staging system (2). Accurate staging and risk stratification are critical determinants guiding the postoperative management of TC patients. This includes the need for $\mathrm{I}^{131}$ therapy, or alternatives such as conservative management without ablation, surgical re-intervention, or external-beam radiation therapy, while deciding the long-term follow-up strategy (126). Therefore, there is an urgent need to identify biomarkers that could aid in the detection, diagnosis, and management of $\mathrm{TC}$, especially those with an aggressive potential. This could help set up clear criteria for patients who require adjuvant treatment, especially RAI ablation where discrepancy currently exists (55).

Advances in proteomic technologies in combination with bioinformatics have provided opportunities to reveal important molecular pathways implicated in cancer progression and for 
the discovery of biomarkers. The challenges of blood proteomics, stemming from the complexity of the fluid, have led researchers to seek alternate sources for the discovery of circulating cancer biomarkers, such as the cancer "secretome" (127). The term secretome refers to proteins released by cells by different mechanisms of secretion (128) . These proteins may be detected by analyzing the conditioned media $(\mathrm{CM})$ of cancer cell lines. Secretome proteins are of particular interest because they are more likely to be detectable in blood, and therefore have the potential for use as minimally-invasive blood-based biomarkers to aid in disease management (129-135). Furthermore, secretome proteins have been shown to be implicated in the interactions between cancer cells and stromal cells that are actively involved in tumour progression and are often differentially expressed in cancer tissues (136-138) .

\subsection{Goals}

The goal of this study was to analyze the secretomes of aggressive and non-aggressive thyroid carcinoma cell lines using proteomics and bioinformatics to identify potential diagnostic and/or prognostic biomarkers for aggressive TC. The proteins of interest would then be further analyzed in TC patients' sera and tissues.

\subsection{Hypotheses}

HYPOTHESIS 1: Analysis of proteins secreted from non-aggressive and aggressive TC cell lines may lead to the identification of candidate biomarkers based on important potential biological interactions. 
HYPOTHESIS 2: Of a panel of secretome proteins chosen for further investigation, some are likely to display differential expression in patients' tissues and sera between benign and malignant thyroid tumours. Furthermore, some proteins may serve as diagnostic biomarkers for the detection of more aggressive forms of $\mathrm{TC}$ when assessing different clinico-pathological parameters.

HYPOTHESIS 3: Proteins expressions associated with malignancy may also serve as prognostic markers and correlate with disease-free survival of TC patients.

\subsection{Specific Aims}

AIM 1: Proteomic analysis of secretomes of aggressive (anaplastic-derived) and nonaggressive (papillary-derived) TC cell lines in tandem with bioinformatics for identification of candidate biological markers for aggressive TCs.

AIM 2: Confirm the detectability of a panel of secretome proteins in TC patients' sera using western blotting.

AIM 3: Verification of proteins in TC patients' tissues using immunohistochemistry to determine differences in subcellular expression and to correlate protein staining with clinicpathological parameters and patient survival.

AIM 4: Quantify protein levels in TC patients' sera using enzyme-linked immunosorbent assay and correlate levels with clinico-pathological parameters to assess their potential for use as diagnostic blood-based biomarkers. 


\section{Chapter 3 \\ Methods}

\section{Methods}

\subsection{General Schematic}

A general schematic of the workflow and experimental design used in this study is provided in Figure. 1. Using a secretome approach, candidate biomarkers were identified for potential use in blood-based assays. Our experimental approach included: (i) identifying high confidence secretome proteins from conditioned media of cultured PTC and ATC cells using liquid chromatography - tandem mass spectrometry (LC-MS/MS) proteomic analysis; (ii) using Ingenuity Pathway Analysis (IPA) to identify key protein-protein interactions in signaling pathways pivotal in cancer; (iii) selecting a panel of proteins from this analysis for further investigation in patients' sera using western blots and/or ELISA; (iv) investigating potential alterations in expression of these proteins in patients' tumours using IHC. 
Culture PTC cell
line: BCPAP

(Non-Aggressive)
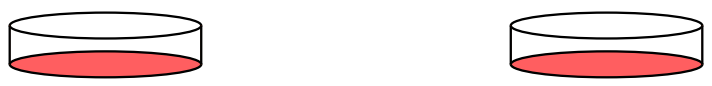

Collect conditioned media
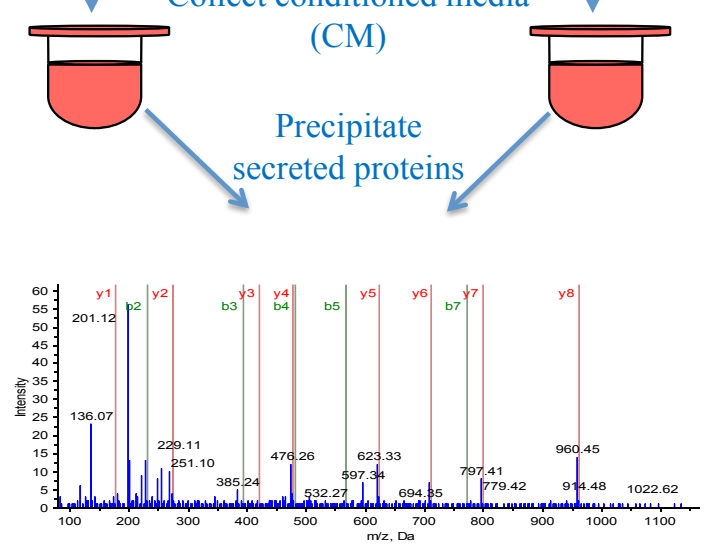

LC-MS/MS
Culture ATC cell

lines: C643, SW1736

(Aggressive)

\section{Identify Secretome Proteins}

\section{Criteria for Protein Panel Selection}

-Select high confidence identifications

-Secreted by anaplastic-derived cell lines

-Ingenuity Pathway Analysis

-Tumorigenic pathways

-Protein-protein interactions

-Known biological functions and

expression in cancer
1. Confirm detectability in sera of patients - western blot

2. Determine expression in human thyroid cancer tissues immunohistochemistry

3. Quantify serum levels - ELISA

Figure 1. Schematic of experimental workflow 
Figure 1. Schematic of experimental workflow. PTC (BCPAP) and ATC (C643, SW1736) cell lines were cultured. Conditioned media was collected, proteins were precipitated, and high confidence secretome proteins were identified using liquid chromatography - tandem mass spectrometry (LC-MS/MS). Ingenuity Pathway Analysis was used to identify key proteinprotein interactions in cell signalling networks that are pivotal in cancer, as well as literature review of protein expression and their roles in cancer. Nine proteins were chosen to study their expression in human sera and tissues using western blots, ELISA, and IHC to assess their applicability as potential biomarkers for aggressive TC. 


\subsection{Detailed Methods}

\section{Cell Lines}

Three TC cell lines, non-aggressive BCPAP (PTC-derived), and aggressive SW1736 and C643 (ATC-derived) were used in this study. SW1736 was provided by Dr. E. Heldin (Rudbeck Laboratory, Uppsala University, Finland), and C643 by Dr. G. Salvatore (University of Naples, Italy). BCPAP was obtained from the German Collection of Microorganisms and Cell Cultures (DSMZ, Braunschh, Germany). Short tandem repeat (STR) profiles of all the cell lines were determined and matched to those of the original TC-derived cell lines to confirm their identity (139). These cell lines have been demonstrated to express thyroid specific genes, thereby confirming their thyroid origin (139) .

\section{Cell culture, conditioned media collection and protein precipitation}

TC cell lines (BCPAP, SW1736, and C643) were propagated in RPMI-1640 containing $100 \mu \mathrm{g} / \mathrm{mL}$ streptomycin and $100 \mathrm{U} / \mathrm{mL}$ penicillin, 10\% FBS and $1 \mathrm{X}$ non-essential amino acids in $150 \mathrm{~mm}$ dishes to about $65 \%$ confluence at $37^{\circ} \mathrm{C}$ in a humidified atmosphere of $5 \% \mathrm{CO}_{2}-95 \%$ air. For secretome analysis, cells were grown in serum-free medium for $48 \mathrm{~h}$ as previously described by us (140). Trypan blue staining was performed following collection of the conditioned media at $48 \mathrm{~h}$ to estimate the number of dead cells. Since $\geq 98 \%$ cells were viable at $48 \mathrm{~h}$, this time period was chosen for further study. This was done to maintain secretome integrity by limiting secretome contamination from lysis of dead cells. Thereafter, the $\mathrm{CM}$ were collected, centrifuged at $5000 \mathrm{~g}$ for 5 minutes at $4^{\circ} \mathrm{C}$, filtered using a $0.2 \mu \mathrm{m}$ nylon filter, snap frozen, and stored at $-80^{\circ} \mathrm{C}$ until further use. Proteins were precipitated from 
the pooled CM using sodium deoxycholate-trichloroacetic acid method and prepared for LCMS/MS analysis as described earlier (140). Briefly, following $2 \mathrm{~h}$ incubation on ice, the samples were centrifuged at $11,000 \mathrm{~g}$ for 30 minutes and washed twice with ice-cold acetone. The precipitated proteins were then dissolved in $50 \mathrm{mM} \mathrm{NH}_{4} \mathrm{HCO}_{3}$ buffer, $\mathrm{pH}$ 7.5. The protein concentration was determined using the Bradford assay (Bio-Rad, Hercules, CA). Protein samples were then heated for $1 \mathrm{~h}$ at $65^{\circ} \mathrm{C}$ in the presence of $5 \mathrm{mM}$ dithiothreitol, cooled to room temperature, and incubated in dark for $1 \mathrm{~h}$ with $10 \mathrm{mM}$ iodoacetamide for alkylation. Sequencing grade trypsin (Promega, WI) at 1:20 (w/v) in $50 \mathrm{mM}$ ammonium bicarbonate buffer was subsequently added and the samples were incubated at $37^{\circ} \mathrm{C}$ overnight. The trypsindigested samples were then dried under vacuum and dissolved in $10 \mu \mathrm{L}$ of $0.1 \%$ formic acid. Experiments were repeated twice and each set was analyzed separately using LC-MS/MS as described below.

\section{Liquid chromatography - tandem mass spectrometry}

Samples were analyzed by online nanoflow LC-MS/MS using the Eksigent Tempo LC (Dublin, CA) fitted with a 10- $\mu 1$ sample loop. A part of the trypsin-digested samples were loaded onto a 5-mm RP C18 precolumn (LC Packings, Amsterdam, The Netherlands) at 20 $\mu 1 . \mathrm{min}^{-1}$ and washed for $5 \mathrm{~min}$ before switching the precolumn inline with the separation column. The separation column was a $75-\mu$ m-internal diameter $\times 150-\mathrm{mm}$-length capillary column (Integrafrit capillary from New Objective, Woburn, MA) packed in-house with 3.5- $\mu \mathrm{m}$ C18 beads with 100-Å pores from Kromasil (Akzo Nobel/EKA Chemicals inc, NY). Gradient elution was performed at a flow rate of $200 \mathrm{~nL} / \mathrm{min}$ with solvent A being $5 \%$ acetonitrile and $0.1 \%$ formic acid in water, and solvent B $95 \%$ acetonitrile in $0.1 \%$ formic acid. The gradient 
was as follow: start at $95 \% \mathrm{~A}, 5 \% \mathrm{~B}$, hold until $\mathrm{t}=5$ min.; $\mathrm{B}$ increased to $15 \%$ by $\mathrm{t}=10 \mathrm{~min}$, then to $35 \%$ by $t=70 \mathrm{~min}$, and finally to $80 \%$ by $t=85 \mathrm{~min}$, hold until $\mathrm{t}=95 \mathrm{~min}$; then $\mathrm{B}$ is lowered to $5 \%$ by $\mathrm{t}=98 \mathrm{~min}$, and the column equilibrated until $\mathrm{t}=135 \mathrm{~min}$. This HPLC was connected on-line to a Q-Star Elite mass spectrometer (AB SCIEX, Foster City, CA) via a nanoflow II electrospray ionization interface. Samples were analyzed in information-dependent acquisition mode with the scan cycles set to perform a 1-s MS survey scan with a mass range of 400-1500 Da followed by MS/MS scans of the four most abundant peaks with a mass range of 80-2000 Da for $2 \mathrm{~s}$ each, The collision energy (CE) was automatically controlled by the IDA CE Parameters script. Switching criteria were set to ions with $\mathrm{m} / \mathrm{z} \geq 400$ and $\leq 1500$, charge states of $2-4$, and abundances of $\geq 10$ counts. Former target ions were excluded for $30 \mathrm{~s}$, and ions within a 6-Da window were ignored. The controlling software was Analyst QS 2.0 (AB SCIEX). Performance of the analytical system, including sensitivity, resolution, and mass accuracy, was evaluated and re-optimized once every day, using 95 fmol of a bovine serum albumin tryptic digest as control.

\section{Bioinformatics}

The MS/MS spectra were processed by ProteinPilot version 2 (Applied Biosystems), using the Paragon algorithm in Thorough Search mode, with iodoacetamide selected as the cysteine modification, and the search option 'emphasis on biological modifications' checked (129). The confidence threshold was set at 95\% (ProteinPilot protein Unused Score of 1.3), and the search was performed against a Swiss-Prot database concatenated in June 2010, containing 66082 distinct human protein entries. SignalP (http://www.cbs.dtu.dk/services/SignalP 3.0) was used to analyze identified proteins for 
classical protein secretion features (141). SignalP predicts the presence and the location of signal peptide cleavage sites in the amino-acid sequences by a combination of artificial neural networks and hidden Markov model algorithms to detect signal peptides from input protein sequences. The presence of secretory signal peptide sequences was determined with a probability $\geq 0$.9. SecretomeP (http://www.cbs.dtu.dk/services/SecretomeP 2.0) was used for non-classical and leaderless protein secretion (142). A given protein was considered nonclassically secreted if it contains a non-classical (non-signal) peptide-triggered protein secretion with score $\geq 0.5$; only proteins that did not contain a signal peptide as determined by SignalP were legitimate candidates for this analysis. IPA (Ingenuity Systems, www.ingenuity.com) was used to determine the subcellular localization and biological functions of the identified proteins (for detailed information on IPA, visit www.ingenuity.com). We classified a protein as "secreted" if it satisfied at least one of the following four criteria: (i) its subcellular location is extracellular or membrane-bound, according to IPA; (ii) it is classically secreted, according to SignalP; (iii) it is non-classically secreted, according to SecretomeP; or (iv) it is non-classically secreted by the exosome pathway, according to the literature. IPA was used to generate potential cellular networks for all proteins to aid in the selection of a panel of proteins for immunohistochemical and serological analysis. Proteins were considered for further analysis if they were identified with at least 2 unique peptides ( $\geq 95 \%$ confidence) and were secreted from ATC-derived cell lines. 14-3-3 zeta and activated leukocyte cell adhesion molecule (ALCAM/CD166) were identified with only one high confidence peptide, yet these proteins were also considered for further verification because 14-3-3 zeta was previously identified as a candidate biomarker in head and neck squamous cell carcinomas by some in our group (143), and ALCAM has recently been reported to play a potential tumourigenic role in head and neck and in TC cells $(143,144)$, and 
also identified as a predictor of disease progression and reduced survival in oral cancer patients $(145)$.

\section{Patient specimens}

The study was approved by Mount Sinai Hospital (MSH) Research Ethics Board (REB), Toronto, Canada. Informed consent for the scientific use of anonymized patients' data and tumour tissues had been obtained from all patients as per REB guidelines. All data were analysed anonymously. Five $\mathrm{mL}$ of blood was collected from TC patients and patients with benign nodules attending the thyroid clinic at MSH. Blood was allowed to coagulate for 30 min at room temperature, centrifuged at $1000 \mathrm{~g}$ for $10 \mathrm{~min}$, and sera stored in $1.5 \mathrm{~mL}$ freezer vials at $-80^{\circ} \mathrm{C}$. Archived formalin-fixed paraffin-embedded (FFPE) tissue blocks from the MSH Tumour Bank were retrieved and reviewed by the pathologist (CM) to select tissues from patients with benign nodules, early stage PTC and variants of PTC, and advanced stage TCs of different subtypes. Clinico-pathological parameters were obtained from histopathological analyses and the clinical database (IK). Sera and tissue samples from patients with benign thyroid nodules, non-aggressive TCs, and aggressive TCs were analyzed. Benign nodules were obtained from patients with multinodular goiters, Grave's disease, Hashimoto's thyroiditis, or hyperplastic nodules. Non-aggressive TCs were those of well-differentiated tumour histology and determined to be Stage I or II according to the AJCC tumour staging criteria and did not have lymph node metastasis, distal metastasis, and/or extrathyroidal extension. Aggressive carcinomas were those that were determined to be Stage III or IV according to AJCC tumour staging criteria, and/or have poorly differentiated histology, lymph node metastasis or distal metastasis, or extrathyroidal extension. Patients under 45 years of age with stage II TC were 
classified under aggressive carcinomas, as these patients have distant metastases. The age of patients ranged from 16 to 85 years, median 47 years, including 47 males and 156 females. Forty-five benign thyroid nodules and 158 malignant tissues were analyzed for ALCAM expression.

\section{Detection of proteins in thyroid carcinoma and benign patients' sera by} western blot

Six benign (non-cancerous) sera and 12 sera from TC patients were analyzed for detection of 9 proteins namely, ALCAM, tyrosine protein kinase receptor UFO (AXL), amyloid beta A4 protein (APP), amyloid-like protein 2 (APLP2), heterogeneous nuclear ribonucleoprotein K (hnRNP K), phosphoglycerate kinase 1 (PGK1), phosphatase 2A inhibitor (SET), 14-3-3 zeta, and pyruvate kinase muscle isozyme M2 (PKM2) using western blots. Of the carcinoma patients, 6 were diagnosed with non-aggressive TC and 6 with aggressive TC. Sera $(24 \mu \mathrm{L})$ from TC patients were treated and concentrated using the ProteoPrep 20 Immunodepletion Kit (Sigma) as described (140) . Proteins were separated by denaturing electrophoresis on polyacrylamide gels and blotted onto a polyvinylidenedifluoride (PVDF) membrane (Millipore, Billerica, MA). Blots were pre-incubated at room temperature for $1 \mathrm{~h}$ in a blocking solution consisting of $5 \%(\mathrm{w} / \mathrm{v})$ skimmed milk powder in $20 \mathrm{mM}$ Tris- $\mathrm{HCl}$ buffer $\mathrm{pH}$ 7.6, $140 \mathrm{mM}$ sodium chloride (TBS) containing $0.1 \%$ Tween 20 (TBST). Primary antibodies were diluted with $5 \%(\mathrm{w} / \mathrm{v})$ skimmed milk powder in TBS prior to incubation $(2 \mathrm{~h})$ with the following antibodies from Abcam (Cambridge, MA): ALCAM monoclonal mouse antibody (1:500 dilution); APLP2 rabbit polyclonal antibody (1:100); SET rabbit polyclonal antibody (1:1000); PKM2 rabbit polyclonal antibody (1:250); APP rabbit monoclonal antibody 
(1:750); AXL rabbit polyclonal antibody (1:100); and 14-3-3 zeta mouse monoclonal antibody obtained from Imgenex (1:200). Following incubation, blots were washed (3 times, $5 \mathrm{~min}$ ) with TBST and incubated for $1 \mathrm{~h}$ with horseradish peroxidase-conjugated goat anti-mouse or antirabbit IgG (Santa Cruz Biotechnology, Santa Cruz, CA) at a dilution of 1:2000 in TBS containing 5\% skimmed milk powder. Blots were washed again with TBST and developed using Western Lightning Plus-ECL Enhanced Chemiluminescence Substrate (PerkinElmer Inc, Waltham, MA, USA). Ponceau S staining was used to confirm equal protein loading in different lanes.

\section{Immunohistochemical analysis in human thyroid tissues}

Immunohistochemistry was performed on archived FFPE human benign and TC tissue sections to determine the expression patterns of ALCAM, APP, APLP2, AXL, SET, PGK1, 14-3-3 zeta, PKM2 and hnRNP K. Serial TC and benign tissue sections $(4 \mu \mathrm{m}$ thickness) were deparaffinised in xylene and hydrated with graded alcohol series as described earlier by us (143). All incubations were conducted at room temperature. The VECTASTAIN rapid protocol was used. The slides were incubated with $10 \%$ blocking serum (normal horse serum for anti-mouse secondary antibodies or normal goat serum for anti-rabbit secondary antibodies) for $20 \mathrm{~min}$. After blocking the non-specific binding sites, sections were incubated with the following anti-human antibodies from Abcam (Cambridge, MA): ALCAM mouse monoclonal antibody (1:200), APP rabbit monoclonal antibody (1:200), APLP2 rabbit polyclonal antibody (1:100), hnRNP K mouse monoclonal (1:500), PKM2 rabbit polyclonal (1:50), SET rabbit polyclonal (1:200), AXL rabbit polyclonal (1:100), PGK1 mouse monoclonal (1:100) from Santa Cruz Biotechnology (Santa Cruz, CA), and 14-3-3 zeta mouse 
monoclonal antibody (1:100) from Imgenex (San Diego, CA) for $1 \mathrm{~h}$. Tissues were then treated with $3 \% \mathrm{H}_{2} \mathrm{O}_{2}$ in TBS for 10 min to block the endogenous peroxidase activity, and were subsequently incubated with a biotinylated secondary antibody (horse anti-mouse or goat antirabbit) for $10 \mathrm{~min}$. The sections were finally incubated with VECTASTAIN Elite ABC Reagent (Vector labs, Burlingame, CA) for $10 \mathrm{~min}$ and diaminobenzidine was used as the chromogen. Negative control tissues were incubated with biotinylated secondary antibody (horse anti-mouse or goat anti-rabbit) with the omission of primary antibody, following the same protocol. Slides were counterstained with haematoxylin.

\section{Evaluation of immunohistochemistry}

The immunostaining scores were based on percentage positivity and staining intensity. Sections were scored as positive if epithelial cells showed immunoreactivity in the membrane, cytoplasm and/or nucleus when observed by two evaluators (SC, IK). Percentage positive scores were assigned according to the following scale: $0,<10 \%$ cells; $1,10-30 \%$ cells; 2, 31-50\% cells; $3,51-70 \%$ cells; and $4,>70 \%$. Staining intensity was then also scored semiquantitatively as follows: 0 , none; 1 , mild; 2 , moderate; and 3 , intense. A total score was then obtained (ranging from 0 to 7 ) by adding the percentage positivity scores and intensity scores for each section. Average scores of three representative areas for the histotype on diagnosis of the tissues were calculated to obtain a final score for the immunostained slide. The average scores of the two evaluators were used for subsequent analyses; inter-examiner variability was minimal. Scatter plots were used to determine the distribution of total score of membrane, cytoplasmic, and/or nuclear expression for proteins analyzed. Also, to assess the total expression of ALCAM in the tissues, the membrane and cytoplasm scores were added to obtain 
a total score out of 14 . Box plots were used to determine the distribution of membranous, cytoplasmic, and total expression IHC scores for ALCAM.

\section{Enzyme Linked Immunosorbent Assay}

For ALCAM, sera from 44 patients with benign thyroid nodules, 29 with nonaggressive TC, and 17 with aggressive TC were analyzed using ELISA. For AXL, sera from 48 patients with benign thyroid nodules, 32 with non-aggressive TC, and 18 with aggressive TC were analyzed. Serum levels of ALCAM and AXL proteins were analyzed in duplicates using commercially available human AXL ELISA kit and CD166 (ALCAM) ELISA kit (R \& D Systems, Minneapolis, MN). For both ALCAM and AXL, primary antibodies were diluted to a concentration of $2.0 \mu \mathrm{g} / \mathrm{mL}$ in PBS and $100 \mu \mathrm{L}$ of the diluted antibody was used to coat 96 well microtiter plates overnight at room temperature. The plate was then washed three times with $0.05 \%$ Tween 20 in PBS after each step and aspirated prior to blocking with 1\% BSA in PBS (reagent diluent) for $1 \mathrm{~h}$. Then $100 \mu \mathrm{L}$ of patient sera samples (diluted 1:500 with reagent diluent), were added to each well and incubated for $2 \mathrm{~h}$. Thereafter, $100 \mu \mathrm{L}$ of secondary antibody (diluted to a concentration of $50 \mathrm{ng} / \mathrm{mL}$ with reagent diluent) was added for $2 \mathrm{~h}$. After washing, $100 \mu \mathrm{L}$ of streptavidin-HRP was added to each well of the plate for $20 \mathrm{~min}$. The color was developed with $100 \mu \mathrm{L}$ of tetramethylbenzadine for $20 \mathrm{~min}$ and the reaction was stopped with $50 \mu \mathrm{L}$ of $2 \mathrm{~N} \mathrm{H}_{2} \mathrm{SO}_{4}$. The absorbance was measured with a microtiter plate reader at 450 nm. 


\section{Statistical analyses}

The immunohistochemical data were subjected to statistical analyses using SPSS 20.0 software (SPSS Inc., Chicago, IL). Frequencies were reported for categorical variables and mean \pm standard deviation was reported for continues variables. Area-under-curve (AUC), sensitivity, and specificity were determined using receiver operating characteristic (ROC) analysis. The relationships between protein expression and clinico-pathological parameters were tested using Chi-Square and/or Fischer's exact test. Two-sided $\mathrm{p}$ values were calculated and $\mathrm{p}<$ 0.05 was considered to be significant. For ALCAM IHC data, cut-off values of $\geq 3, \geq 4.5$, and $\geq$ 7 were defined as positive criteria of immunoreactivity for membrane, cytoplasmic, and total ALCAM expression, respectively, based on sensitivity and specificity values, for statistical analysis. The relationships between ALCAM expression (positive/ negative) and categorical variables- clinico-pathological parameters were tested using Chi-square and/or Fischer's exact test. Positive predictive value (PPV), negative predictive value (NPV), odds ratio (OR), and 95\% confidence interval $(\mathrm{CI})$ were also calculated. Kaplan-Meier survival plots were used to determine correlation of ALCAM expression and disease-free survival in TC patients, to determine the suitability of ALCAM as a prognostic marker. Disease-free survival analysis was thyroid cancer specific, whereby an event (no survival) was defined as thyroid cancer recurrence, metastasis, or death during patient follow-up. Hazard ratios (HR) were also calculated. Cox-regression (multivariate) analysis was performed to determine the prognostic potential of ALCAM expression in comparison with known clinical and pathological parameters. Student's $t$ test was used to analyze serum ALCAM and AXL data, separately. 
Chi-Square and Fischer's exact test was used to analyze the two proteins in combination, and a cut-off sera value of $42 \mathrm{ng} / \mathrm{mL}$ was used as the positive criteria for each ALCAM and AXL in the analysis. All scatterplots were produced using GraphPad Prism 5.0 Software (La Jolla, CA, USA). 


\section{Chapter 4 \\ Results}

\section{Results}

\subsection{Protein Identification and Bioinformatics}

To identify potential serum biomarkers for aggressive TC, the secretomes of two aggressive TC cell lines (anaplastic-derived; SW1736, C643) and a non-aggressive (papillaryderived; BCPAP) cell line were systematically analyzed. All 83 high confidence ( $\geq 95 \%)$ secretome proteins identified by proteomics were analyzed by IPA to investigate their potential interactions in cellular networks. A refined network of important interactions of our secretome proteins is shown in Figure 2. The network generated suggests that several of the identified secretome proteins (shown in red and highlighted in yellow, Figure 2) interact with cytoplasmic proteins via membrane-bound receptors such as EGFR, L1 cell adhesion molecule (L1CAM), and nerve growth factor receptor (NGFR). These membrane receptors play key roles in regulating cancer progression. Furthermore, AXL was found to interact with GRB2 and SRC, both intermediates of EGFR signaling pathways. As mentioned earlier, EGFR is associated with tumour aggressiveness and is often chosen as a target for different therapeutic agents used in clinical trials of cancer patients. 14-3-3 zeta (YWHAZ) is a major cytoplasmic hub protein having direct interactions (shown with bold lines in Figure 2) with a large number of identified secretome proteins and EGFR-signalling pathways. ALCAM was found to have direct interactions with L1CAM and NGFR, and indirect interactions with EGFR and 14-3-3 zeta signalling. From this network, 14-3-3 zeta, APLP2, APP, ALCAM, AXL, hnRNP K, PGK1, PKM2, and SET were selected for further analyses in sera and tissues of TC patients. 
This panel of nine proteins was chosen based on their reported roles in tumour progression in the literature $(144,146-153)$, and importantly, these proteins were all identified in the CM of anaplastic-derived cell lines. Furthermore, the potential direct or indirect interactions these secretome proteins have in cancer relevant pathways, namely EGFR-activated pathways, make them of great interest to further investigate. Some of these proteins have been previously studied in several different types of cancer, though some of them have not been investigated in thyroid carcinomas $(144,146-153)$. The peptide sequences identified by mass spectrometric analysis for these nine proteins are listed in Appendix I and their mass spectra and information are given in Appendix II. 


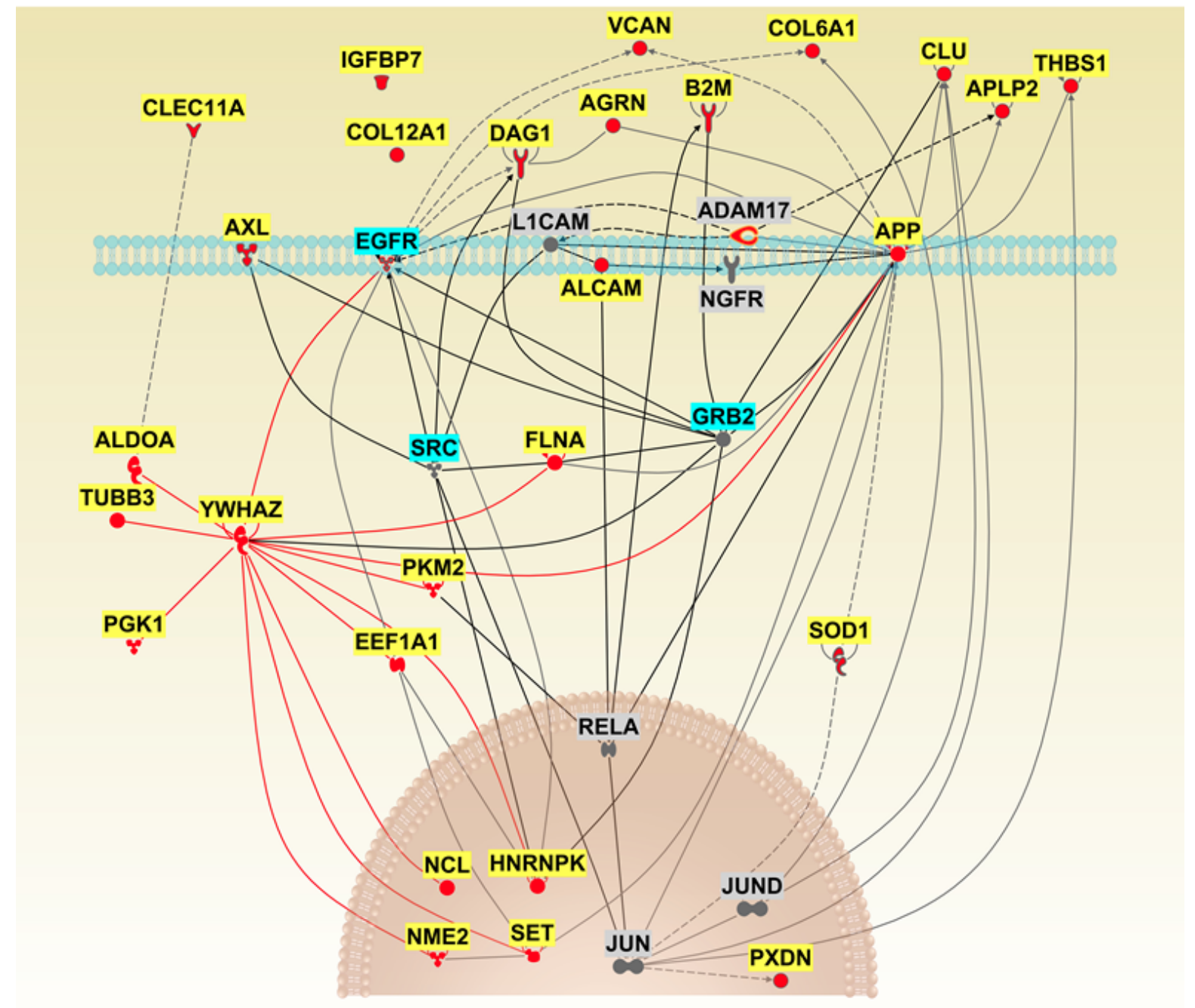

Figure 2. Ingenuity Pathway Analysis 
Figure 2. Ingenuity Pathway Analysis reveals several important protein-protein interactions of identified secretome proteins. The network generated suggests several extracellular secretome proteins (labelled in red and highlighted in yellow) interact with cytoplasmic proteins via membrane-bound receptors such as EGFR, L1CAM, and NGFR. Furthermore, AXL interacts with GRB2 and SRC, both intermediates of EGFR signalling pathways. 14-3-3 zeta (YWHAZ) was also observed to be a potential central cytoplasmic hub mediating interactions between many of the secretome proteins and EGFR-signalling pathways. ALCAM was found to have interactions with L1CAM and NGFR, and indirect associations to the EGFR-activated pathways. From this network, 14-3-3 zeta, APLP2, APP, ALCAM, AXL, hnRNP K, PGK1, PKM2, and SET were selected for further analysis in sera and/or tissues of thyroid cancer patients. Bold lines represent direct protein-protein interactions and dashed lines represent indirect interactions. 


\subsection{Detection of Secretome Proteins in Human Sera by Western Blots}

To confirm that these proteins are secreted and can be detected in TC patients' sera, the presence of these 9 proteins was examined in sera from patients with benign nodules $(n=6)$, non-aggressive TC $(\mathrm{n}=6)$, and aggressive TC $(\mathrm{n}=6)$. As shown in Figure 3, AXL (A1,A2), APP (B1, B2), APLP2 (C1, C2), ALCAM (D), 14-3-3 zeta (E), PKM2 (F), and SET (G) were all detected in sera of patients with benign thyroid nodules, non-aggressive and aggressive TCs. hnRNP K and PGK1 could not be detected in sera of either benign or TC patients analyzed in this study. Differences were observed between the sera of patients with benign nodules and TCs for ALCAM, APP, AXL, 14-3-3 zeta, and PKM2. Two immunoblot panels are shown for AXL, APP, and APLP2 in Figure 3 (A-C) to depict the variations observed in sera from patients with benign nodules, non-aggressive TC and aggressive TC. The variations observed within these groups for AXL were also observed using ELISA (section 4.4). Ponceau $\mathrm{S}$ staining was performed to confirm equal protein loading (Figure $3 \mathrm{H}$, full blot Appendix III). Although the immunodepletion of abundant proteins in sera may cause off-target size bands, the observed size of protein bands were as would be expected according to what is reported in the literature and the antibody datasheets. 


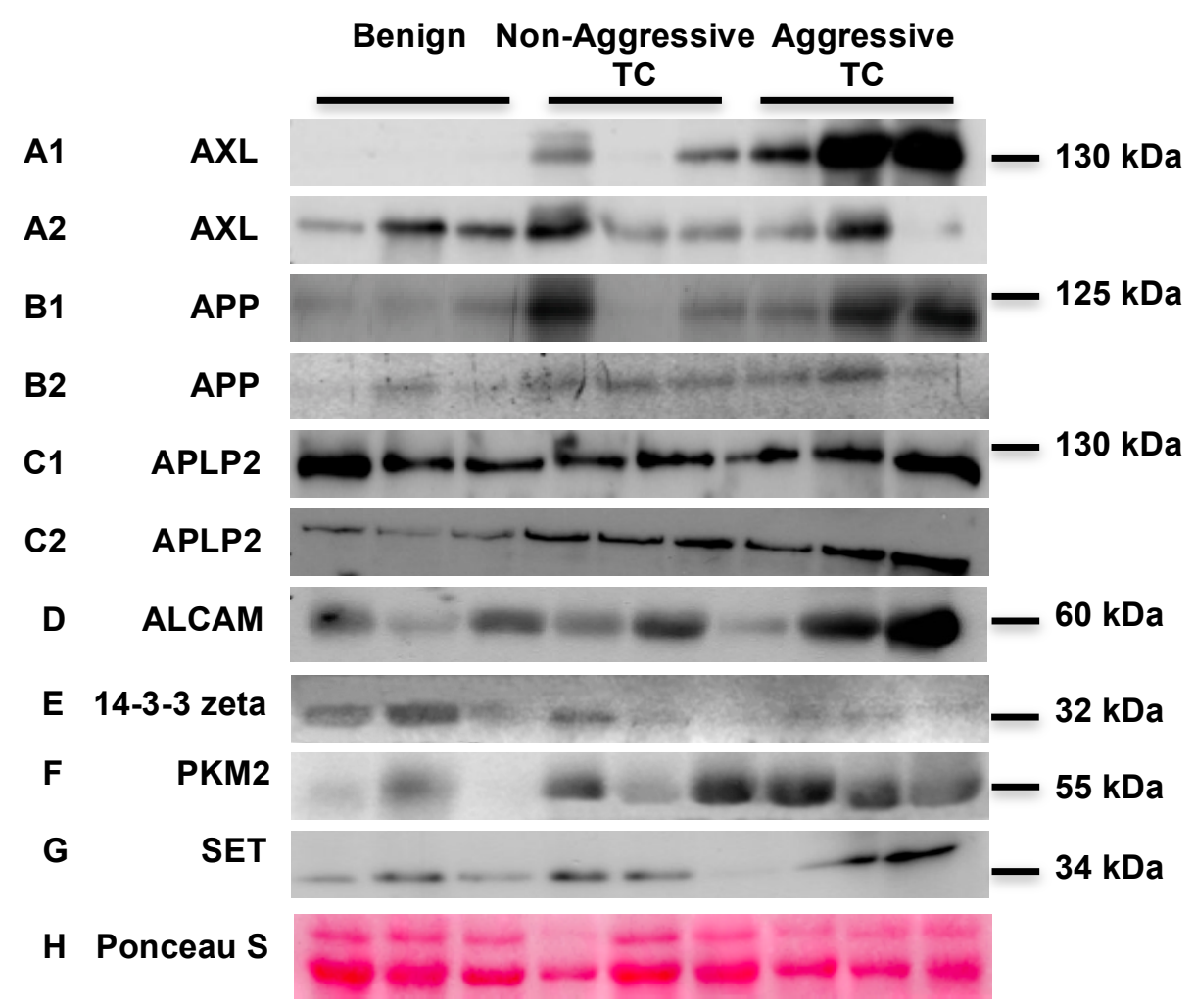

Figure 3. Identified secretome proteins are detected in benign and thyroid cancer patients' sera using western blot analysis. Protein samples $(50 \mu \mathrm{g})$ were prepared from the sera of cancer-free individuals and TC patients. AXL (A1, A2), APP (B1, B2), APLP2 (C1, C2), ALCAM (D), 14-3-3 zeta (E), PKM2 (F), and SET (G) were all detected in sera of patients with benign thyroid nodules, non-aggressive and aggressive TCs using western blot analysis, and show potential differences between TC subgroups. Aggressive cancer group consisted of individuals with PTC with stage IV TC and/or having distant metastasis, and nonaggressive cancer as stage I PTC with no metastasis. Single blots are shown, except for AXL, APP, and APLP2, which are represented by two blots to show variations in sera levels within different patient groups. Ponceau S stained blot is shown to demonstrate equal loading $(\mathbf{H})$. 


\subsection{Immunohistochemical Analysis of Identified Proteins in Human Thyroid Tissues}

Immunohistochemical analysis of proteins APLP2, APP, AXL, PGK1, hnRNP K, SET, PKM2, and 14-3-3 zeta was carried out to investigate alterations in their expression in benign and malignant thyroid tissues (Fig.4). Scatter plots showing the distribution of immunohistochemical scores for these proteins are shown in Figure 5. The clinico-pathological information of patients is listed in Appendix IV. All eight proteins were detected in benign and malignant thyroid tissues and showed differential expression (Fig. 4 and Table V). An increase in cytoplasmic expression of APLP2 was observed in cancer as compared to benign tissues ( $p$ $=0.044$; Fig. 4IA). Nuclear APP expression was significantly downregulated in malignant as compared to benign tissues $(\mathrm{p}<0.001$, AUC $=0.937$; Fig. 4IB). ROC curves for all protein expressions are shown in Appendix V, and AUC, sensitvity, specificity, PPV, and NPV values for statistical tests of protein IHC scores are listed in Appendix VI. No significant difference was observed in the cytoplasmic APP expression in benign and malignant thyroid tissues. Nuclear AXL expression could distinguish malignant tumours from benign nodules with the greatest accuracy in comparison to the rest of the proteins. AXL nuclear expression was decreased in TCs compared to benign nodules $(\mathrm{p}<0.001, \mathrm{AUC}=0.995$, sensitivity $=100 \%$, specificity $=90 \%, \mathrm{PPV}=90.9 \%, \mathrm{NPV}=100 \%)$. Cytoplasmic AXL expression was also decreased in malignant tissues $(p=0.001$, AUC $=0.788$; Fig. 4IC). A decrease in nuclear expression of SET was observed in TCs as compared to the benign tissues $(\mathrm{p}<0.001$, AUC $=$ 0.963; Fig. 4ID). Both nuclear and cytoplasmic staining was obseved for PKM2 with a significant decrease in nuclear expression in TCs $(p<0.001, \mathrm{AUC}=0.977$; Fig. 4IIE). 

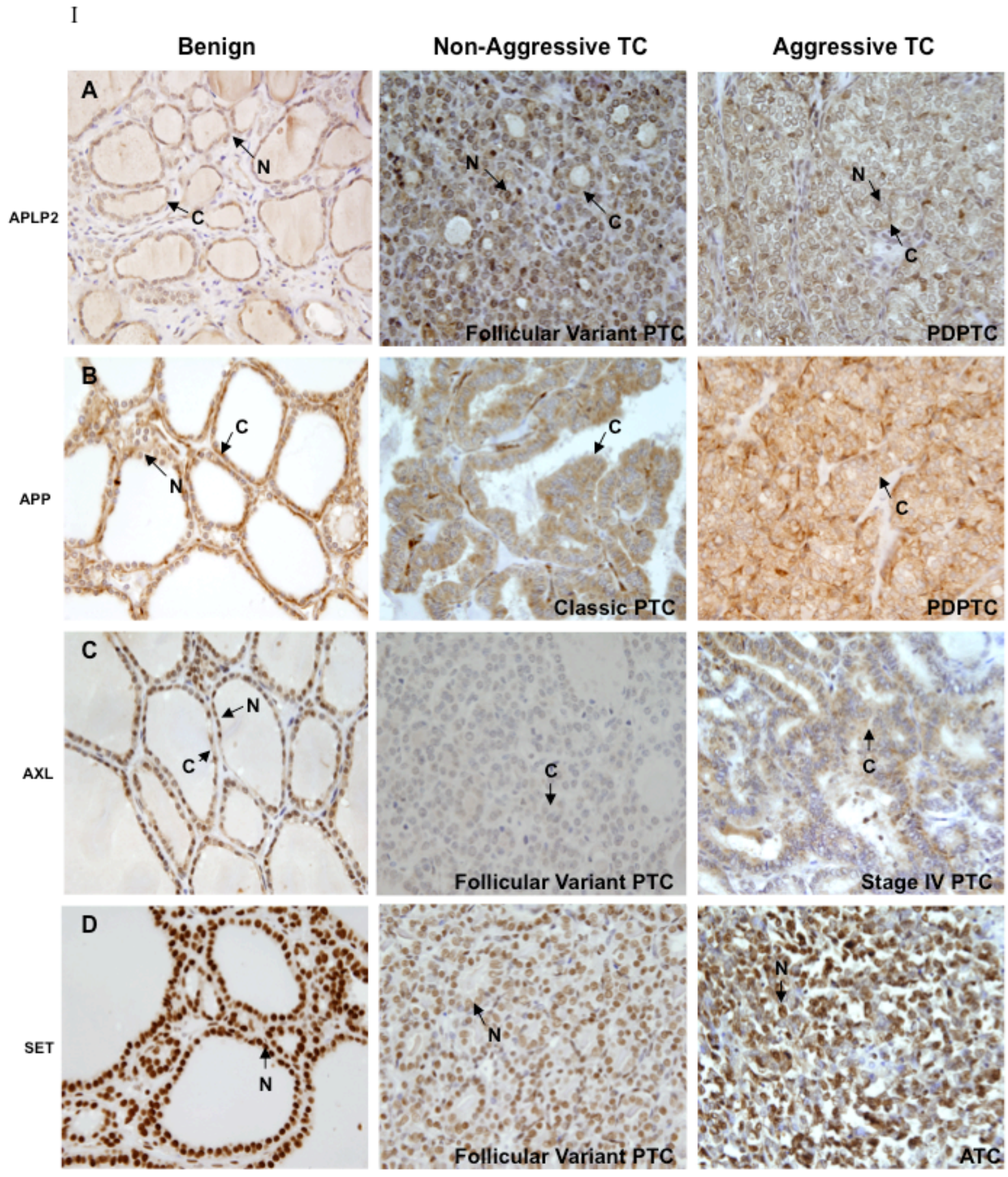

Figure 4. Immunostaining of secretome proteins 


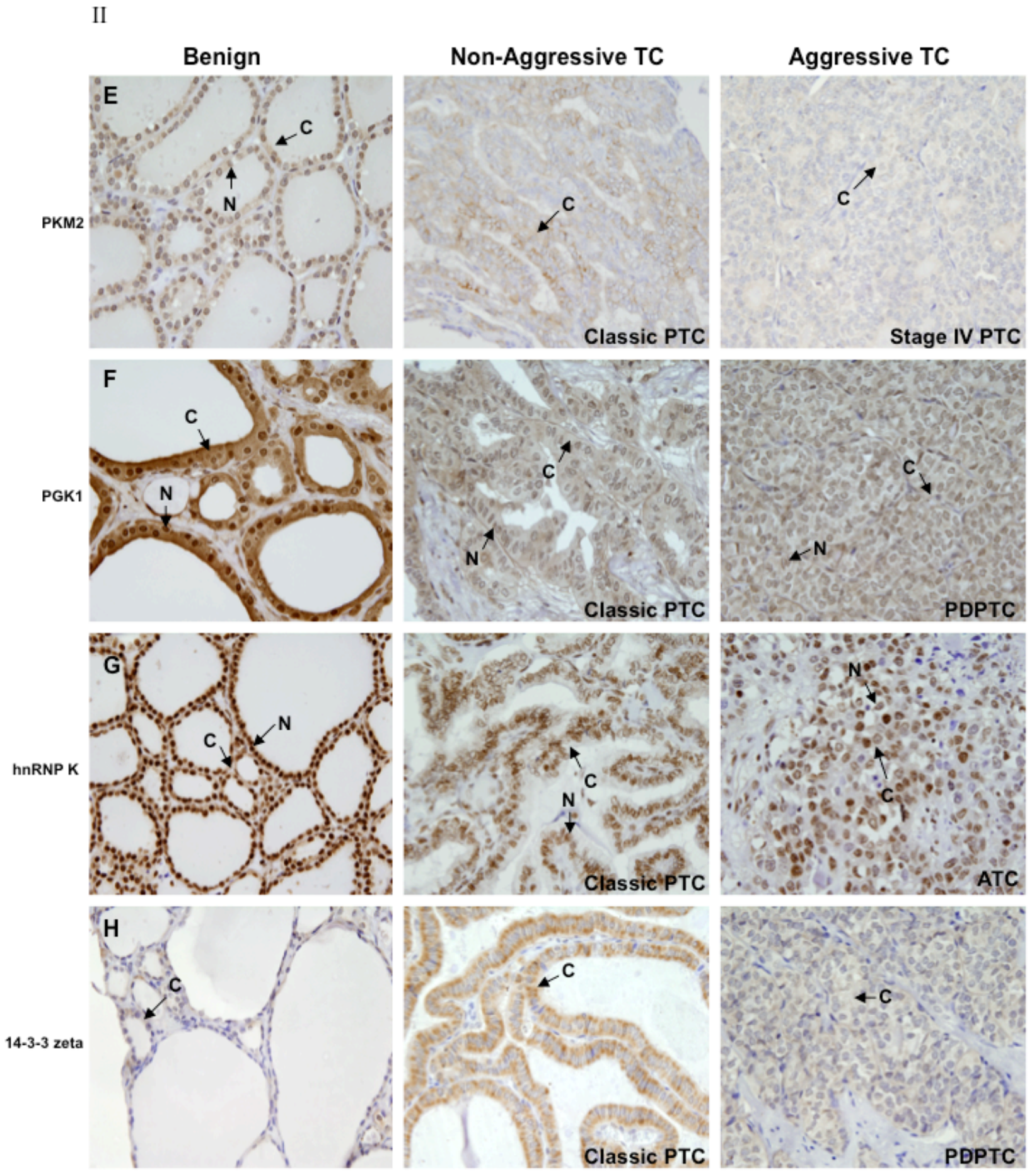

Figure 4. Continued 
Figure 4. Immunostaining of proteins in human benign and thyroid cancer tissues shows differences in subcellular localization. Tissues were classified as benign, non-aggressive (Stage 1 PTC) or aggressive (stage 4 PTC, insular, PDPTC, or ATC). Differential nuclear (N) or cytoplasmic (C) expression of all proteins was observed in benign and malignant tissues using immunohistochemistry. (IA) Cytoplasmic and nuclear expression of APLP2 is shown in benign and malignant tissues; (IB) A decrease in nuclear APP expression in both aggressive and non-aggressive TC tissues is shown compared to benign tissue; (IC) A decrease in nuclear and cytoplasmic AXL expression is observed for cancer compared to benign tissues; (ID) Decreased SET nuclear expression observed in cancer tissues compared to benign tissues; (IIE) Cytoplasmic staining for PKM2 is shown while nuclear expression is only observed in benign tissues; (IIF) Nuclear and cytoplasmic staining for PGK1 was observed in benign tissues, and decrease in nuclear and cytoplasmic staining was observed in cancer tissues; (IIG) Decreased nuclear and cytoplasmic staining of hnRNP $\mathrm{K}$ is shown for cancers compared to benign tissue; (IIH) An increase in cytoplasmic staining of 14-3-3 zeta is shown for nonaggressive cancer compared to benign, while a decrease is observed in aggressive tissue compared to non-aggressive. Magnification is $400 \mathrm{X}$. 

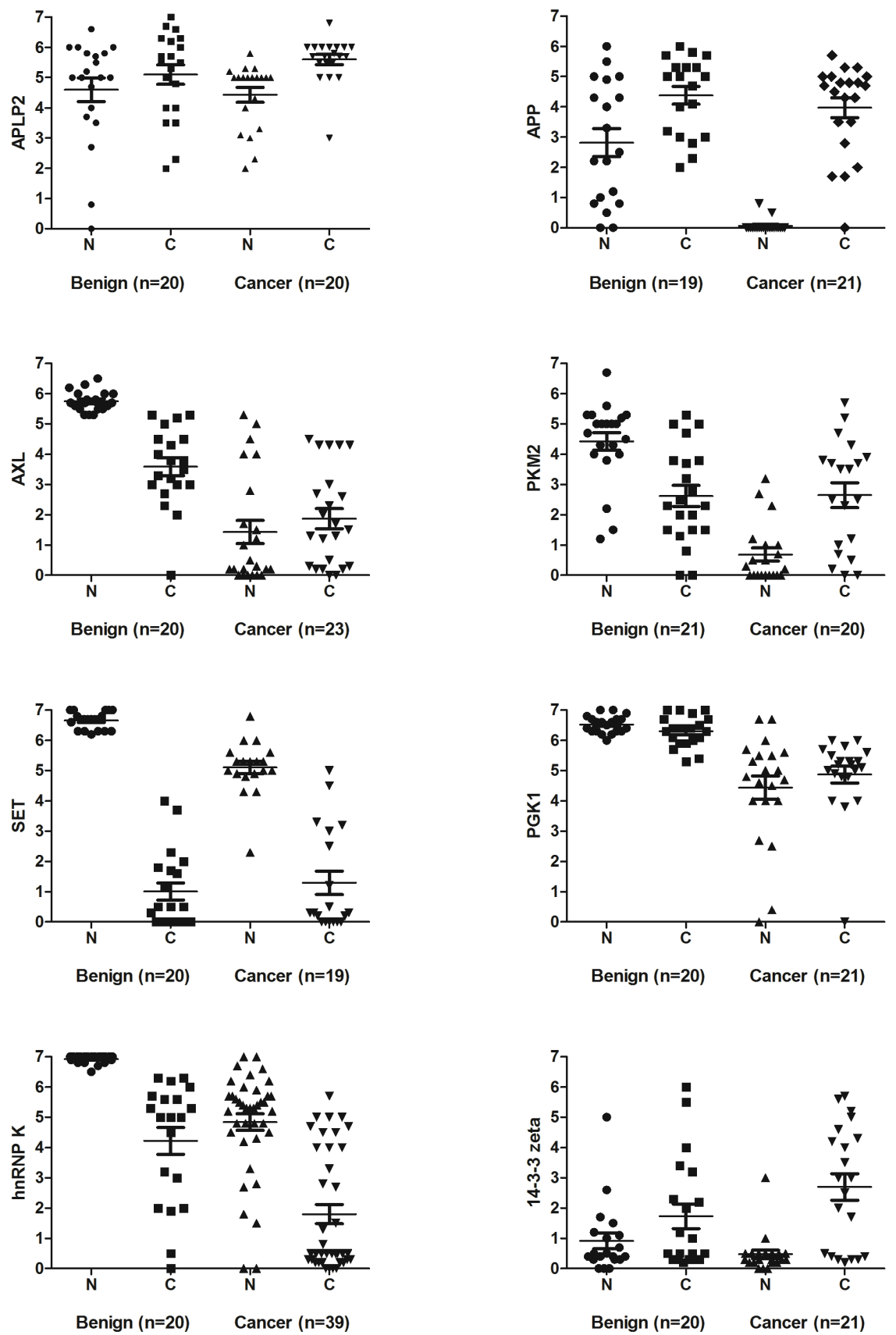

Figure 5. Scatterplot analysis for immunohistochemical thyroid tissue scores 
Figure 5. Scatterplot analysis for immunohistochemical (IHC) scores of proteins in thyroid tissues. Each symbol corresponds to an individual patient. Thick horizontal bars denote mean IHC score values for each group \pm standard error. Significantly reduced nuclear expression of APP, AXL, PKM2, PGK1, hnRNP $\mathrm{K}$ and SET was observed in malignant compared to benign tissues. Cytoplasmic expression of AXL, PGK1 and hnRNP K was significantly decreased in malignant tissues compared to benign, while increased APLP2 expression was observed in malignant tissues. $\mathrm{N}=$ nuclear and $\mathrm{C}=$ cytoplasmic. 


\section{TABLE V}

Immunohistochemical analysis of secretome proteins in benign versus malignant thyroid tissues

\begin{tabular}{|c|c|c|c|c|c|c|c|}
\hline \multirow[t]{2}{*}{ Proteins } & \multirow{2}{*}{$\begin{array}{c}\text { Total } \\
\text { Cases } \\
\\
\mathbf{N}\end{array}$} & \multicolumn{2}{|c|}{$\begin{array}{l}\text { Nuclear } \\
\text { Positivity }\end{array}$} & \multirow[t]{2}{*}{$p$} & \multicolumn{2}{|c|}{$\begin{array}{c}\text { Cytoplasmic } \\
\text { Positivity }\end{array}$} & \multirow[t]{2}{*}{$p$} \\
\hline & & $\mathbf{N}$ & $\%$ & & $\mathbf{N}$ & $\%$ & \\
\hline \multicolumn{8}{|l|}{ APLP2 } \\
\hline Benign & 20 & 13 & 65 & 1.000 & 13 & 65 & 0.044 \\
\hline Cancer & 20 & 13 & 65 & & 19 & 95 & \\
\hline \multicolumn{8}{|l|}{ APP } \\
\hline Benign & 19 & 12 & 63 & $<0.001$ & 11 & 58 & 0.745 \\
\hline Cancer & 21 & 0 & 0 & & 14 & 67 & \\
\hline \multicolumn{8}{|l|}{ AXL } \\
\hline Benign & 20 & 20 & 100 & $<0.001$ & 16 & 80 & 0.001 \\
\hline Cancer & 23 & 2 & 9 & & 6 & 26 & \\
\hline \multicolumn{8}{|l|}{ hnRNP K } \\
\hline Benign & 20 & 20 & 100 & $<0.001$ & 15 & 75 & 0.002 \\
\hline Cancer & 39 & 22 & 56 & & 12 & 31 & \\
\hline \multicolumn{8}{|l|}{ PGK1 } \\
\hline Benign & 20 & 20 & 100 & $<0.001$ & 20 & 100 & $<0.001$ \\
\hline Cancer & 21 & 8 & 38 & & 9 & 43 & \\
\hline \multicolumn{8}{|l|}{ PKM2 } \\
\hline Benign & 21 & 18 & 86 & $<0.001$ & 7 & 33 & 0.350 \\
\hline Cancer & 20 & 0 & 0 & & 10 & 50 & \\
\hline \multicolumn{8}{|l|}{ SET } \\
\hline Benign & 20 & 20 & 100 & $<0.001$ & 4 & 20 & 0.480 \\
\hline Cancer & 19 & 5 & 26 & & 6 & 32 & \\
\hline \multicolumn{8}{|l|}{ 14-3-3 zeta } \\
\hline Benign & 20 & 7 & 35 & 0.067 & 5 & 25 & 0.058 \\
\hline Cancer & 21 & 2 & 9.5 & & 12 & 57 & \\
\hline
\end{tabular}


Reduced PGK1 nuclear and cytoplasmic expression was observed in malignant tissues as compared to benign nodules $(\mathrm{p}<0.001$, AUC $=0.926$ and $\mathrm{p}<0.001$, AUC $=0.950$, respectively; Fig. 4IIF). A decrease in nuclear $(\mathrm{p}<0.001, \mathrm{AUC}=0.962)$ and cytoplasmic $(\mathrm{p}=$ 0.002, $\mathrm{AUC}=0.816$ ) expression of hnRNP K was also observed in TCs as compared to the benign tissues (Fig. 4IIG). There was an increase in 14-3-3 zeta cytoplasmic expression in malignant compared to benign tissues, though not significant (Fig. 4IIH).

\section{Immunohistochemical analysis of ALCAM in human thyroid tissues}

Immunohistochemical analysis of ALCAM was carried out to determine differences in its subcellular localization and levels of expresssion, including total expression, in benign thyroid tissues and different subtypes of TC in a large patient cohort. ALCAM expression in relation to patients' clinico-pathological characteristics is listed in Table VI. Representative tissues sections showing the immunostaining pattern of ALCAM in benign thyroid nodules and several variants of TCs are shown in Figure 6. Intense membrane and cytoplasmic staining was observed in Stage I classic PTC compared to benign thyroid tissues (Fig. 6a, 6b), whereas decreased membrane expression was observed in the stage IV PTC (Fig. 6c). No membrane staining and very mild cytoplasmic staining was seen in ATCs (Fig. 6d). The PDPTC and insular carcinomas (poorly-differentiated TCs) showed reduced membrane and cytoplasmic staining (Fig. 6e, 6f). Differences in patterns of staining were observed among the PTC variants. The tall cell variant PTCs displayed strong membrane and cytoplasmic staining (Fig. 6g); follicular variant showed decreased positivity and mild membrane staining with mild to moderate cytoplasmic staining (Fig. 6h); while the oncocytic variant showed moderate cytoplasmic staining and mild membrane staining (Fig. 6i). 


\section{TABLE VI}

\section{Analysis of ALCAM expression with clinical and pathological characteristics}

\begin{tabular}{|c|c|c|c|c|c|c|c|c|c|c|}
\hline $\begin{array}{l}\text { Clinico- } \\
\text { pathological } \\
\text { Feature }\end{array}$ & $\begin{array}{l}\text { Total } \\
\text { Cases }\end{array}$ & $\begin{array}{c}\text { Membrane } \\
\text { Positivity } \\
\mathrm{N}(\%)\end{array}$ & $\begin{array}{c}p \\
\text { value }\end{array}$ & $\begin{array}{c}\text { OR } \\
(95 \% \mathrm{CI})\end{array}$ & $\begin{array}{c}\text { Cytoplasmic } \\
\text { Positivity } \\
\text { N (\%) }\end{array}$ & $\begin{array}{c}p \\
\text { value }\end{array}$ & $\begin{array}{c}\text { OR } \\
(95 \% \mathrm{CI})\end{array}$ & $\begin{array}{c}\text { Total } \\
\text { Positivity } \\
\text { N }(\%)\end{array}$ & $\begin{array}{c}p \\
\text { value }\end{array}$ & $\begin{array}{c}\text { OR } \\
(95 \% \mathrm{CI})\end{array}$ \\
\hline \multicolumn{11}{|l|}{ Age } \\
\hline$<45$ & 91 & $70(76.9)$ & 0.010 & $\begin{array}{c}2.31 \\
(1.24-4.28)\end{array}$ & $77(84.6)$ & 0.576 & $\begin{array}{c}1.30 \\
(0.62-2.73)\end{array}$ & $80(87.9)$ & 0.020 & $\begin{array}{c}2.48 \\
(1.16-5.32)\end{array}$ \\
\hline$\geq 45$ & 110 & $65(48.1)$ & & & $89(53.6)$ & & & $82(50.6)$ & & \\
\hline \multicolumn{11}{|l|}{ Gender } \\
\hline Male & 47 & $26(55.3)$ & 0.051 & $\begin{array}{c}1.99 \\
(1.02-3.90) \\
\end{array}$ & $35(74.5)$ & 0.121 & $\begin{array}{c}1.98 \\
(0.90-4.37) \\
\end{array}$ & $33(70.2)$ & 0.055 & $\begin{array}{c}2.22 \\
(1.04-4.74) \\
\end{array}$ \\
\hline Female & 156 & $111(71.2)$ & & & $133(85.3)$ & & & $131(84)$ & & \\
\hline \multicolumn{11}{|l|}{ Pathology } \\
\hline Benign & 45 & $41(91.1)$ & $<0.001$ & $\begin{array}{c}6.62 \\
(2.26-19.40) \\
\end{array}$ & $44(97.8)$ & 0.001 & $\begin{array}{c}12.07 \\
(1.60-90.77) \\
\end{array}$ & $44(97.8)$ & $<0.001$ & $\begin{array}{c}13.93 \\
(1.86-104.55) \\
\end{array}$ \\
\hline Cancer & 158 & $96(60.8)$ & & & $124(78.5)$ & & & $120(75.9)$ & & \\
\hline \multicolumn{11}{|l|}{$\begin{array}{l}\text { Histological } \\
\text { Grade }\end{array}$} \\
\hline $\begin{array}{l}\text { Well- } \\
\text { Differentiated }\end{array}$ & 135 & $90(66.7)$ & $<0.001$ & $\begin{array}{c}5.67 \\
(2.09-15.36) \\
\end{array}$ & $116(85.9)$ & $<0.001$ & $\begin{array}{c}11.45 \\
(4.27-30.68)\end{array}$ & $114(84.4)$ & $<0.001$ & $\begin{array}{c}15.38 \\
(5.43-43.54) \\
\end{array}$ \\
\hline $\begin{array}{l}\text { Poorly/Un- } \\
\text { Differentiated }\end{array}$ & 23 & $6(26)$ & & & $8(34.8)$ & & & $6(26)$ & & \\
\hline \multicolumn{11}{|l|}{ Histotype } \\
\hline Classic PTC & 77 & $54(70.1)$ & 0.009 & - & $67(87)$ & $<0.001$ & - & $66(85.7)$ & $<0.001$ & \\
\hline Follicular PTC & 44 & $28(63.6)$ & & & $37(84)$ & & & $37(84)$ & & \\
\hline Tall cell PTC & 5 & $4(80)$ & & & $4(80)$ & & & $4(80)$ & & \\
\hline Oncocytic PTC & 9 & $4(44.4)$ & & & $8(88.9)$ & & & $7(77.8)$ & & \\
\hline PDPTC & 2 & $0(0)$ & & & $2(100)$ & & & $2(100)$ & & \\
\hline Insular TC & 8 & $2(25)$ & & & $3(37.5)$ & & & $2(25)$ & & \\
\hline ATC & 13 & $4(30.8)$ & & & $3(23.1)$ & & & $2(15.4)$ & & \\
\hline \multicolumn{11}{|l|}{ AJCC Stage } \\
\hline I & 93 & $64(68.8)$ & 0.290 & 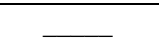 & $77(82.8)$ & 0.380 & 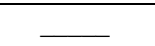 & $78(83.9)$ & 0.472 &  \\
\hline II & 11 & $5(45.5)$ & & & $9(81.8)$ & & & $8(72.7)$ & & \\
\hline III & 10 & $5(50)$ & & & $10(100)$ & & & $8(80)$ & & \\
\hline IV & 24 & $14(58.3)$ & & & $18(75)$ & & & $17(70.8)$ & & \\
\hline LN Metastasis & 50 & $34(68)$ & 0.581 & $\begin{array}{c}0.76 \\
(0.37-1.58) \\
\end{array}$ & $41(82)$ & 0.813 & $\begin{array}{c}1.18 \\
(0.47-2.95) \\
\end{array}$ & $40(80)$ & 0.822 & $\begin{array}{c}1.14 \\
(0.47-2.75) \\
\end{array}$ \\
\hline $\begin{array}{l}\text { Distant } \\
\text { Metastasis }\end{array}$ & 7 & $2(28.6)$ & 0.096 & $\begin{array}{c}5.00 \\
(0.93-26.86) \\
\end{array}$ & $3(42.9)$ & 0.017 & $\begin{array}{c}7.51 \\
(1.56-36.25) \\
\end{array}$ & $4(57.1)$ & 0.148 & $\begin{array}{c}3.19 \\
(0.67-15.19) \\
\end{array}$ \\
\hline $\begin{array}{l}\text { Extrathyroida } \\
\text { l Extension }\end{array}$ & 38 & $22(57.9)$ & 0.327 & $\begin{array}{c}1.48 \\
(0.69-3.18) \\
\end{array}$ & $25(65.8)$ & 0.002 & $\begin{array}{c}4.21 \\
(1.68-10.53) \\
\end{array}$ & $26(68.4)$ & 0.052 & $\begin{array}{c}2.62 \\
(1.09-6.29) \\
\end{array}$ \\
\hline Multifocality & 85 & $50(58.8)$ & 0.153 & $\begin{array}{c}1.75 \\
(0.85-3.61) \\
\end{array}$ & $68(80)$ & 0.659 & $\begin{array}{c}1.31 \\
(0.54-3.18) \\
\end{array}$ & $67(78.8)$ & 1.000 & $\begin{array}{c}1.10 \\
(0.48-2.55) \\
\end{array}$ \\
\hline $\begin{array}{l}\text { Perineural } \\
\text { Invasion }\end{array}$ & 6 & $2(33.3)$ & 0.187 & $\begin{array}{c}3.83 \\
(0.68-21.68) \\
\end{array}$ & $5(83.3)$ & 1.000 & $\begin{array}{c}0.92 \\
(0.10-8.21) \\
\end{array}$ & $3(50)$ & 0.094 & $\begin{array}{c}4.36 \\
(0.83-22.89) \\
\end{array}$ \\
\hline
\end{tabular}



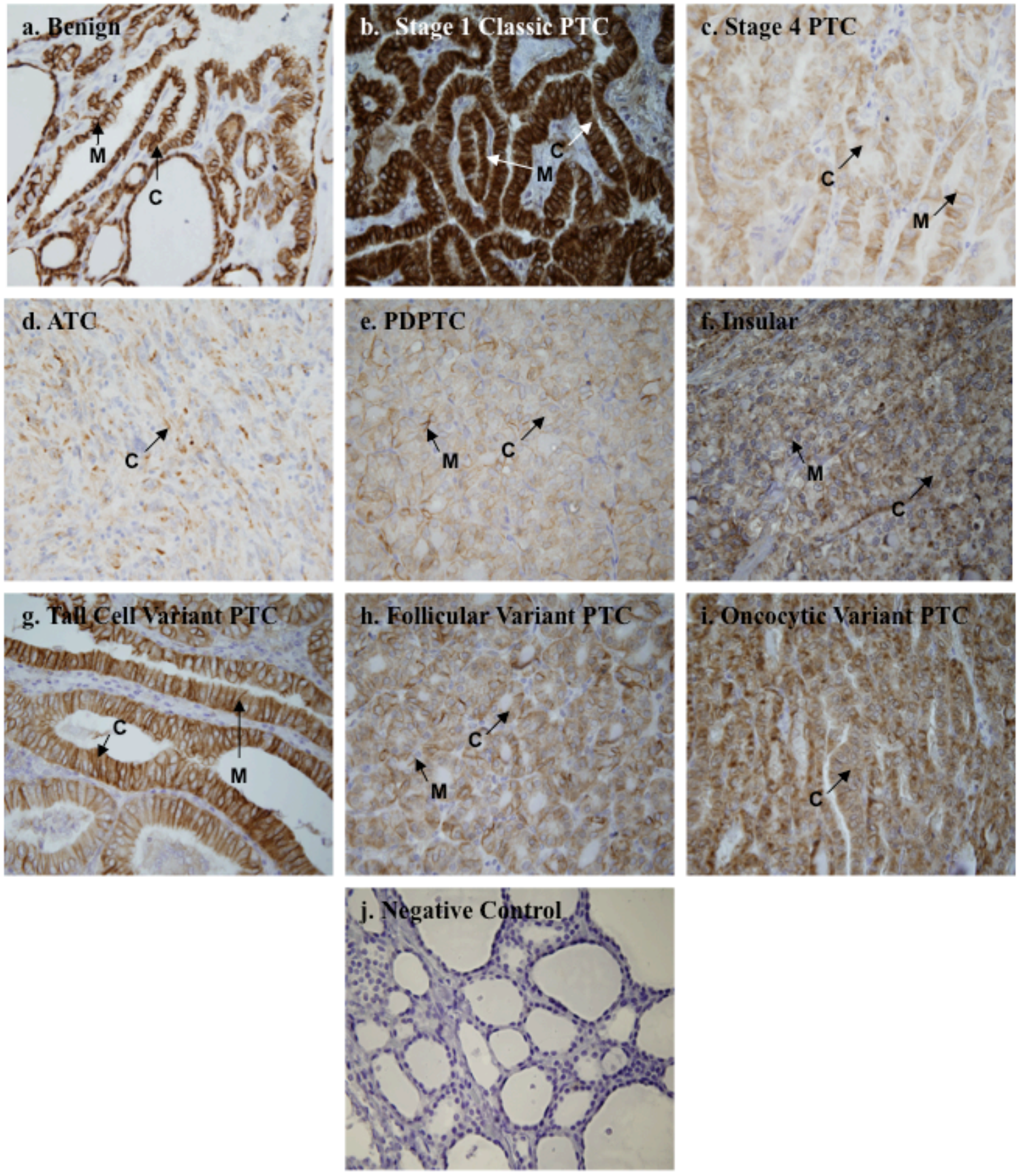

Figure 6. Immunostaining of ALCAM in different thyroid cancer subtypes 
Figure 6. Immunostaining of ALCAM shows different expression between benign, nonaggressive, and aggressive human thyroid cancer tissues. Paraffin-embedded sections of benign thyroid nodules and different subtypes of thyroid carcinomas were immunostained using anti-CD166 monoclonal antibody as described in the Methods section. The photomicrographs of representative immunostained tissues depict: (a) benign nodule showing ALCAM membrane and cytoplasmic expression; (b) classic PTC showing strong membrane and cytoplasmic expression; (c) stage IV PTC showing mild membrane and cytoplasmic staining; (d) ATC showing no membrane and scant cytoplasmic expression; (e) PDPTC and (f) insular carcinoma showing some mild membrane and cytoplasmic expression; (g) tall cell variant PTC showing strong membrane and moderate cytoplasmic expression; (h) follicular variant PTC depicting some membrane expression and moderate cytoplasmic expression; (i) oncocytic cell variant PTC showing predominantly cytoplasmic expression; and (j) negative control showing no immunostaining. Arrows show membranous (M) and cytoplasmic (C) ALCAM expression. Magnification is 400x. 
Comparison of the staining patterns of histological variants of TC revealed significant differences in levels of ALCAM staining intensity and percentage positivity among the different groups for both total and subcellular ALCAM expression; membrane $\mathrm{p}=0.009$, cytoplasm $\mathrm{p}<0.001$, and total $\mathrm{p}<0.001$ (Table VI). Membrane, cytoplasmic, and total ALCAM expression were significatly decreased in TCs as compared to benign tissues ( $p<$ 0.001). Comparing ALCAM staining across the four stages of TC did not reveal significance, though an overall decrease in expression was observed in advanced stage TC. Membrane, cytoplasmic, and total ALCAM expression was also decreased in TC cases with distant metastasis. Cytoplasmic ALCAM was positive in 3 of 7 distant metastasis cases, while only 2 of 7 cases were positive for membrane ALCAM expression. Decreased cytoplasmic ALCAM expression was significantly associated with extrathyroidal extension $(p=0.002$, Table VI).

To evaluate the ability of ALCAM to serve as a marker for aggressive TC, the malignant cases were subdivided into two groups according to histological grade; welldifferentiated (non-aggressive) and poorly/undifferentiated (aggressive) TC (Figure 7A). Significantly decreased membrane $(\mathrm{p}<0.001)$, cytoplasmic $(\mathrm{p}<0.001)$, and total ALCAM ( $\mathrm{p}$ $<0.001)$ expression was observed in the aggressive group compared to non-aggressive. Using ROC analysis, AUC for total ALCAM expression was 0.865 (Figure 7B) and the sensitivity and specificity were $82 \%$ and $74 \%$ respectively $(\mathrm{OR}=15.38,95 \% \mathrm{CI}=5.43-43.54 ; \mathrm{PPV}=95 \%$, $\mathrm{NPV}=45 \%$, Tables VI and VII). The AUC values were 0.790 and 0.802 for membrane and cytoplasmic ALCAM expression, respectively. Membrane expression sensitivity and specificity were $62.2 \%$ and $78.3 \%$ respectively; PPV was $93.8 \%$ and NPV was $27.4 \%$, and cytoplasmic expression sensitivity and specificity were $80 \%$ and $69.6 \%$ respectively (PPV $=93.5 \%$, and NPV $=44.1 \%$; Tables VI and VII). 
A
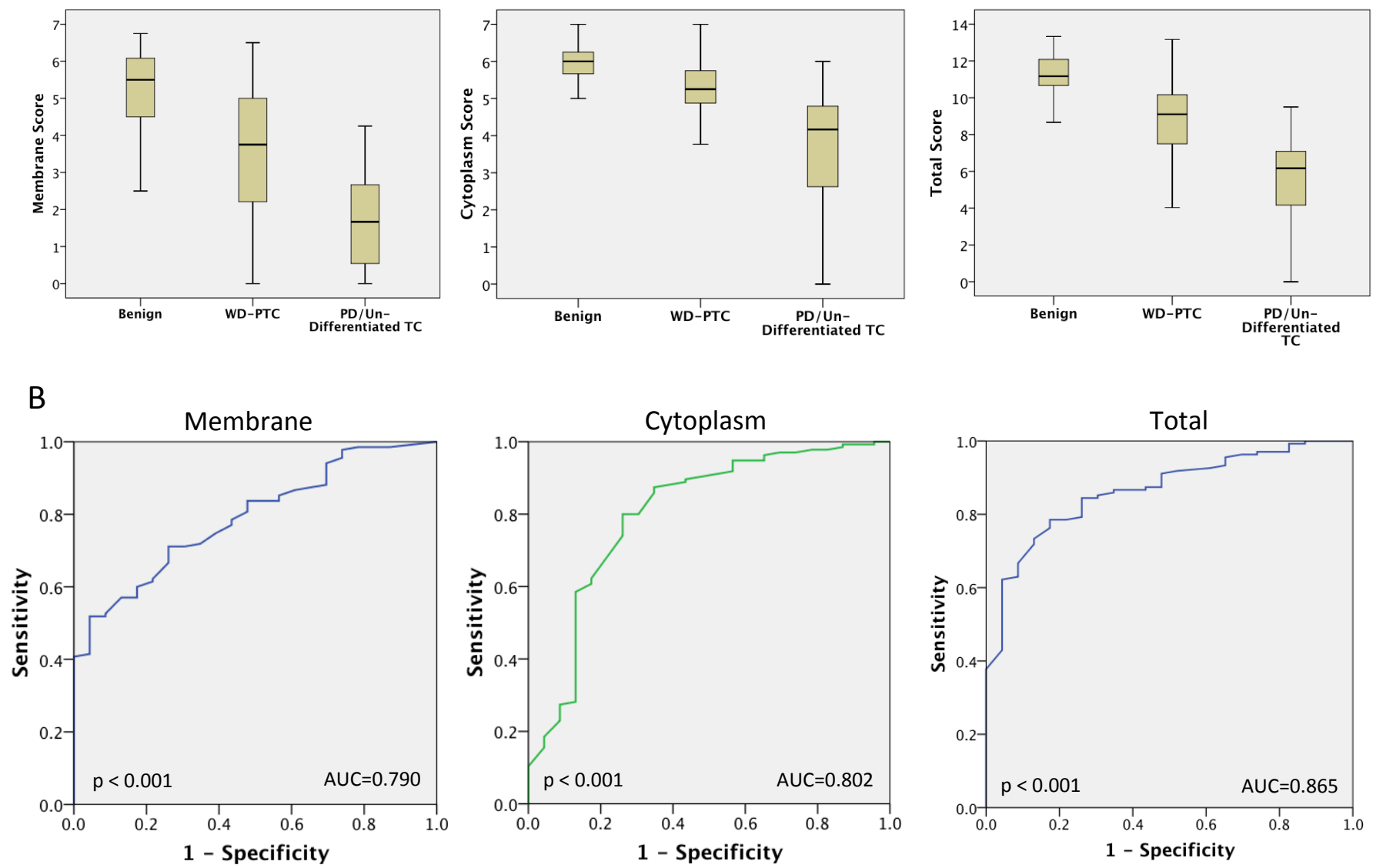

Figure 7. ALCAM expression is decreased in poorly/undifferentiated thyroid cancer tissues. Categories include benign nodules, well-differentiated PTC (WD-PTC), and poorlydifferentiated PTC (PDPTC) or undifferentiated TC. (A) Box plots for immunohistochemical scores are shown, thick horizontal bars denote mean values for each group \pm standard deviation. Membrane, cytoplasmic, and total ALCAM expression significantly varied among the groups $(\mathrm{p}<0.001)$ and showed decreased staining in poorly/undifferentiated tumours. (B) Receiver operating characteristics curve of ALCAM immunohistochemical scores for welldifferentiated versus poorly/undifferentiated TC. Membrane, cytoplasmic, and total ALCAM area-under-curve (AUC) values were $0.790,0.802$, and 0.865 respectively. 


\section{TABLE VII}

Receiver operating curve analysis of ALCAM expression in association with clinicopathological parameters*

\begin{tabular}{|l|c|c|c|c|c|}
\hline \multicolumn{1}{|c|}{ ALCAM } & Sensitivity & Specificity & PPV & NPV & AUC \\
\hline Membrane Staining & & & & & \\
\hline Age $<45$ vs. $\geq 45$ & 59.1 & 23.1 & 48.1 & 31.8 & 0.567 \\
\hline Benign vs. Cancer & 91.1 & 39.2 & 93.9 & 29.9 & 0.814 \\
\hline Well vs. poorly/undifferentiated & 62.2 & 78.3 & 93.8 & 27.4 & 0.790 \\
\hline Distant metastasis vs. none & 66.7 & 71.4 & 97.7 & 10.6 & 0.763 \\
\hline Extrathyroidal extension vs. none & 67.0 & 42.1 & 75.3 & 32.7 & 0.604 \\
\hline Cytoplasmic Staining & & & & & \\
\hline Age $<45$ vs. $\geq 45$ & 80.9 & 15.4 & 53.6 & 40.0 & 0.551 \\
\hline Benign vs. Cancer & 97.8 & 21.5 & 26.2 & 97.1 & 0.808 \\
\hline Well vs. poorly/undifferentiated & 80.0 & 69.6 & 93.5 & 44.1 & 0.802 \\
\hline Distant metastasis vs. none & 84.9 & 57.1 & 97.3 & 17.4 & 0.731 \\
\hline Extrathyroidal extension vs. none & 89.0 & 34.2 & 78.1 & 54.2 & 0.629 \\
\hline Total Staining & & & & & \\
\hline Age $<45$ vs. $\geq 45$ & 75 & 12 & 51 & 28 & 0.539 \\
\hline Benign vs. Cancer & 97.8 & 24.1 & 26.8 & 97.4 & 0.868 \\
\hline Well vs. poorly/undifferentiated & 82.0 & 74.0 & 95.0 & 45.0 & 0.865 \\
\hline Distant metastasis vs. none & 81.0 & 42.9 & 96.2 & 11.1 & 0.803 \\
\hline Extrathyroidal extension vs. none & 85.0 & 31.6 & 76.6 & 34.4 & 0.626 \\
\hline
\end{tabular}

* Chi-square analysis was used to generate sensitivity, specificity, PPV, and NPV 
Kaplan-Meier survival analysis of follow-up data of 134 TC patients showed significantly reduced disease-free survival for TC patients with decreased ALCAM membrane expression ( $p=$ 0.016 , median survival 8.3 years, range 0.2 to 11.8 years), as compared to median survival of 13.7 years for those with higher ALCAM membrane expression (Figure 8A). Similarly, TC patients with decreased ALCAM cytoplasmic expression had reduced disease-free survival $(p<0.001$, median survival 6 years) as compared to a median survival of 13.7 years for those with higher ALCAM cytoplasmic expression (Figure 8B). Total ALCAM expression also emerged as a prognostic marker; overall decreased expression correlated with poor prognosis $(\mathrm{p}=0.002)$, with a median survival of 7.3 years for patients with decreased expression as compared to 13.5 years for patients with higher ALCAM expression (Figure 8C).

Cox-regression (multivariate) analysis was performed to determine the prognostic potential of ALCAM expression in comparison to clinical and pathological parameters that were independently significant in Kaplan-Meier analysis. The parameters tested were ALCAM staining (membrane, cytoplasmic, total), age, histological grade, extrathyroidal extension, as well as combined ALCAM staining with each of the clinico-pathological parameters. The most significant parameters for prognosis were combined cytoplasmic ALCAM expression and histological grade $(\mathrm{p}<0.001, \mathrm{HR}=21.71,95 \% \mathrm{CI}=6.71-106.25)$, and extrathyroidal extension $(\mathrm{p}=0.002, \mathrm{HR}=9.78,95 \% \mathrm{CI}=1.80-12.91)$. 

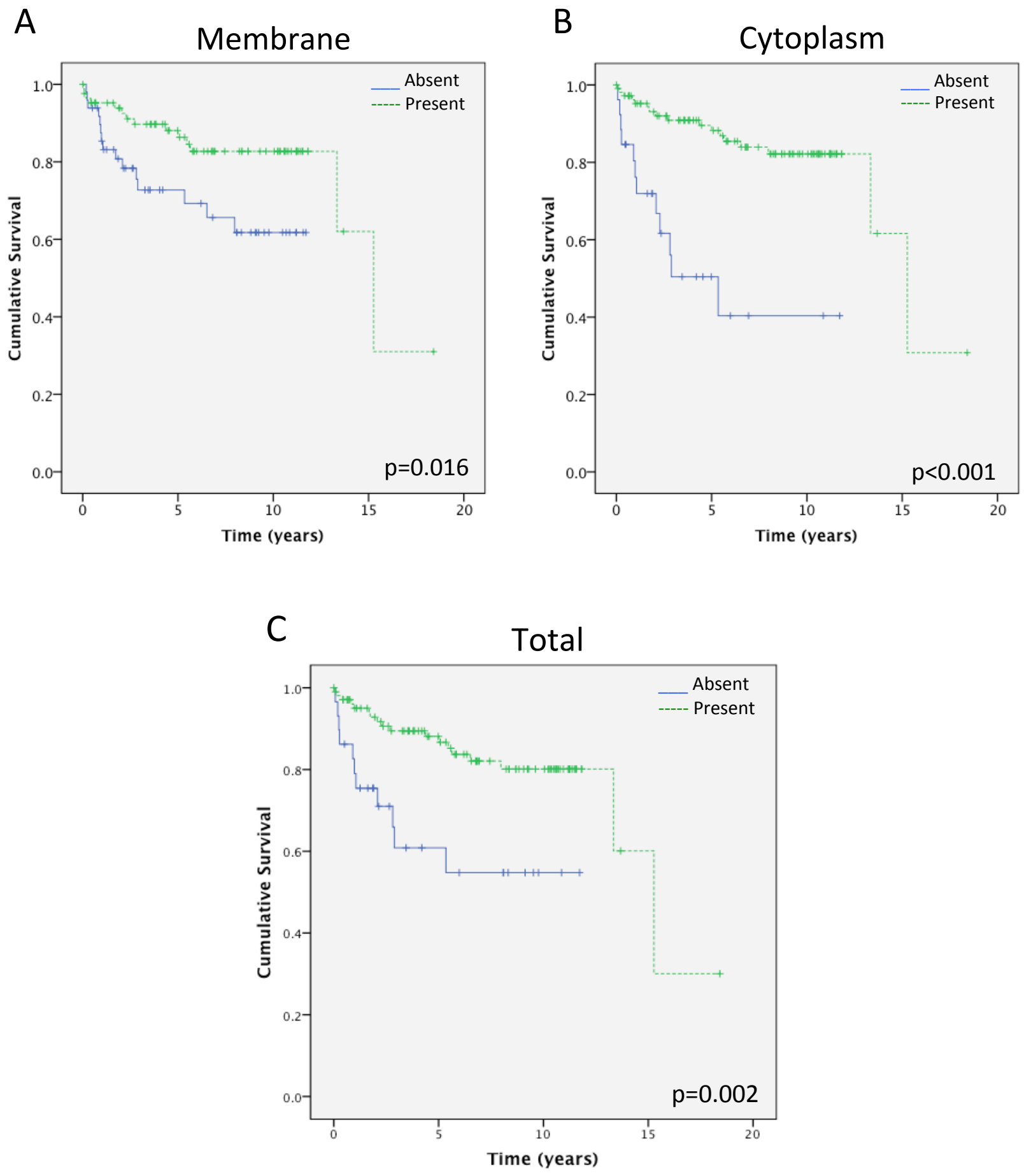

Figure 8. Kaplan-Meier analysis of ALCAM tissue expression 
Figure 8. Decreased ALCAM expression is associated with reduced patient disease-free survival. Kaplan-Meier estimation of cumulative proportion of disease-free survival was assessed. (A) Significantly reduced disease-free survival for thyroid cancer patients with decreased ALCAM membrane expression $(\mathrm{p}=0.016$, median survival 8.3 years), as compared to a median survival of 13.7 years for those with higher ALCAM membrane expression. (B) TC patients with decreased cytoplasmic ALCAM expression had reduced disease-free survival ( $\mathrm{p}<$ 0.001 , median survival 6 years) as compared to a median survival of 13.7 years for those with higher cytoplasmic ALCAM expression. (C) TC patients with decreased total ALCAM expression had reduced disease-free survival $(\mathrm{p}=0.002$, median survival 7.3 years) as compared to a median survival of 13.5 years for those with higher total ALCAM expression. Absence of ALCAM expression is defined as IHC scores below the respective cut-offs, whereas presence of ALCAM is defined as IHC scores above the respective cut-offs (see Appendix VI). 


\subsection{Comparison of Serum ALCAM and AXL levels Between Benign, Non-Aggressive, and Aggressive TC Patients}

To build upon the efforts established with western blot and IHC analysis to evaluate the diagnostic potential of the proteins, ELISA was used to quantify the levels of the proteins in TC patients' sera. To evaluate their potential as blood-based biomarkers, serum ALCAM and AXL levels were measured in benign, non-aggressive and aggressive TC patients' pre-surgical sera and correlated with clinico-pathological parameters (Table VIII and Fig. 9). Increased ALCAM levels were associated with advanced AJCC tumour stage $(p=0.007)$ and presence of lymph node metastasis $(\mathrm{p}=0.018)$. An increase in ALCAM levels was observed in patients with extrathyroidal extension; however, it did not reach statistical significance $(p=0.078)$. Serum AXL levels were increased in patients with extrathyroidal extension $(p=0.027)$. The circulating levels of ALCAM and AXL varied among the PTC variants, with tall cell, diffuse sclerosing, PDPTC, and Hürthle cell (follicular) carcinoma patients showing higher ALCAM and/or AXL sera levels compared to those with non-aggressive variants of PTC (Table VIII). Circulating ALCAM levels were significantly higher in aggressive TC patients (mean \pm standard deviation $(\mathrm{SD}), 67.2 \mathrm{ng} / \mathrm{mL} \pm 36.4)$ as compared to non-aggressive $(50.0 \mathrm{ng} / \mathrm{mL} \pm$ 13.7, $p=0.04$, Fig. 9A). Serum ALCAM levels distinguished aggressive from non-aggressive TCs with a sensitivity of $65 \%$, specificity $38 \%$, and area-under-curve (AUC) of 0.606 based on ROC curve analysis with a cut-off value of $42 \mathrm{ng} / \mathrm{mL}$. Serum AXL levels were not significantly different between the non-aggressive $(49.2 \pm 20.2 \mathrm{ng} / \mathrm{mL})$ and aggressive TC patient groups $(55.0 \pm 24.8 \mathrm{ng} / \mathrm{mL}$, Fig. 9B). Furthermore, combined ALCAM and AXL sera positivity (level above $42 \mathrm{ng} / \mathrm{mL}$ ) could not more accurately detect aggressive TCs than the independent use of ALCAM (data shown in Appendix VII). 


\section{TABLE VIII}

Correlation of ALCAM and AXL sera levels with clinico-pathological characteristics

\begin{tabular}{|c|c|c|c|c|c|c|c|c|}
\hline $\begin{array}{c}\text { Clinico- } \\
\text { pathological } \\
\text { Parameter }\end{array}$ & $\begin{array}{l}\text { Total } \\
\text { Cases }\end{array}$ & $\begin{array}{c}\text { s-AXL } \\
\text { Mean } \pm \text { SD }\end{array}$ & $p$ & $95 \%$ CI & $\begin{array}{l}\text { Total } \\
\text { Cases }\end{array}$ & $\begin{array}{l}\text { s-ALCAM } \\
\text { Mean } \pm \text { SD }\end{array}$ & $p$ & $95 \% \mathrm{CI}$ \\
\hline \multicolumn{9}{|l|}{ Age } \\
\hline$<45$ & 34 & $55.3 \pm 23.6$ & 0.171 & $-2.893-16.027$ & 27 & $48.2 \pm 24.3$ & 0.470 & $-14.427-6.241$ \\
\hline$\geq 45$ & 64 & $48.8 \pm 21.9$ & & & 63 & $51.8 \pm 20.2$ & & \\
\hline \multicolumn{9}{|l|}{ Gender } \\
\hline Male & 18 & $52.2 \pm 23.7$ & 0.820 & $-13.091-10.389$ & 17 & $57.5 \pm 31.5$ & 0.308 & $-24.929-8.813$ \\
\hline Female & 80 & $50.8 \pm 22.4$ & & & 73 & $49.2 \pm 18.3$ & & \\
\hline \multicolumn{9}{|l|}{ Pathology } \\
\hline Benign & 48 & $50.8 \pm 23.5$ & 0.920 & $-9.560-8.633$ & 44 & $46.9 \pm 14.3$ & 0.091 & $-16.411-1.233$ \\
\hline Cancer & 50 & $51.3 \pm 21.9$ & & & 46 & $54.4 \pm 26.2$ & & \\
\hline \multicolumn{9}{|l|}{ TC Aggressiveness } \\
\hline Non-aggressive & 32 & $49.2 \pm 20.2$ & 0.379 & $-7.255-18.742$ & 29 & $50.0 \pm 13.7$ & 0.040 & $0.985-39.503$ \\
\hline Aggressive & 18 & $55.0 \pm 24.8$ & & & 17 & $67.2 \pm 36.4$ & & \\
\hline \multicolumn{9}{|l|}{ Histotype } \\
\hline Classic PTC & 22 & $44.3 \pm 16.9$ & 0.158 & - & 21 & $50.7 \pm 23.3$ & 0.080 & - \\
\hline Follicular PTC & 19 & $54.7 \pm 22.5$ & & & 17 & $51.9 \pm 21.8$ & & \\
\hline Tall cell PTC & 2 & $82.8 \pm 54.1$ & & & 2 & $79.0 \pm 58.0$ & & \\
\hline Oncocytic PTC & 3 & $46.6 \pm 16$ & & & 3 & $43.8 \pm 10.3$ & & \\
\hline $\begin{array}{l}\text { Diffuse sclerosing } \\
\text { PTC }\end{array}$ & 3 & $58.3 \pm 23.7$ & & & 2 & $78.3 \pm 48.4$ & & \\
\hline $\begin{array}{l}\text { Poorly-differentiated } \\
\text { PTC }\end{array}$ & 1 & 68.5 & & & - & - & - & - \\
\hline $\begin{array}{l}\text { Hurthle Cell } \\
\text { Carcinoma }\end{array}$ & - & - & - & - & 1 & 113 & & \\
\hline \multicolumn{9}{|l|}{ AJCC Stage } \\
\hline I & 38 & $47.7 \pm 18.3$ & 0.168 & - & 35 & $49.2 \pm 20.9$ & 0.007 & - \\
\hline II & 5 & $56.3 \pm 24.3$ & & & 5 & $55.8 \pm 21.8$ & & \\
\hline III & 3 & $66.8 \pm 30.4$ & & & 2 & $62.0 \pm 34.6$ & & \\
\hline IV & 4 & $67.7 \pm 38.4$ & & & 4 & $95.0 \pm 42.1$ & & \\
\hline \multicolumn{9}{|l|}{ LN metastasis } \\
\hline Absent & 36 & $47.7 \pm 19.6$ & 0.064 & $-0.790-26.239$ & 33 & $46.2 \pm 13$ & 0.018 & $14.125-44.256$ \\
\hline Present & 14 & $60.4 \pm 25.5$ & & & 13 & $75.4 \pm 38.2$ & & \\
\hline \multicolumn{9}{|l|}{ Distal Metastasis } \\
\hline Absent & 49 & $50.9 \pm 22.0$ & - & - & 45 & $53.1 \pm 24.9$ & - & - \\
\hline Present & 1 & 68.5 & & & 1 & 113 & & \\
\hline \multicolumn{9}{|l|}{$\begin{array}{l}\text { Extrathyroidal } \\
\text { Extension }\end{array}$} \\
\hline Absent & 42 & $48.3 \pm 18.8$ & 0.027 & $2.234-34.822$ & 39 & $49.1 \pm 17.6$ & 0.078 & $-5.378-76.112$ \\
\hline Present & 8 & $66.8 \pm 30.9$ & & & 7 & $84.4 \pm 44$ & & \\
\hline \multicolumn{9}{|l|}{ Angioinvasion } \\
\hline Absent & 44 & $51.4 \pm 22.7$ & 0.904 & $-20.518-18.190$ & 41 & $52.6 \pm 24$ & 0.418 & $-33.560-66.897$ \\
\hline Present & 6 & $50.3 \pm 16.6$ & & & 5 & $69.3 \pm 40.9$ & & \\
\hline \multicolumn{9}{|l|}{ Multifocality } \\
\hline Absent & 25 & $50.0 \pm 20.3$ & 0.684 & $-10.002-15.114$ & 23 & $49.6 \pm 15.6$ & 0.348 & $-8.217-22.602$ \\
\hline Present & 25 & $52.6 \pm 23.7$ & & & 22 & $56.8 \pm 31.9$ & & \\
\hline
\end{tabular}


A

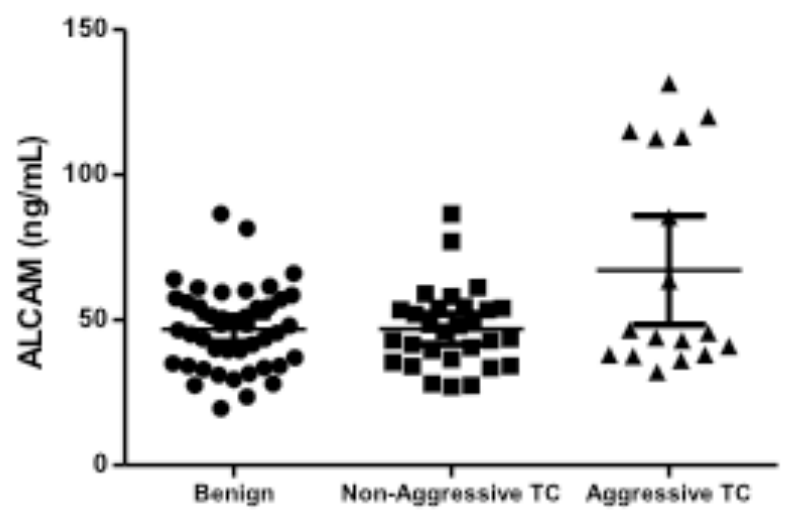

B

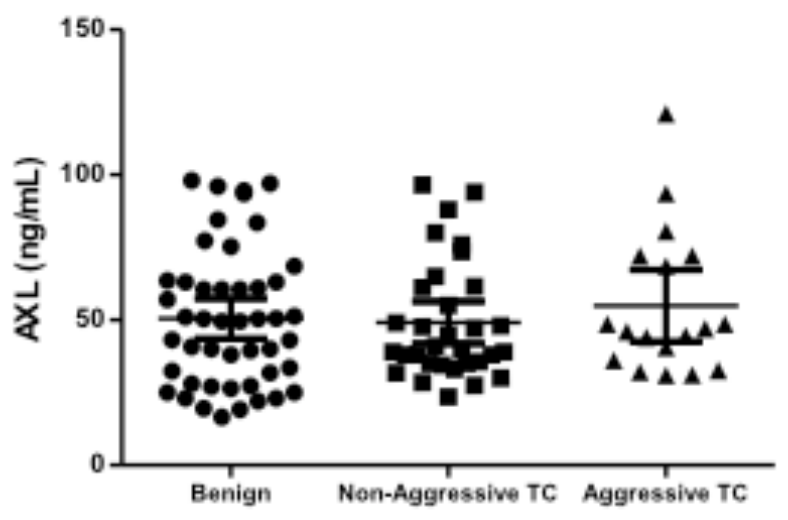

Figure 9. ALCAM and AXL expression in thyroid cancer patient sera using enzymelinked immunosorbent assay. Pre-surgery blood samples were obtained from patients with benign nodules, aggressive TC (stage IV TC, poorly-differentiated tumours, and/or having distant metastasis), and non-aggressive TC (stage I or II PTC, no metastasis). (A) ALCAM sera levels were significantly higher in the aggressive TC patients $(\mathrm{p}=0.04$, mean $=67.2 \mathrm{ng} / \mathrm{mL} \pm$ 36.4 standard deviation) compared to non-aggressive ( $50.0 \mathrm{ng} / \mathrm{mL} \pm 13.7)$. (B) AXL sera levels were not significantly different between the non-aggressive $(49.2 \mathrm{ng} / \mathrm{mL} \pm 20.2)$ and aggressive TC $(55.0 \mathrm{ng} / \mathrm{mL} \pm 24.8)$. 


\section{Chapter 5 \\ Discussion, Conclusions, Future Directions}

\subsection{Discussion}

The first aim of this study was the identification of candidate biomarkers for tumour aggressiveness using a secretome-based LC-MS/MS analysis of proteins secreted by aggressive and non-aggressive thyroid cancer cell lines in tandem with bioinformatics. In light of bioinformatics advances, the use of tools such as IPA software has directed identification of several important potential interactions that may otherwise not have been considered by researchers. However, experimental verification of protein-protein interactions is warranted to establish their functional significance in thyroid malignancy and aggressiveness of TC. Furthermore, proteins secreted by aggressive TC cell lines are important to consider because of the significance of tumour cell interactions with the extracellular environment that play vital roles in tumour growth, invasion, and metastasis $(137,138)$. Investigation of the thyroid cancer secretome is of particular importance because of the urgent need for blood-based clinical biomarkers to aid in disease management. Secreted proteins, in addition to the role they have within cells, also have the potential to be detectable in blood, which will allow for future development of minimially-invasive blood-based assays to aid in the management of TC (129, 130). This is of paramount importance in preventing unneccessary surgery and its inherent complications and morbidity. The development of these assays will also allow healthcare resources and efforts to be directed in a focused manner to high risk patients. 
We initially identified 188 proteins using LC-MS/MS, of which 83 had high confidence peptide identifications and were chosen for further analyses. Quantitative proteomics was not used in this study and this was a limitation. Although the number of proteins identified herein is substantially smaller than that of other studies using more recent advanced methods, we did identify enough secreted proteins having key roles in cancer development for subsequent analyses.

The IPA networks that were generated herein suggested nine secretome proteins potentially interacted, either directly or indirectly with components of EGFR-activated pathways. EGFR is a cell membrane receptor that plays an important role in cancer development and progression (108), and it is suggested that overexpression of the EGFR gene is correlated with aggressive tumour behaviour and poor clinical outcome in several cancers including lung, colorectal, breast, bladder, and head and neck carcinomas $(154,155)$. It is noteworthy that activation of EGFR signalling has recently been reported to play an important role in $\mathrm{TC}$ tumour aggressiveness, favouring progression towards an angiogenic, poorlydifferentiated, and TSH-independent phenotype (154). Importantly, epithelial-mesenchymal transition (EMT) has been demonstrated by other studies to be an important step in the progression of well-differentiated TC to aggressive TC such as PDPTC and ATC (156-158) . EMT is involved in the disassembly of junctional structures of epithelial cells and in the remodelling of the extracellular matrix, thereby making the cells more migratory (159). These events are key to the metastatic potential of cancer cells. Furthermore, a growing body of evidence has found that EGFR pathway overexpression may be a critical part of this progression, and that EGFR signaling promotes EMT $(154,160-162)$. Also in support of this were findings by Grande et al that overexpression of EGF and transforming growth factor $\beta$ (TGF- $\beta$ ) in pig thyrocytes led to their progression towards EMT phenotypes (163) . 
The IPA network analysis also revealed a potential direct interaction of AXL, an identified secretome protein, with SRC and GRB2. SRC and GRB2 are both components of the EGFR signalling pathway and have important roles in several cell processes including apoptosis, cell migration, and gene transcription (146). In TC cell lines, AXL has been shown to have a high level of tyrosine phosphorylation due to the constitutive expression of its ligand GAS6 (146). Furthermore, knockdown of AXL decreased TC cell viability and invasiveness, while also reducing growth of thyroid tumour xenografts in nude mice (146). AXL overexpression and its association with invasiveness and metastasis has been reported in several cancer types including breast, prostate, and lung cancer (164-166). In our study, IHC analysis on patient tissues revealed decreased nuclear and cytoplasmic AXL expression in malignant compared to benign tissues. AXL could be a potential therapeutic target because of its function as a tyrosine kinase receptor. AXL could be targeted by available drugs being used for the treatment of other cancers that are regulated by tyrosine kinases (167). As discussed previously under new therapies for thyroid cancer, several agents tested in clinical trials for TC patients target tyrosine kinase receptors that subsequently affect the RAF, EGFR, and/or VEGFR pathways. Therefore, the type and function of this protein deem it of interest to investigate on several different levels.

14-3-3 zeta emerged as a major cytoplasmic hub in IPA analysis, mediating many of the aforementioned potential interactions. This is experimentally supported by other recent studies which have shown that depletion of 14-3-3 zeta leads to reduced EGFR signaling in breast cancer (168). Another important interaction of 14-3-3 zeta includes that with filamin A, a protein that is involved in EMT of cells, and is also proposed to play a role in response to DNA damage via interactions with BRCA1 and BRCA2 (169-172). 14-3-3 zeta is an adaptor protein that functions as an intracellular signalling molecule that can affect cell migration and 
metastatic properties of tumour cells (173). Some types of molecules that 14-3-3 zeta can bind to include transcription factors, biosynthetic enzymes, cytoskeletal proteins, signalling molecules, apoptosis factors, and tumour suppressors. There are seven isoforms in the family of 14-3-3 proteins.

Overexpression of 14-3-3 zeta has been reported in esophageal cancer tissues (174), and decreased serum levels have been reported in ovarian cancer (175). The sera and tissue expression of 14-3-3 zeta observed herein is in support of these findings. Our western blots showed decreasing 14-3-3 zeta levels with increasing aggressiveness, though this must be taken as only a preliminary trend that requires further verification using the ELISA. We also observed an overall increase cytoplasmic expression of 14-3-3 zeta in malignant compared to benign tissues, though this was not significant as there was a large variation in the expression. A recent thyroid cancer study demonstrated 14-3-3 zeta expression by proteomic profiling of a total of 9 FTC and 10 PTC well-differentiated tissues (176). They reported 14-3-3 zeta cytoplasmic expression in 6 FTCs and 8 PTCs. Tissue proteomic profiling could have alternatively been used for our study if the aim was to search for tissue-based biomarkers. Since our ultimate goal is to find a blood-based biomarker for use in minimally-invasive assays, we deemed secretome proteomics of thyroid cancer cell lines more suitable to identify secreted proteins. Using secretome proteomics does not limit one to the discovery of bloodbased biomarkers. As we have observed in this study, differences in the subcellular localization of several of these proteins were confirmed in thyroid cancer patients' tissues, and these proteins can be taken further as tissue biomarkers, if not as blood biomarkers.

Other secretome proteins investigated in our selected panel of candidate markers have also been shown to have important biological functions relating to cancer. Although APP is known for its role in the development of Alzheimer's disease, recent studies have shown that 
the proteolytic cleavage of APP is associated with growth factors and NF- $\mathrm{B}$ pathway activation, and alteration of calcium signalling and cytoskeletal dynamics (177). These interactions, among others, suggest a role for APP in cancer development. Overexpression of APP has been reported in pancreatic, prostate, colon, and oral squamous cell carcinoma tissues $(150,177-181)$. We report a loss in nuclear APP expression in thyroid carcinomas as compared to benign tissues with no notable changes in cytoplasmic expression. A study by Krause et al. demonstrated an increase in cytoplasmic expression of the endo-domain of APP and an increase in cell surface expression of the ecto-domain in thyroid cancer compared to benign tissues (182). APLP2 is a homologue of APP which is similarly cleaved, and interestingly, shown to have functional redundancy to APP (183). Herein, we report increased cytoplasmic APLP2 expression in malignant compared to benign tissues. Unlike APP, no apparent changes were observed in nuclear APLP2 expression.

Some of the secretome proteins investigated in this study are involved in cell metabolism. PGK1 is well known as a glycolytic enzyme that catalyzes the conversion of 1,3diphosphoglycerate to 3-phosphoglycerate for the generation of adenosine triphosphate (ATP). However, studies have shown PGK1 to have other functions important in disease progression. In the nucleus, PGK1 affects DNA replication and repair; therefore, it is assumed that its affect on glycolysis-related genes plays a critical role in tumourigenesis (184). In prostate cancer, overexpression of PGK1 reduces VEGF and increases angiostatin, a vascular inhibitor (184) . Therefore, they demonstrate that overexpression of PGK1 may restrict tumour growth by limiting angiogenesis (184). Though interestingly, they report that at metastatic sites, the chemokine signalling responsible for metastatic growth reduces PGK1 expression, thereby releasing the angiogenic response (184). Another study reports that PGK1-overexpressing lung cancer cells reduce cyclooxygenase 2 expression and promote anti-tumour immunity in mice 
(185). These findings suggest a coordinated control in PGK1 expression between its affects on energy consumption and metastatic potential as the tumour progresses. We report both decreased nuclear and cytoplasmic PGK1 expression in thyroid cancer tissues compared to benign tissues. Therefore, the regulatory functions suggested in these PGK1 studies could explain the events behind thyroid tumourigenesis and account for the decreased expression we have observed in cancer tissues. PGK1 is expressed in several other cancers such as breast, ovarian, pancreatic, and gastric cancer (186-189) .

PKM2 is another important protein involved in cell metabolism. PKM2 has dual roles that are critical for tumourigenesis: cancer cell metabolism regulation and gene transcription required for cell proliferation. Two important mechanisms underlying tumour development by regulation of metabolic and non-metabolic functions of PKM2 have been delineated: (i) PKM2 enhances aerobic glycolysis $(190,191)$ and (ii) upon EGFR activation, PKM2 promotes tumour cell proliferation by binding to and transactivating Y333-phosphorylated $\beta$-catenin (192). Thus, the coordinated control of metabolism and proliferation by PKM2 is essential for tumourigenesis (192). In our immunohistochemical analysis, we reported nuclear loss of PKM2 in malignant tissues. This could be accounted for by other studies which suggest that nuclear translocation of PKM2 induces cell death; therefore, PKM2 nuclear loss in thyroid cancer could suggest a decrease in apoptosis due to this change in expression that would allow for tumour growth.

SET protein is an oncoprotein known for its role in regulating DNA replication, gene transcription, cellular proliferation, apoptosis, and possibly cell cycle progression by inhibiting cyclin B-cdk1 and protein phosphatase 2A (193). As expected, we observed nuclear and cytoplasmic expression of protein SET. Nuclear expression of SET was decreased in malignant compared to benign tissues. 
hnRNP K plays a role in cancer relevant pathways as well, and is involved in tumour development and progression (194-196). Decreased nuclear expression of hnRNP K in patients with Dukes C stage colorectal cancer has been correlated with poor survival (197), while Hope et al. showed significant aberrant cytoplasmic immunoreactivity in tumour cells related to colorectal cancer with lymph node metastasis (198). We similarly observed decreased nuclear and cytoplasmic expression of hnRNP K in TC tissues.

As a prelude towards evaluating the potential of these secretome proteins to serve as serum-based biomarkers, we sought to first determine the detectability of these proteins in TC patients' sera. Indeed, western blot analysis found the secretome proteins were detectable and suggested a potential for differential expression in some cases. PGK1 and hnRNP K were undetectable using this analysis. This may be due to lower circulating levels and/or the inability of this method and the chosen antibodies to detect the proteins. Importantly, due to the limited sample size and the semi-quantitative nature of western blots, findings obtained using this method must be confirmed with a more accurate quantitative method such as the ELISA, as will be later discussed.

Another aim of our study was to verify the expression of the secretome proteins in thyroid tissues and to observe the pattern of subcellular expression of the proteins using IHC. We also aimed to determine the potential of the secretome proteins for differential subcellular expression when comparing benign nodules and malignant tissues. To our knowledge, this is the first report to detect the expression of APLP2, 14-3-3 zeta, PKM2, PGK1, SET, and hnRNP $\mathrm{K}$ in benign and malignant thyroid tissues and/or sera. IHC analysis of the selected panel of secretome proteins showed differential expression between benign and malignant thyroid tissues. Interestingly, expression of all proteins was found to be significantly decreased in the nucleus and/or cytoplasm of TCs except APLP2 and 14-3-3 zeta, which both showed 
increased cytoplasmic expression in TC compared to benign thyroid nodules. Although increased cytoplasmic expresion of 14-3-3 zeta was not found to be statistically significant, this may possibly be due to the small sample size. Increased expression of 14-3-3 zeta is even more interesting when considering the proposed cellular network generated by IPA, which suggested that 14-3-3 zeta acts as a cytoplasmic hub, mediating interactions between many secretome proteins and important pathways. The sample size for the proteins, excluding ALCAM, was small, nevertheless, our findings provide the proof of principle of biomarker potential of these candidates.

When initially immunostaining a small tissue sample size for ALCAM, we observed a large variation in ALCAM expression among the malignant thyroid tissues. We chose to expand the study of this protein to determine if it is associated with different clinicopathological parameters that are correlated with TC aggressiveness. IHC analysis of tissue specimens from a large cohort of patients, including those with benign nodules, several variants of PTC and aggressive features of TC, revealed ALCAM expression to be negatively correlated with increased tumour aggressiveness. Namely, decreased membrane, cytoplasmic, and total ALCAM expression was associated with poor differentiation, presence of metastasis, and extrathyroidal extension, all of which are characteristic features of aggressive TC. Most importantly, the data demonstrated decreased membrane, cytoplasmic, and total ALCAM expression to be associated with decreased disease-free survival, underscoring its potential applicability as a prognostic marker for TC.

In support of our findings, ALCAM down-regulation has been reported in breast cancer and correlated with poor prognosis, recurrence, and death (199), as well as in highgrade prostate cancer (200). Decreased or lost ALCAM membrane expression was also associated with poorer outcome in epithelial ovarian cancer, whereas cytoplasmic expression 
of ALCAM was found in these patients (201). In contrast, further stratification based on immunohistochemical staining and subcellular localization demonstrated that elevated cytoplasmic ALCAM was significantly associated with shortened disease free survival in breast cancer $(202,203)$. Also, elevated ALCAM expression has been correlated with the vertical phase proliferation in melanomas (204) and poor prognosis (lymph node metastasis, tumour aggressiveness and T3/T4 stage cancers) in esophageal squamous cell carcinoma (205). High ALCAM expression in the primary tumour was reported to be associated with reduced survival or unfavourable prognosis in other tumour types including oral cancer $(145,206)$, pancreatic cancer (207), colorectal cancer $(208,209)$, and neuroblastoma (210). ALCAM has been shown to be a predictive marker in cervical cancer; and interestingly, high expression levels correlated with poor disease free survival and cancer specific survival in patients who did not receive any further therapy after primary tumour excision, whereas high ALCAM was associated with favourable prognosis in patients receiving adjuvant chemoradiation (211). Similar association of high ALCAM expression with favourable prognosis was reported in chemotherapy treated breast cancer patients, which might be explained by its influence on apoptosis $(212,213)$. Collectively these reports underscore the prognostic potential of ALCAM in human cancers, pointing to divergent roles played by ALCAM in progression of different tumour types. Thus, in depth understanding of biological roles of ALCAM is needed to explain the divergent variations in ALCAM expression reported in human cancers.

The molecular basis to explaining the diverse roles that ALCAM plays in TC progression and aggressiveness might lie in the critical triggering event that initiates the change of focus from homotypic adhesion to heterotypic tumour cell interaction with surrounding cell types. The clinical relationship of membrane ALCAM loss with aggressiveness of TC may relate to the process of proteolytic cleavage of ALCAM by a disintegrin and metalloproteinase 
(ADAM)/ tumour necrosis factor $\alpha$ converting enzyme (TACE) and its shedding. The experimental evidence for this rationale has been provided in a recent study that addressed the role of ALCAM in thyroid tumour biology (144) . ALCAM was detected in proteomic analysis of cell lysates from TC cell lines (TPC-1 and SKOV-3) and in their conditioned media, as well as in 4 PTCs and 2 medullary thyroid carcinomas by immunostaining (144). These authors demonstrated extracellular surface domain of ALCAM is cleaved by metalloproteinases ADAM17/TACE, which subsequently translocates to the cytoplasm where it facilitates aggressive transformation of tumour cells. The decreased membrane expression of ALCAM in stage IV TCs we observed, while maintaining cytoplasmic expression, could be explained by this tumourigenic event. In the initial stages of tumour formation the cells must be able to attach to each other, therefore adhesion molecules are required. This was observed in our study as increased expression and intense ALCAM membrane staining was present in the nonaggressive PTC. As the cancer progresses and the initiation of metastases begins as tumour cells originally attached to a particular organ start to spread to distant sites, cells must detach from the primary tumour, and therefore the expression of adhesion molecules are altered to facilitate this process. Herein, ALCAM membrane expression was absent, with low to moderate cytoplasmic expression in the most aggressive TC cases. The increased TACE mediated proteolysis of ALCAM in aggressive TC could account for the loss of membrane ALCAM in these tumours, and consequent relocalization from the cell membrane to the cytoplasm might ultimately enhance the migratory potential of malignant cells facilitating metastasis. Additionally, EGFR has been found to cooperate with the protease ADAM17/TACE to promote ALCAM shedding and soluble ALCAM release into the extracellular fluid (214). The involvement of TACE in increasing the motility of papillary thyroid cancer cells (TPC-1) has been reported (144). The loss of membrane ALCAM by 
proteolysis from the membrane might likely be accompanied by increased levels of cytoplasmic ALCAM. However, in our study we also observed reduced cytoplasmic ALCAM levels in the most aggressive TC, such as ATC. This might be explained by recently reported promoter methylation that mediates silencing of ALCAM, thereby consequently reducing protein expression in these tumours, as was shown in breast cancer (202).

The final aim of our study was to quantify protein levels using the ELISA to assess secretome protein potential as diagnostic blood-based biomarkers. The ability of ALCAM to distinguish aggressive from non-aggressive tumours using IHC made this protein of particular interest to study its potential to serve as a serum-based biomarker. AXL was also of interest because of the variable expression seen in the sera blots and in tissues, as well as its appealing nature as a tyrosine kinase receptor that may be therapeutically targeted. Both of these proteins were also chosen for their key functional significance in cancer progression. The pre-surgical levels of ALCAM were found to correlate with important clinicopathologic characteristics including overall aggressivenss, AJCC tumour stage, lymph node and metastasis. AXL was found to be elevated in the sera of TC patients with extrathyroidal invasion. A limitation of this analysis was a small sample size of patients with aggressive features and/or histotypes of TC for sera analysis. Blood collection from TC patients was performed in a relatively small time frame, therefore presenting difficulty in acquiring large sample numbers from patients with the less prevalent, or aggressive, forms of TC. Also, we did not have sera samples from normal (tumour-free) individuals as a comparison for ALCAM levels to patients with benign nodules. Despite these limitations, these early results provide a look at the potential of these biomarkers. In particular, serum ALCAM has the potential to serve as a diagnostic, or even prognostic, marker given the observed differences between the pre-surgical sera levels with respect to important clinico-pathological parameters associated with TC aggressiveness. 


\subsection{Conclusions}

Although thyroid carcinomas are the most prevalent endocrine malignancy, there still lies many questions about the progression of the disease from a non-aggressive subtype with overall excellent prognosis to an aggressive subtype with significantly reduced survival rates. Futhermore, there are no clinical biomarkers that can objectively identify an aggressive variant of TC before using surgical assessment. The aim of our study was to investigate potential protein biomarkers for the detection of aggressive thyroid carcinomas. These markers then may be presented as tissue or blood-based biomarkers for thyroid cancer patient diagnosis and management.

We hypothesized that analysis of proteins secreted from non-aggressive and aggressive thyroid cancer cell lines may lead to the identification of candidate biomarkers based on important protein-protein interactions. Of 83 high confidence secretome proteins identified using liquid chromatography tandem mass spectrometry, nine were selected for further analyses, which were 14-3-3 zeta, APP, APLP2, AXL, ALCAM, hnRNP K, PGK1, PKM2, and SET. These secreotme proteins were chosen based on their function in cell cycle regulation, metabolism, and tumour progression. Also, several of these proteins are novel to thyroid cancer and have not been previously studied in TC patients' tissues and/or sera. Our protein selection was also based on Ingenuity Pathway Analysis, which revealed several important protein-protein interactions among our secretome proteins, including those with EGFR. These interactions may prove to be of importance in thyroid tumourigeneses upon verification in future experiments.

Also, we hypothesized that some of the proteins may distinguish malignant from benign tumours when analyzing thyroid cancer patients' tissues and sera. All proteins were 
detectable in TC patients' sera using western blot analysis, except for hnRNP K and PGK1. Some proteins showed variability in protein expression among the non-aggressive and aggressive TC patients' sera. Significant differences in subcellular expression in 8 of 9 secretome proteins were found in TC patients' tissues between benign and malignant tumours, as assessed by immunohostochemistry. All proteins showed a decrease in nuclear, cytoplasmic, and/or membrane expression in cancer as compared to benign tissues except for APLP2 and 14-3-3 zeta, whereby a slight increase in cytoplasmic expression was observed.

More importantly, we sought to determine if any of these proteins were associated with thyroid cancer tumour aggressiveness. The study of ALCAM in TC patients' tissues was expanded to answer this question. ALCAM was associated with TC tumour aggressiveness and extrathyroidal extension. Decreased membrane and cytoplasmic expression was observed in poorly/undifferentiated TC tumours as compared to well-differentiated tumours. ALCAM is also a potential clinically useful prognostic biomarker for thyroid cancer. Reduced ALCAM expression correlated with reduced overall disease-free survival.

Increased serum ALCAM levels were associated with some aggressive features of thyroid cancer. ALCAM may be useful in the stratification of aggressive and non-aggressive TC patients.

In conclusion, the objectives of this study were met and the hypotheses are supported. The detection of these proteins in TC patients' sera and tissues underscores their potential for indepth investigation either singly or in combination for future development of minimally invasive markers for aggressive TCs. 


\subsection{Future Directions}

The six proteins, AXL, APP, SET, PGK1, PKM2, and hnRNP K, that were able to distinguish benign from malignant tumours is certainly worthy of further investigation. The sample size of tissues was relatively small in comparison to the number of proteins analyzed as a panel. By expanding the sample size to include at least a total of 200 cases, we can determine if 1) the results are reproducible on large-scale; 2) statistical significance and accuracy in distinguishing benign from malignant nodules is maintained; 3) the variability in immunostaining of each protein observed is decreased; and 4) if some of these proteins can function as a panel for increased accuracy in distinguising malignant from benign tumours.

This panel of candidate biomarkers has the potential to enhance the diagnostic capacity of FNAB in the early stages of TC detection. TC patients' FNABs should be collected to stain for these proteins using the aforementioned immunohistochemistry method. If these proteins are shown useful on FNAB, they can be potentially classified as tissue-based biomarkers. Also, we can take this even further and analyze their expression in sera of TC patients using the ELISA to demonstrate their potential as blood-based biomarkers. Although AXL did not show significant differences in patient sera levels between benign and malignant samples, others proteins may show otherwise. Details on sera analyses will be discussed with ALCAM.

Our results demonstrate ALCAM as a potential clinically useful diagnostic and prognostic tissue and/or serum-based biomarker for TC aggressiveness. Although a total of 203 cases were analyzed for ALCAM tissue expression, the number of aggressive subtypes of TC analyzed was small in comparison to the non-aggressive PTC. More tissues from patients with advanced stage TC, PDPTC, insular carcinoma, and ATC should be analyzed. This would 
allow for the assessment of how well ALCAM can stratify aggressive variants of TC. MTC, which is not of follicular origin as the rest of the TC types, was not analyzed in our study since our focus was on PTC and ATC and the proteins secreted from these thyroid cancer cell lines. However, it would be interesting to collect MTC tissues for ALCAM staining to determine how this aggressive variant of TC stains for ALCAM, and if ALCAM expression can be used as a marker for the detection of MTCs.

Serum ALCAM levels may be useful in the stratification of aggressive and nonaggressive TC patients. Investigation of ALCAM in a large cohort of aggressive TC patients is required to determine its applicability as a blood-based marker for aggressive TC, as this was a limitation in our study. This can be achieved through multi-centre collaboration to recruit more patients. Stratification of aggressive TCs can potentially reduce the large sera level variation observed in this group. It is important to also obtain blood from normal (tumour-free) individuals to compare ALCAM sera levels with cancer-free patients who have benign nodules.

Furthermore, blood collection from TC patients pre-surgery and post-surgery would allow us to assess the ability of the protein to serve as a prognostic marker for TC management. Complete patient follow-up information including all forms of treatment given post-surgery, such as RAI or chemotherapy, should be well documented. Correlating the sera levels with different patient treatments may reveal interesting associations and the standardization of this protein for use in blood-based assays. Similar sera analyses can be performed on the rest of the secretome proteins identified in this study.

The IPA network suggested several imporant protein-protein interaction that warrant further investigation. This can be achieved by TC cell line experimentation using siRNAs to knockdown expression at the mRNA level. Alternatively, inihibitors may be used to 
downregulate protein expression and function in cancer-relevant processes. Applying this method individually to some of the major protein hubs or regulators in our IPA network would allow for the elucidation of its effects on downstream signalling pathways and possible down/upregulations in other secretome proteins that we identified as having potential direct or indirect interactions with oneanother. This would be important in understanding the mechanistic aspect of TC tumour progression and could reveal a pathway worthy of investigating as a therapeutic target. This experiment can be implemented in already available thyroid cancer cell lines, such as those used herein, or in cells cultured from TC patient tumours obtained at the time of surgery, along with surrounding normal thyroid tissue as a control.

It would be important to assess the success of the targeted knockdown of expression in the suggested experiment. This can be achieved by a real-time reverse transcription polymerase chain reaction (qRT-PCR) to quantify mRNA levels and compare them to the control (untreated group). On the other hand, if protein inhibitors are used to downregulate protein expression, western blot analysis may be used to assess if protein downregulation is achieved compared to controls. Also, a cell viability assay could be performed to determine the effect of this knockdown/inhibition on cell survival. Once downregulation of the protien has been achieved, the effects on the levels of downstream molecules can be measured, either by western analysis or flow cytometry. Depending on the function of the protein analyzed, certain functional assays can be performed. This work can be expanded in vivo in TC tumour xenograft mice. Some of the clinical trial drugs listed in this report can also be used in these assays to determine the affect on tumour growth and downstream protein expression. 


\section{References}

1. DeLellis RA. Pathology and genetics of thyroid carcinoma. J Surg Oncol 2006 Dec 15;94(8):662-9.

2. Sipos JA, Mazzaferri EL. Thyroid cancer epidemiology and prognostic variables. Clin Oncol (R Coll Radiol) 2010 Aug;22(6):395-404.

3. Pelizzo MR, Merante Boschin I, Toniato A, Pagetta C, Casal Ide E, Mian C, Rubello D. Diagnosis, treatment, prognostic factors and long-term outcome in papillary thyroid carcinoma. Minerva Endocrinol 2008 Dec;33(4):359-79.

4. Zanotti-Fregonara P, Hindie E, Faugeron I, Moretti JL, Ravasi L, Rubello D, Toubert ME. Update on the diagnosis and therapy of distant metastases of differentiated thyroid carcinoma. Minerva Endocrinol 2008 Dec;33(4):313-27.

5. Durante C, Haddy N, Baudin E, Leboulleux S, Hartl D, Travagli JP, Caillou B, Ricard M, Lumbroso JD, De Vathaire F, Schlumberger M. Long-term outcome of 444 patients with distant metastases from papillary and follicular thyroid carcinoma: Benefits and limits of radioiodine therapy. J Clin Endocrinol Metab 2006 Aug;91(8):2892-9.

6. Are C, Shaha A. Anaplastic thyroid carcinoma: Biology, pathogenesis, prognostic factors, and treatment approaches. Annals of Surgical Oncology 2006;13(4):453-64.

7. Shaha AR. Extent of surgery for papillary thyroid carcinoma: The debate continues: Comment on "surgery for papillary thyroid carcinoma". Arch Otolaryngol Head Neck Surg 2010 Nov;136(11):1061-3.

8. Hundahl SA, Fleming ID, Fremgen AM, Menck HR. A national cancer data base report on 53,856 cases of thyroid carcinoma treated in the U.S., 1985-1995 [see commetns]. Cancer 1998 Dec 15;83(12):2638-48.

9. Khanafshar E, Lloyd RV. The spectrum of papillary thyroid carcinoma variants. Adv Anat Pathol 2011 Jan;18(1):90-7.

10. Hagag P, Hod N, Kummer E, Cohenpour M, Horne T, Weiss M. Follicular variant of papillary thyroid carcinoma: Clinical-pathological characterization and long-term follow-up. Cancer J 2006 Jul-Aug;12(4):275-82.

11. Gupta S, Ajise O, Dultz L, Wang B, Nonaka D, Ogilvie J, Heller KS, Patel KN. Follicular variant of papillary thyroid cancer: Encapsulated, nonencapsulated, and diffuse: Distinct biologic and clinical entities. Arch Otolaryngol Head Neck Surg 2012 Mar;138(3):227-33.

12. Salajegheh A, Petcu EB, Smith RA, Lam AK. Follicular variant of papillary thyroid carcinoma: A diagnostic challenge for clinicians and pathologists. Postgrad Med J 2008 Feb;84(988):78-82.

13. LiVolsi VA. Papillary carcinoma tall cell variant (TCV): A review. Endocr Pathol 2010 Mar;21(1):12-5.

14. Ghossein RA, Leboeuf R, Patel KN, Rivera M, Katabi N, Carlson DL, Tallini G, Shaha A, Singh B, Tuttle RM. Tall cell variant of papillary thyroid carcinoma without extrathyroid extension: Biologic behavior and clinical implications. Thyroid 2007 Jul;17(7):655-61.

15. Albores-Saavedra J, Wu J. The many faces and mimics of papillary thyroid carcinoma. Endocr Pathol 2006 Spring;17(1):1-18. 
16. Silver CE, Owen RP, Rodrigo JP, Rinaldo A, Devaney KO, Ferlito A. Aggressive variants of papillary thyroid carcinoma. Head Neck 2010 Sep 7.

17. Rufini V, Salvatori M, Fadda G, Pinnarelli L, Castaldi P, Maussier ML, Galli G. Thyroid carcinomas with a variable insular component. Cancer 2007;110(6):1209-17.

18. O'Neill JP, Power D, Condron C, Bouchier-Hayes D, Walsh M. Anaplastic thyroid cancer, tumorigenesis and therapy. Ir J Med Sci 2010 Mar;179(1):9-15.

19. Basolo F, Pollina L, Fontanini G, Fiore L, Pacini F, Baldanzi A. Apoptosis and proliferation in thyroid carcinoma: Correlation with bcl-2 and p53 protein expression. Br J Cancer 1997;75(4):537-41.

20. Green LD, Mack L, Pasieka JL. Anaplastic thyroid cancer and primary thyroid lymphoma: A review of these rare thyroid malignancies. Journal of Surgical Oncology 2006;94(8):725-36.

21. Tan RK, Finley RK,3rd, Driscoll D, Bakamjian V, Hicks WL,Jr, Shedd DP. Anaplastic carcinoma of the thyroid: A 24-year experience. Head Neck 1995 Jan-Feb;17(1):41,7; discussion 47-8.

22. Ain KB. Anaplastic thyroid carcinoma: Behavior, biology, and therapeutic approaches. Thyroid 1998 Aug;8(8):715-26.

23. McIver B, Hay ID, Giuffrida DF, Dvorak CE, Grant CS, Thompson GB, van Heerden JA, Goellner JR. Anaplastic thyroid carcinoma: A 50-year experience at a single institution. Surgery 2001 Dec;130(6):1028-34.

24. Besic N, Auersperg M, Us-Krasovec M, Golouh R, Frkovic-Grazio S, Vodnik A. Effect of primary treatment on survival in anaplastic thyroid carcinoma. Eur J Surg Oncol 2001 Apr;27(3):260-4.

25. Pitt SC, Moley JF. Medullary, anaplastic, and metastatic cancers of the thyroid. Seminars in Oncology 2010;37(6):567-79.

26. Ron E, Lubin JH, Shore RE, Mabuchi K, Modan B, Pottern LM, Schneider AB, Tucker MA, Boice JD,Jr. Thyroid cancer after exposure to external radiation: A pooled analysis of seven studies. Radiat Res 1995 Mar;141(3):259-77.

27. Kent WD, Hall SF, Isotalo PA, Houlden RL, George RL, Groome PA. Increased incidence of differentiated thyroid carcinoma and detection of subclinical disease. CMAJ 2007 Nov 20;177(11):1357-61.

28. Baker SR, Bhatti WA. The thyroid cancer epidemic: Is it the dark side of the CT revolution? Eur J Radiol 2006 Oct;60(1):67-9.

29. Clavel-Chapelon F, Guillas G, Tondeur L, Kernaleguen C, Boutron-Ruault MC. Risk of differentiated thyroid cancer in relation to adult weight, height and body shape over life: The french E3N cohort. Int J Cancer 2010 Jun 15;126(12):2984-90.

30. Davies L, Welch HG. Increasing incidence of thyroid cancer in the united states, 1973-2002. JAMA 2006 May 10;295(18):2164-7.

31. Enewold L, Zhu K, Ron E, Marrogi AJ, Stojadinovic A, Peoples GE, Devesa SS. Rising thyroid cancer incidence in the united states by demographic and tumor characteristics, 1980-2005. Cancer Epidemiol Biomarkers Prev 2009 Mar;18(3):784-91. 
32. Langer JE, Baloch ZW, McGrath C, Loevner LA, Mandel SJ. Thyroid nodule fine-needle aspiration. Semin Ultrasound CT MR 2012 Apr;33(2):158-65.

33. Degirmenci B, Haktanir A, Albayrak R, Acar M, Sahin DA, Sahin O, Yucel A, Caliskan G. Sonographically guided fine-needle biopsy of thyroid nodules: The effects of nodule characteristics, sampling technique, and needle size on the adequacy of cytological material. Clin Radiol 2007 Aug;62(8):798-803.

34. Cibas ES, Ali SZ. The bethesda system for reporting thyroid cytopathology. Thyroid 2009 Nov;19(11):115965.

35. Baloch ZW, LiVolsi VA, Asa SL, Rosai J, Merino MJ, Randolph G, Vielh P, DeMay RM, Sidawy MK, Frable WJ. Diagnostic terminology and morphologic criteria for cytologic diagnosis of thyroid lesions: A synopsis of the national cancer institute thyroid fine-needle aspiration state of the science conference. Diagn Cytopathol 2008 Jun;36(6):425-37.

36. Cantara S, Capezzone M, Marchisotta S, Capuano S, Busonero G, Toti P, Di Santo A, Caruso G, Carli AF, Brilli L, Montanaro A, Pacini F. Impact of proto-oncogene mutation detection in cytological specimens from thyroid nodules improves the diagnostic accuracy of cytology. J Clin Endocrinol Metab 2010 Mar;95(3):1365-9.

37. Moses W, Weng J, Sansano I, Peng M, Khanafshar E, Ljung BM, Duh QY, Clark OH, Kebebew E. Molecular testing for somatic mutations improves the accuracy of thyroid fine-needle aspiration biopsy. World J Surg 2010 Nov;34(11):2589-94.

38. Ferraz C, Eszlinger M, Paschke R. Current state and future perspective of molecular diagnosis of fine-needle aspiration biopsy of thyroid nodules. J Clin Endocrinol Metab 2011 Jul;96(7):2016-2.

39. Chudova D, Wilde JI, Wang ET, Wang H, Rabbee N, Egidio CM, Reynolds J, Tom E, Pagan M, Rigl CT, Friedman L, Wang CC, et al. Molecular classification of thyroid nodules using high-dimensionality genomic data. J Clin Endocrinol Metab 2010 Dec;95(12):5296-304.

40. Brander A, Viikinkoski P, Tuuhea J, Voutilainen L, Kivisaari L. Clinical versus ultrasound examination of the thyroid gland in common clinical practice. J Clin Ultrasound 1992 Jan;20(1):37-42.

41. Gharib H, Goellner JR. Fine-needle aspiration biopsy of the thyroid: An appraisal. Ann Intern Med $1993 \mathrm{Feb}$ 15;118(4):282-9.

42. Gharib H. Changing concepts in the diagnosis and management of thyroid nodules. Endocrinol Metab Clin North Am 1997 Dec;26(4):777-800.

43. Nikiforov YE, Steward DL, Robinson-Smith TM, Haugen BR, Klopper JP, Zhu Z, Fagin JA, Falciglia M, Weber K, Nikiforova MN. Molecular testing for mutations in improving the fine-needle aspiration diagnosis of thyroid nodules. J Clin Endocrinol Metab 2009 Jun;94(6):2092-8.

44. Paschke R, Hegedus L, Alexander E, Valcavi R, Papini E, Gharib H. Thyroid nodule guidelines: Agreement, disagreement and need for future research. Nat Rev Endocrinol 2011 Jun;7(6):354-61.

45. Schlinkert RT, van Heerden JA, Goellner JR, Gharib H, Smith SL, Rosales RF, Weaver AL. Factors that predict malignant thyroid lesions when fine-needle aspiration is "suspicious for follicular neoplasm". Mayo Clin Proc 1997 Oct;72(10):913-6.

46. Cooper DS, Doherty GM, Haugen BR, Kloos RT, Lee SL, Mandel SJ, Mazzaferri EL, McIver B, Pacini F, Schlumberger M, Sherman SI, Steward DL, et al. Revised american thyroid association management guidelines for patients with thyroid nodules and differentiated thyroid cancer. Thyroid 2009 Nov;19(11):1167-214. 
47. Van Nostrand D. The benefits and risks of I-131 therapy in patients with well-differentiated thyroid cancer. Thyroid 2009 Dec;19(12):1381-91.

48. Spencer CA, Lopresti JS. Measuring thyroglobulin and thyroglobulin autoantibody in patients with differentiated thyroid cancer. Nat Clin Pract Endocrinol Metab 2008 Apr;4(4):223-3.

49. Spencer CA, LoPresti JS. Technology insight: Measuring thyroglobulin and thyroglobulin autoantibody in patients with differentiated thyroid cancer. Nat Clin Pract End Met 2008;4(4):223-3.

50. Spencer CA. Serum thyroglobulin autoantibodies: Prevalence, influence on serum thyroglobulin measurement and prognostic significance in patients with differentiated thyroid carcinoma. J Clin Endocrinol Metab 1998;83:1121-7.

51. Spencer CA, Wang CC. Thyroglobulin measurement. techniques, clinical benefits, and pitfalls. Endocrinol Metab Clin North Am 1995 Dec;24(4):841-63.

52. Ozata M, Suzuki S, Miyamoto T, Liu RT, Fierro-Renoy F, DeGroot LJ. Serum thyroglobulin in the follow-up of patients with treated differentiated thyroid cancer. J Clin Endocrinol Metab 1994 Jul;79(1):98-105.

53. Schlumberger M. Comparison of seven serum thyroglobulin assays in the follow-up of papillary and follicular thyroid cancer patients. J Clin Endocrinol Metab 2007;92:2487-95.

54. Smallridge RC. Monitoring thyroglobulin in a sensitive immunoassay has comparable sensitivity to recombinant human TSH-stimulated thyroglobulin in follow-up of thyroid cancer patients. J Clin Endocrinol Metab 2007;92:82-7.

55. Vaisman A, Orlov S, Yip J, Hu C, Lim T, Dowar M, Freeman JL, Walfish PG. Application of post-surgical stimulated thyroglobulin for radioiodine remnant ablation selection in low-risk papillary thyroid carcinoma. Head \& Neck 2010;32(6):689-98.

56. Sawka AM, Orlov S, Gelberg J, Stork B, Dowar M, Shaytzag M, Tabatabaie V, Freeman JL, Walfish PG. Prognostic value of postsurgical stimulated thyroglobulin levels after initial radioactive iodine therapy in welldifferentiated thyroid carcinoma. Head \& Neck 2008;30(6):693-700.

57. Solans R, Bosch JA, Galofre P, Porta F, Rosello J, Selva-O'Callagan A, Vilardell M. Salivary and lacrimal gland dysfunction (sicca syndrome) after radioiodine therapy. J Nucl Med 2001 May;42(5):738-43.

58. Silberstein EB. Reducing the incidence of 131I-induced sialadenitis: The role of pilocarpine. J Nucl Med 2008 Apr;49(4):546-9.

59. Levendag PC, De Porre PM, van Putten WL. Anaplastic carcinoma of the thyroid gland treated by radiation therapy. Int J Radiat Oncol Biol Phys 1993 Apr 30;26(1):125-8.

60. Sugino K, Ito K, Mimura T, Nagahama M, Fukunari N, Kubo A, Iwasaki H, Ito K. The important role of operations in the management of anaplastic thyroid carcinoma. Surgery 2002 Mar;131(3):245-8.

61. Mazzaferri EL, Jhiang SM. Long-term impact of initial surgical and medical therapy on papillary and follicular thyroid cancer. Am J Med 1994 Nov;97(5):418-28.

62. Siironen P, Louhimo J, Nordling S, Ristimaki A, Maenpaa H, Haapiainen R, Haglund C. Prognostic factors in papillary thyroid cancer: An evaluation of 601 consecutive patients. Tumour Biol 2005 Mar-Apr;26(2):57-64. 
63. Witt RL, McNamara AM. Prognostic factors in mortality and morbidity in patients with differentiated thyroid cancer. Ear Nose Throat J 2002 Dec;81(12):856-63.

64. Lang BH, Lo CY, Chan WF, Lam KY, Wan KY. Prognostic factors in papillary and follicular thyroid carcinoma: Their implications for cancer staging. Ann Surg Oncol 2007 Feb;14(2):730-8.

65. Kim S, Wei JP, Braveman JM, Brams DM. Predicting outcome and directing therapy for papillary thyroid carcinoma. Arch Surg 2004 Apr;139(4):390,4; discussion 393-4.

66. Oyer SL, Smith VA, Lentsch EJ. Reevaluating the prognostic significance of age in differentiated thyroid cancer. Otolaryngol Head Neck Surg 2012 Mar 30.

67. Jonklaas J, Nogueras-Gonzalez G, Munsell M, Litofsky D, Ain KB, Bigos ST, Brierley JD, Cooper DS, Haugen BR, Ladenson PW, Magner J, Robbins J, et al. The impact of age and gender on papillary thyroid cancer survival. J Clin Endocrinol Metab 2012 Apr 10.

68. Kouvaraki MA, Shapiro SE, Fornage BD, Edeiken-Monro BS, Sherman SI, Vassilopoulou-Sellin R, Lee JE, Evans DB. Role of preoperative ultrasonography in the surgical management of patients with thyroid cancer. Surgery 2003 Dec;134(6):946,54; discussion 954-5.

69. Stulak JM, Grant CS, Farley DR, Thompson GB, van Heerden JA, Hay ID, Reading CC, Charboneau JW. Value of preoperative ultrasonography in the surgical management of initial and reoperative papillary thyroid cancer. Arch Surg 2006 May;141(5):489,94; discussion 494-6.

70. Bhattacharyya N. A population-based analysis of survival factors in differentiated and medullary thyroid carcinoma. Otolaryngol Head Neck Surg 2003 Jan;128(1):115-23.

71. Hay ID, Bergstralh EJ, Goellner JR, Ebersold JR, Grant CS. Predicting outcome in papillary thyroid carcinoma: Development of a reliable prognostic scoring system in a cohort of 1779 patients surgically treated at one institution during 1940 through 1989. Surgery 1993 Dec;114(6):1050,7; discussion 1057-8.

72. Ito Y, Higashiyama T, Takamura Y, Miya A, Kobayashi K, Matsuzuka F, Kuma K, Miyauchi A. Risk factors for recurrence to the lymph node in papillary thyroid carcinoma patients without preoperatively detectable lateral node metastasis: Validity of prophylactic modified radical neck dissection. World J Surg 2007 Nov;31(11):208591.

73. Podnos YD, Smith D, Wagman LD, Ellenhorn JD. The implication of lymph node metastasis on survival in patients with well-differentiated thyroid cancer. Am Surg 2005 Sep;71(9):731-4.

74. Zaydfudim V, Feurer ID, Griffin MR, Phay JE. The impact of lymph node involvement on survival in patients with papillary and follicular thyroid carcinoma. Surgery 2008 Dec;144(6):1070,7; discussion 1077-8.

75. Yip J, Orlov S, Orlov D, Vaisman A, Hernandez KG, Etarsky D, Kak I, Parvinnejad N, Freeman JL, Walfish PG. Predictive value of metastatic cervical lymph node ratio in papillary thyroid carcinoma recurrence. Head Neck 2012 Jun 23.

76. Beal SH, Chen SL, Schneider PD, Martinez SR. An evaluation of lymph node yield and lymph node ratio in well-differentiated thyroid carcinoma. Am Surg 2010 Jan;76(1):28-32.

77. Leggett MD, Chen SL, Schneider PD, Martinez SR. Prognostic value of lymph node yield and metastatic lymph node ratio in medullary thyroid carcinoma. Ann Surg Oncol 2008 Sep;15(9):2493-9. 
78. Gemsenjager E, Heitz PU, Seifert B, Martina B, Schweizer I. Differentiated thyroid carcinoma. follow-up of 264 patients from one institution for up to 25 years. Swiss Med Wkly 2001 Mar 24;131(11-12):157-63.

79. Chiang FY, Lin JC, Lee KW, Wang LF, Tsai KB, Wu CW, Lu SP, Kuo WR. Thyroid tumors with preoperative recurrent laryngeal nerve palsy: Clinicopathologic features and treatment outcome. Surgery 2006 Sep;140(3):413-7.

80. McCaffrey JC. Evaluation and treatment of aerodigestive tract invasion by well-differentiated thyroid carcinoma. Cancer Control 2000 May-Jun;7(3):246-52.

81. Brierley J, Tsang R, Panzarella T, Bana N. Prognostic factors and the effect of treatment with radioactive iodine and external beam radiation on patients with differentiated thyroid cancer seen at a single institution over 40 years. Clin Endocrinol (Oxf) 2005 Oct;63(4):418-27.

82. Jukkola A, Bloigu R, Ebeling T, Salmela P, Blanco G. Prognostic factors in differentiated thyroid carcinomas and their implications for current staging classifications. Endocr Relat Cancer 2004 Sep;11(3):571-9.

83. Lee SH, Lee SS, Jin SM, Kim JH, Rho YS. Predictive factors for central compartment lymph node metastasis in thyroid papillary microcarcinoma. Laryngoscope 2008 Apr;118(4):659-62.

84. Benbassat CA, Mechlis-Frish S, Hirsch D. Clinicopathological characteristics and long-term outcome in patients with distant metastases from differentiated thyroid cancer. World J Surg 2006 Jun;30(6):1088-95.

85. Lee J, Soh EY. Differentiated thyroid carcinoma presenting with distant metastasis at initial diagnosis clinical outcomes and prognostic factors. Ann Surg 2010 Jan;251(1):114-9.

86. Sampson E, Brierley JD, Le LW, Rotstein L, Tsang RW. Clinical management and outcome of papillary and follicular (differentiated) thyroid cancer presenting with distant metastasis at diagnosis. Cancer 2007 Oct 1;110(7):1451-6.

87. Schlumberger M, Pacini F, Wiersinga WM, Toft A, Smit JW, Sanchez Franco F, Lind P, Limbert E, Jarzab B, Jamar F, Duntas L, Cohen O, et al. Follow-up and management of differentiated thyroid carcinoma: A european perspective in clinical practice. Eur J Endocrinol 2004 Nov;151(5):539-48.

88. Bachelot A, Cailleux AF, Klain M, Baudin E, Ricard M, Bellon N, Caillou B, Travagli JP, Schlumberger M. Relationship between tumor burden and serum thyroglobulin level in patients with papillary and follicular thyroid carcinoma. Thyroid 2002 Aug;12(8):707-11.

89. Burgess JR, Duffield A, Wilkinson SJ, Ware R, Greenaway TM, Percival J, Hoffman L. Two families with an autosomal dominant inheritance pattern for papillary carcinoma of the thyroid. J Clin Endocrinol Metab 1997 Feb;82(2):345-8.

90. Hemminki K, Eng C, Chen B. Familial risks for nonmedullary thyroid cancer. J Clin Endocrinol Metab 2005 Oct;90(10):5747-53.

91. Gilfillan CP. Review of the genetics of thyroid tumours: Diagnostic and prognostic implications. ANZ J Surg 2010 Jan;80(1-2):33-40.

92. MacCorkle RA, Tan TH. Mitogen-activated protein kinases in cell-cycle control. Cell Biochem Biophys 2005;43(3):451-6.

93. Xing M. BRAF mutation in papillary thyroid cancer: Pathogenic role, molecular bases, and clinical implications. Endocr Rev 2007 Dec;28(7):742-6. 
94. Fugazzola L, Puxeddu E, Avenia N, Romei C, Cirello V, Cavaliere A, Faviana P, Mannavola D, Moretti S, Rossi S, Sculli M, Bottici V, et al. Correlation between B-RAFV600E mutation and clinico-pathologic parameters in papillary thyroid carcinoma: Data from a multicentric italian study and review of the literature. Endocr Relat Cancer 2006 Jun;13(2):455-64.

95. Davies H, Bignell GR, Cox C, Stephens P, Edkins S, Clegg S, Teague J, Woffendin H, Garnett MJ, Bottomley W, Davis N, Dicks E, et al. Mutations of the BRAF gene in human cancer. Nature 2002 Jun 27;417(6892):949-54.

96. Pratilas CA, Taylor BS, Ye Q, Viale A, Sander C, Solit DB, Rosen N. (V600E)BRAF is associated with disabled feedback inhibition of RAF-MEK signaling and elevated transcriptional output of the pathway. Proc Natl Acad Sci U S A 2009 Mar 17;106(11):4519-24.

97. Elisei R, Ugolini C, Viola D, Lupi C, Biagini A, Giannini R, Romei C, Miccoli P, Pinchera A, Basolo F. BRAF(V600E) mutation and outcome of patients with papillary thyroid carcinoma: A 15-year median follow-up study. J Clin Endocrinol Metab 2008 Oct;93(10):3943-9.

98. Kebebew E, Weng J, Bauer J, Ranvier G, Clark OH, Duh QY, Shibru D, Bastian B, Griffin A. The prevalence and prognostic value of BRAF mutation in thyroid cancer. Ann Surg 2007 Sep;246(3):466,70; discussion 470-1.

99. Lupi C, Giannini R, Ugolini C, Proietti A, Berti P, Minuto M, Materazzi G, Elisei R, Santoro M, Miccoli P, Basolo F. Association of BRAF V600E mutation with poor clinicopathological outcomes in 500 consecutive cases of papillary thyroid carcinoma. J Clin Endocrinol Metab 2007 Nov;92(11):4085-90.

100. Koperek O, Kornauth C, Capper D, Berghoff AS, Asari R, Niederle B, von Deimling A, Birner P, Preusser M. Immunohistochemical detection of the BRAF V600E-mutated protein in papillary thyroid carcinoma. Am J Surg Pathol 2012 Jun;36(6):844-50.

101. Tang KT, Lee CH. BRAF mutation in papillary thyroid carcinoma: Pathogenic role and clinical implications. J Chin Med Assoc 2010 Mar;73(3):113-28.

102. Cohen Y, Rosenbaum E, Clark DP, Zeiger MA, Umbricht CB, Tufano RP, Sidransky D, Westra WH. Mutational analysis of BRAF in fine needle aspiration biopsies of the thyroid: A potential application for the preoperative assessment of thyroid nodules. Clin Cancer Res 2004 Apr 15;10(8):2761-5.

103. Nikiforova MN, Kimura ET, Gandhi M, Biddinger PW, Knauf JA, Basolo F, Zhu Z, Giannini R, Salvatore G, Fusco A, Santoro M, Fagin JA, et al. BRAF mutations in thyroid tumors are restricted to papillary carcinomas and anaplastic or poorly differentiated carcinomas arising from papillary carcinomas. J Clin Endocrinol Metab 2003 November 1, 2003;88(11):5399-404.

104. Knauf JA, Ma X, Smith EP, Zhang L, Mitsutake N, Liao XH, Refetoff S, Nikiforov YE, Fagin JA. Targeted expression of BRAFV600E in thyroid cells of transgenic mice results in papillary thyroid cancers that undergo dedifferentiation. Cancer Res 2005 May 15;65(10):4238-45.

105. Taccaliti A, Silvetti F, Palmonella G, Boscaro M. Anaplastic thyroid carcinoma. Front Endocrinol (Lausanne) 2012;3:84.

106. Moretti F, Nanni S, Farsetti A, Narducci M, Crescenzi M, Giuliacci S, Sacchi A, Pontecorvi A. Effects of exogenous p53 transduction in thyroid tumor cells with different p53 status. J Clin Endocrinol Metab 2000 Jan;85(1):302-8.

107. Hou P, Liu D, Shan Y, Hu S, Studeman K, Condouris S, Wang Y, Trink A, El-Naggar AK, Tallini G, Vasko V, Xing M. Genetic alterations and their relationship in the phosphatidylinositol 3-kinase/akt pathway in thyroid cancer. Clin Cancer Res 2007 Feb 15;13(4):1161-70. 
108. Hynes NE, MacDonald G. ErbB receptors and signaling pathways in cancer. Curr Opin Cell Biol 2009 Apr;21(2):177-84.

109. Ensinger C, Spizzo G, Moser P, Tschoerner I, Prommegger R, Gabriel M, Mikuz G, Schmid KW. Epidermal growth factor receptor as a novel therapeutic target in anaplastic thyroid carcinomas. Ann N Y Acad Sci 2004 Dec;1030:69-77.

110. Antonelli A, Fallahi P, Ferrari SM, Ruffilli I, Santini F, Minuto M, Galleri D, Miccoli P. New targeted therapies for thyroid cancer. Curr Genomics 2011 Dec;12(8):626-31.

111. Gupta-Abramson V, Troxel AB, Nellore A, Puttaswamy K, Redlinger M, Ransone K, Mandel SJ, Flaherty KT, Loevner LA, O'Dwyer PJ, Brose MS. Phase II trial of sorafenib in advanced thyroid cancer. J Clin Oncol 2008 Oct 10;26(29):4714-9.

112. Kloos RT, Ringel MD, Knopp MV, Hall NC, King M, Stevens R, Liang J, Wakely PE,Jr, Vasko VV, Saji M, Rittenberry J, Wei L, et al. Phase II trial of sorafenib in metastatic thyroid cancer. J Clin Oncol 2009 Apr 1;27(10):1675-84.

113. Hoftijzer H, Heemstra KA, Morreau H, Stokkel MP, Corssmit EP, Gelderblom H, Weijers K, Pereira AM, Huijberts M, Kapiteijn E, Romijn JA, Smit JW. Beneficial effects of sorafenib on tumor progression, but not on radioiodine uptake, in patients with differentiated thyroid carcinoma. Eur J Endocrinol 2009 Dec;161(6):923-31.

114. Cohen EE, Rosen LS, Vokes EE, Kies MS, Forastiere AA, Worden FP, Kane MA, Sherman E, Kim S, Bycott P, Tortorici M, Shalinsky DR, et al. Axitinib is an active treatment for all histologic subtypes of advanced thyroid cancer: Results from a phase II study. J Clin Oncol 2008 Oct 10;26(29):4708-13.

115. Carr LL, Mankoff DA, Goulart BH, Eaton KD, Capell PT, Kell EM, Bauman JE, Martins RG. Phase II study of daily sunitinib in FDG-PET-positive, iodine-refractory differentiated thyroid cancer and metastatic medullary carcinoma of the thyroid with functional imaging correlation. Clin Cancer Res 2010 Nov 1;16(21):5260-8.

116. Bible KC, Suman VJ, Molina JR, Smallridge RC, Maples WJ, Menefee ME, Rubin J, Sideras K, Morris JC,3rd, McIver B, Burton JK, Webster KP, et al. Efficacy of pazopanib in progressive, radioiodine-refractory, metastatic differentiated thyroid cancers: Results of a phase 2 consortium study. Lancet Oncol 2010 Oct;11(10):962-7.

117. Pennell NA, Daniels GH, Haddad RI, Ross DS, Evans T, Wirth LJ, Fidias PH, Temel JS, Gurubhagavatula S, Heist RS, Clark JR, Lynch TJ. A phase II study of gefitinib in patients with advanced thyroid cancer. Thyroid 2008 Mar;18(3):317-23.

118. Therasse P, Arbuck SG, Eisenhauer EA, Wanders J, Kaplan RS, Rubinstein L, Verweij J, Van Glabbeke M, van Oosterom AT, Christian MC, Gwyther SG. New guidelines to evaluate the response to treatment in solid tumors. european organization for research and treatment of cancer, national cancer institute of the united states, national cancer institute of canada. J Natl Cancer Inst 2000 Feb 2;92(3):205-16.

119. Blumenthal RD, Goldenberg DM. Methods and goals for the use of in vitro and in vivo chemosensitivity testing. Mol Biotechnol 2007 Feb;35(2):185-97.

120. Sawyers CL. Disabling abl-perspectives on abl kinase regulation and cancer therapeutics. Cancer Cell 2002 Feb;1(1):13-5.

121. Gomez-Rivera F, Santillan-Gomez AA, Younes MN, Kim S, Fooshee D, Zhao M, Jasser SA, Myers JN. The tyrosine kinase inhibitor, AZD2171, inhibits vascular endothelial growth factor receptor signaling and growth of anaplastic thyroid cancer in an orthotopic nude mouse model. Clin Cancer Res 2007 Aug 1;13(15 Pt 1):4519-27. 
122. Hsieh YJ, Ke CC, Liu RS, Wang FH, Tang KT, Chi CW, Chen FD, Lee CH. Radioiodide imaging and treatment of ARO cancer xenograft in a mouse model after expression of human sodium iodide symporter. Anticancer Res 2007 Jul-Aug;27(4B):2515-22.

123. Damante G, Scaloni A, Tell G. Thyroid tumors: Novel insights from proteomics studies. Expert Rev Proteomics 2009;6(4):363-76.

124. Carpi A, Di Coscio G, Iervasi G, Antonelli A, Mechanick J, Sciacchitano S, Nicolini A. Thyroid fine needle aspiration: How to improve clinicians' confidence and performance with the technique. Cancer Lett 2008 Jun 18;264(2):163-71.

125. Nikiforov YE, Biddinger PW, Thompson LDR. Diagnostic pathology and molecular genetics of the thyroid, Baltimore: Lippincott Williams \& Wilkins, 2009. 163-167 214-219p.

126. Avram AM. Radioiodine scintigraphy with SPECT/CT: An important diagnostic tool for thyroid cancer staging and risk stratification. J Nucl Med 2012 May;53(5):754-6.

127. Xue H, Lu B, Lai M. The cancer secretome: A reservoir of biomarkers. Journal of Translational Medicine 2008;6(1):52.

128. Tjalsma H, Bolhuis A, Jongbloed JDH, Bron S, van Dijl JM. Signal peptide-dependent protein transport in bacillus subtilis: A genome-based survey of the secretome. Microbiol. Mol. Biol. Rev. 2000 September 1, 2000;64(3):515-47.

129. DeSouza LV, Grigull J, Ghanny S, Dube V, Romaschin AD, Colgan TJ, Siu KW. Endometrial carcinoma biomarker discovery and verification using differentially tagged clinical samples with multidimensional liquid chromatography and tandem mass spectrometry. Mol Cell Proteomics 2007 Jul;6(7):1170-82.

130. Volmer MW, Stuhler K, Zapatka M, Schoneck A, Klein-Scory S, Schmiegel W, Meyer HE, SchwarteWaldhoff I. Differential proteome analysis of conditioned media to detect Smad4 regulated secreted biomarkers in colon cancer. Proteomics 2005 Jul;5(10):2587-601.

131. Sardana G, Jung K, Stephan C, Diamandis EP. Proteomic analysis of conditioned media from the PC3, LNCaP, and 22Rv1 prostate cancer cell lines: Discovery and validation of candidate prostate cancer biomarkers. J Proteome Res 2008 Aug;7(8):3329-38.

132. Kulasingam V, Diamandis EP. Proteomics analysis of conditioned media from three breast cancer cell lines: A mine for biomarkers and therapeutic targets. Mol Cell Proteomics 2007 Nov;6(11):1997-2011.

133. Lawlor K, Nazarian A, Lacomis L, Tempst P, Villanueva J. Pathway-based biomarker search by highthroughput proteomics profiling of secretomes. J Proteome Res 2009 Mar;8(3):1489-503.

134. Gourin CG, Zhi W, Adam BL. Proteomic identification of serum biomarkers for head and neck cancer surveillance. Laryngoscope 2009 Jul;119(7):1291-302 .

135. Bijian K, Mlynarek AM, Balys RL, Jie S, Xu Y, Hier MP, Black MJ, Di Falco MR, LaBoissiere S, AlaouiJamali MA. Serum proteomic approach for the identification of serum biomarkers contributed by oral squamous cell carcinoma and host tissue microenvironment. J Proteome Res 2009 May;8(5):2173-85.

136. Karagiannis GS, Pavlou MP, Diamandis EP. Cancer secretomics reveal pathophysiological pathways in cancer molecular oncology. Molecular Oncology 2010;4(6):496-510. 
137. Chung LW, Baseman A, Assikis V, Zhau HE. Molecular insights into prostate cancer progression: The missing link of tumor microenvironment. J Urol 2005 Jan;173(1):10-2.

138. Liotta LA, Ferrari M, Petricoin E. Clinical proteomics: Written in blood. Nature 2003 Oct 30;425(6961):905.

139. Schweppe RE, Klopper JP, Korch C, Pugazhenthi U, Benezra M, Knauf JA, Fagin JA, Marlow LA, Copland JA, Smallridge RC, Haugen BR. Deoxyribonucleic acid profiling analysis of 40 human thyroid cancer cell lines reveals cross-contamination resulting in cell line redundancy and misidentification. J Clin Endocrinol Metab 2008 Nov;93(11):4331-41.

140. Kashat L, So AKC, Masui O, Wang XS, Cao J, Meng X, MacMillan C, Ailles LE, Siu KWM, Ralhan R, Walfish PG. Secretome-based identification and characterization of potential biomarkers in thyroid cancer. Journal of Proteome Research 2010;9(11):5757-69.

141. Bendtsen JD, Nielsen H, von Heijne G, Brunak S. Improved prediction of signal peptides: SignalP 3.0. J Mol Biol 2004 Jul 16;340(4):783-95.

142. Bendtsen JD, Jensen LJ, Blom N, Von Heijne G, Brunak S. Feature-based prediction of non-classical and leaderless protein secretion. Protein Eng Des Sel 2004 Apr;17(4):349-56.

143. Ralhan R, Desouza LV, Matta A, Chandra Tripathi S, Ghanny S, Datta Gupta S, Bahadur S, Siu KW. Discovery and verification of head-and-neck cancer biomarkers by differential protein expression analysis using iTRAQ labeling, multidimensional liquid chromatography, and tandem mass spectrometry. Mol Cell Proteomics 2008 Jun;7(6):1162-73.

144. Micciche F, Da Riva L, Fabbi M, Pilotti S, Mondellini P, Ferrini S, Canevari S, Pierotti MA, Bongarzone I. Activated leukocyte cell adhesion molecule expression and shedding in thyroid tumors. PLoS One 2011 Feb 22;6(2):e17141.

145. Sawhney M, Matta A, Macha MA, Kaur J, DattaGupta S, Shukla NK, Ralhan R. Cytoplasmic accumulation of activated leukocyte cell adhesion molecule is a predictor of disease progression and reduced survival in oral cancer patients. Int J Cancer 2009 May 1;124(9):2098-105.

146. Avilla E, Guarino V, Visciano C, Liotti F, Svelto M, Krishnamoorthy G, Franco R, Melillo RM. Activation of TYRO3/AXL tyrosine kinase receptors in thyroid cancer. Cancer Research 2011;71(5):1792-804.

147. Chen M, Zhang J, Manley JL. Turning on a fuel switch of cancer: hnRNP proteins regulate alternative splicing of pyruvate kinase mRNA. Cancer Research 2010 November 15, 2010;70(22):8977-80.

148. Ralhan R, Masui O, DeSouza LV, Matta A, Macha M, Michael Siu KW. Identification of proteins secreted by head and neck cancer cell lines using LC-MS/MS: Strategy for discovery of candidate serological biomarkers. Proteomics 2011:n/a,n/a.

149. Simon V, Guidry J, Gettys TW, Tobin AB, Lanier SM. The proto-oncogene SET interacts with muscarinic receptors and attenuates receptor signaling. Journal of Biological Chemistry 2006 December 29, 2006;281(52):40310-2.

150. Venkataramani V, Rossner C, Iffland L, Schweyer S, Tamboli IY, Walter J, Wirths O, Bayer TA. Histone deacetylase inhibitor valproic acid inhibits cancer cell proliferation via down-regulation of the alzheimer amyloid precursor protein. Journal of Biological Chemistry 2010 April 2, 2010;285(14):10678-89. 
151. Holback S, Adlerz L, Iverfeldt K. Increased processing of APLP2 and APP with concomitant formation of APP intracellular domains in BDNF and retinoic acid-differentiated human neuroblastoma cells. Journal of Neurochemistry 2005;95(4):1059-68.

152. Zhang P, Huang L, Ma Y, Peng J, Shen T, Chen H, Zhou Y, Zhang M, Chu Z, Qin H. HnRNP K and PDI marked response to chemotherapy to human colorectal cancer cells. ELECTROPHORESIS 2010;31(10):1731-8.

153. Goldberg MS, Sharp PA. Pyruvate kinase M2-specific siRNA induces apoptosis and tumor regression. J Exp Med 2012 Feb 13;209(2):217-24.

154. Landriscina M, Pannone G, Piscazzi A, Toti P, Fabiano A, Tortorella S, Occhini R, Ambrosi A, Bufo P, Cignarelli M. Epidermal growth factor receptor 1 expression is upregulated in undifferentiated thyroid carcinomas in humans. Thyroid 2011 Nov;21(11):1227-34.

155. Dei Tos AP. The biology of epidermal growth factor receptor and its value as a prognostic/predictive factor. Int J Biol Markers 2007 Jan-Mar;22(1 Suppl 4):S3-9.

156. Knauf JA, Sartor MA, Medvedovic M, Lundsmith E, Ryder M, Salzano M, Nikiforov YE, Giordano TJ, Ghossein RA, Fagin JA. Progression of BRAF-induced thyroid cancer is associated with epithelial-mesenchymal transition requiring concomitant MAP kinase and TGFbeta signaling. Oncogene 2011 Jul 14;30(28):3153-62.

157. Montero-Conde C, Martin-Campos JM, Lerma E, Gimenez G, Martinez-Guitarte JL, Combalia N, Montaner D, Matias-Guiu X, Dopazo J, de Leiva A, Robledo M, Mauricio D. Molecular profiling related to poor prognosis in thyroid carcinoma. combining gene expression data and biological information. Oncogene $2008 \mathrm{Mar}$ 6;27(11):1554-61.

158. Wiseman SM, Griffith OL, Deen S, Rajput A, Masoudi H, Gilks B, Goldstein L, Gown A, Jones SJ. Identification of molecular markers altered during transformation of differentiated into anaplastic thyroid carcinoma. Arch Surg 2007 Aug;142(8):717,27; discussion 727-9.

159. Kalluri R, Weinberg RA. The basics of epithelial-mesenchymal transition. J Clin Invest 2009 Jun;119(6):1420-8.

160. Liu Z, Hou P, Ji M, Guan H, Studeman K, Jensen K, Vasko V, El-Naggar AK, Xing M. Highly prevalent genetic alterations in receptor tyrosine kinases and phosphatidylinositol 3-kinase/akt and mitogen-activated protein kinase pathways in anaplastic and follicular thyroid cancers. J Clin Endocrinol Metab 2008 Aug;93(8):3106-1.

161. Lee DH, Lee GK, Kong SY, Kook MC, Yang SK, Park SY, Park SH, Keam B, Park do J, Cho BY, Kim SW, Chung KW, et al. Epidermal growth factor receptor status in anaplastic thyroid carcinoma. J Clin Pathol 2007 Aug;60(8):881-4.

162. Hardy KM, Booth BW, Hendrix MJ, Salomon DS, Strizzi L. ErbB/EGF signaling and EMT in mammary development and breast cancer. J Mammary Gland Biol Neoplasia 2010 Jun;15(2):191-9.

163. Grande M, Franzen A, Karlsson JO, Ericson LE, Heldin NE, Nilsson M. Transforming growth factor-beta and epidermal growth factor synergistically stimulate epithelial to mesenchymal transition (EMT) through a MEK-dependent mechanism in primary cultured pig thyrocytes. J Cell Sci 2002 Nov 15;115(Pt 22):4227-36.

164. Meric F, Lee WP, Sahin A, Zhang H, Kung HJ, Hung MC. Expression profile of tyrosine kinases in breast cancer. Clinical cancer research : an official journal of the American Association for Cancer Research 2002 Feb;8(2):361-7. 
165. Sainaghi PP, Castello L, Bergamasco L, Galletti M, Bellosta P, Avanzi GC. Gas6 induces proliferation in prostate carcinoma cell lines expressing the axl receptor. J Cell Physiol 2005 Jul;204(1):36-44.

166. Shieh YS, Lai CY, Kao YR, Shiah SG, Chu YW, Lee HS, Wu CW. Expression of axl in lung adenocarcinoma and correlation with tumor progression. Neoplasia 2005 Dec;7(12):1058-64.

167. Verma A, Warner SL, Vankayalapati H, Bearss DJ, Sharma S. Targeting axl and mer kinases in cancer. Molecular cancer therapeutics 2011 Oct;10(10):1763-73.

168. Bergamaschi A, Christensen BL, Katzenellenbogen BS. Reversal of endocrine resistance in breast cancer: Interrelationships among 14-3-3zeta, FOXM1, and a gene signature associated with mitosis. Breast Cancer Res 2011 Jun 29;13(3):R70.

169. Yue J, Lu H, Liu J, Berwick M, Shen Z. Filamin-A as a marker and target for DNA damage based cancer therapy. DNA Repair (Amst) 2012 Feb 1;11(2):192-200.

170. Gay O, Gilquin B, Nakamura F, Jenkins ZA, McCartney R, Krakow D, Deshiere A, Assard N, Hartwig JH, Robertson SP, Baudier J. RefilinB (FAM101B) targets filamin A to organize perinuclear actin networks and regulates nuclear shape. Proc Natl Acad Sci U S A 2011 Jul 12;108(28):11464-9.

171. Velkova A, Carvalho MA, Johnson JO, Tavtigian SV, Monteiro AN. Identification of filamin A as a BRCA1-interacting protein required for efficient DNA repair. Cell Cycle 2010 Apr 1;9(7):1421-33.

172. Yuan Y, Shen Z. Interaction with BRCA2 suggests a role for filamin-1 (hsFLNa) in DNA damage response. J Biol Chem 2001 Dec 21;276(51):48318-24.

173. Deakin NO, Bass MD, Warwood S, Schoelermann J, Mostafavi-Pour Z, Knight D, Ballestrem C, Humphries MJ. An integrin-alpha4-14-3-3zeta-paxillin ternary complex mediates localised Cdc42 activity and accelerates cell migration. Journal of cell science 2009 May 15;122(Pt 10):1654-64.

174. Bajpai U, Sharma R, Kausar T, Dattagupta S, Chattopadhayay TK, Ralhan R. Clinical significance of 14-3-3 zeta in human esophageal cancer. The International journal of biological markers 2008 Oct-Dec;23(4):231-7.

175. He Y, Wu X, Liu X, Yan G, Xu C. LC-MS/MS analysis of ovarian cancer metastasis-related proteins using a nude mouse model: 14-3-3 zeta as a candidate biomarker. Journal of proteome research 2010 Dec 3;9(12):618090.

176. Sofiadis A, Becker S, Hellman U, Hultin-Rosenberg L, Dinets A, Hulchiy M, Zedenius J, Wallin G, Foukakis T, Hoog A, Auer G, Lehtio J, et al. Proteomic profiling of follicular and papillary thyroid tumors. Eur J Endocrinol 2012 Apr;166(4):657-6.

177. Chang KA, Suh YH. Possible roles of amyloid intracellular domain of amyloid precursor protein. BMB reports 2010 Oct;43(10):656-63.

178. Hansel DE, Rahman A, Wehner S, Herzog V, Yeo CJ, Maitra A. Increased expression and processing of the alzheimer amyloid precursor protein in pancreatic cancer may influence cellular proliferation. Cancer research 2003 Nov 1;63(21):7032-7.

179. Ko SY, Lin SC, Chang KW, Wong YK, Liu CJ, Chi CW, Liu TY. Increased expression of amyloid precursor protein in oral squamous cell carcinoma. International journal of cancer Journal international du cancer 2004 Sep 20;111(5):727-32. 
180. Ko SY, Chang KW, Lin SC, Hsu HC, Liu TY. The repressive effect of green tea ingredients on amyloid precursor protein (APP) expression in oral carcinoma cells in vitro and in vivo. Cancer letters 2007 Jan 8;245(12):81-9.

181. Takayama K, Tsutsumi S, Suzuki T, Horie-Inoue K, Ikeda K, Kaneshiro K, Fujimura T, Kumagai J, Urano T, Sakaki Y, Shirahige K, Sasano H, et al. Amyloid precursor protein is a primary androgen target gene that promotes prostate cancer growth. Cancer research 2009 Jan 1;69(1):137-42.

182. Krause K, Karger S, Sheu SY, Aigner T, Kursawe R, Gimm O, Schmid KW, Dralle H, Fuhrer D. Evidence for a role of the amyloid precursor protein in thyroid carcinogenesis. J Endocrinol 2008 Aug;198(2):291-9.

183. Jacobsen KT, Iverfeldt K. Amyloid precursor protein and its homologues: A family of proteolysis-dependent receptors. Cellular and molecular life sciences : CMLS 2009 Jul;66(14):2299-318.

184. Wang J, Wang J, Dai J, Jung Y, Wei CL, Wang Y, Havens AM, Hogg PJ, Keller ET, Pienta KJ, Nor JE, Wang CY, et al. A glycolytic mechanism regulating an angiogenic switch in prostate cancer. Cancer Res 2007 Jan $1 ; 67(1): 149-5$.

185. Tang SJ, Ho MY, Cho HC, Lin YC, Sun GH, Chi KH, Wang YS, Jhou RS, Yang W, Sun KH. Phosphoglycerate kinase 1-overexpressing lung cancer cells reduce cyclooxygenase 2 expression and promote anti-tumor immunity in vivo. Int J Cancer 2008 Dec 15;123(12):2840-8.

186. Hwang TL, Liang Y, Chien KY, Yu JS. Overexpression and elevated serum levels of phosphoglycerate kinase 1 in pancreatic ductal adenocarcinoma. Proteomics 2006 Apr;6(7):2259-72.

187. Duan Z, Lamendola DE, Yusuf RZ, Penson RT, Preffer FI, Seiden MV. Overexpression of human phosphoglycerate kinase 1 (PGK1) induces a multidrug resistance phenotype. Anticancer research 2002 JulAug;22(4):1933-41.

188. Zieker D, Konigsrainer I, Traub F, Nieselt K, Knapp B, Schillinger C, Stirnkorb C, Fend F, Northoff H, Kupka S, Brucher BL, Konigsrainer A. PGK1 a potential marker for peritoneal dissemination in gastric cancer. Cellular physiology and biochemistry : international journal of experimental cellular physiology, biochemistry, and pharmacology 2008;21(5-6):429-36.

189. Zhang D, Tai LK, Wong LL, Chiu LL, Sethi SK, Koay ES. Proteomic study reveals that proteins involved in metabolic and detoxification pathways are highly expressed in HER-2/neu-positive breast cancer. Molecular \& cellular proteomics : MCP 2005 Nov;4(11):1686-96.

190. Christofk HR, Vander Heiden MG, Harris MH, Ramanathan A, Gerszten RE, Wei R, Fleming MD, Schreiber SL, Cantley LC. The M2 splice isoform of pyruvate kinase is important for cancer metabolism and tumour growth. Nature 2008 Mar 13;452(7184):230-3.

191. Luo W, Hu H, Chang R, Zhong J, Knabel M, O'Meally R, Cole RN, Pandey A, Semenza GL. Pyruvate kinase M2 is a PHD3-stimulated coactivator for hypoxia-inducible factor 1. Cell 2011 May 27;145(5):732-44.

192. Yang W, Xia Y, Ji H, Zheng Y, Liang J, Huang W, Gao X, Aldape K, Lu Z. Nuclear PKM2 regulates betacatenin transactivation upon EGFR activation. Nature 2011 Nov 6.

193. Vera J, Jaumot M, Estanyol JM, Brun S, Agell N, Bachs O. Heterogeneous nuclear ribonucleoprotein A2 is a SET-binding protein and a PP2A inhibitor. Oncogene 2006 Jan 12;25(2):260-70.

194. Dreyfuss G, Matunis MJ, Pinol-Roma S, Burd CG. hnRNP proteins and the biogenesis of mRNA. Annual review of biochemistry 1993;62:289-321. 
195. He Y, Smith R. Nuclear functions of heterogeneous nuclear ribonucleoproteins A/B. Cellular and molecular life sciences : CMLS 2009 Apr;66(7):1239-56.

196. Bomsztyk K, Denisenko O, Ostrowski J. hnRNP K: One protein multiple processes. BioEssays : news and reviews in molecular, cellular and developmental biology 2004 Jun;26(6):629-38.

197. Carpenter B, McKay M, Dundas SR, Lawrie LC, Telfer C, Murray GI. Heterogeneous nuclear ribonucleoprotein $\mathrm{K}$ is over expressed, aberrantly localised and is associated with poor prognosis in colorectal cancer. British journal of cancer 2006 Oct 9;95(7):921-7.

198. Hope NR, Murray GI. The expression profile of RNA-binding proteins in primary and metastatic colorectal cancer: Relationship of heterogeneous nuclear ribonucleoproteins with prognosis. Human pathology 2011 Mar;42(3):393-402.

199. King JA, Ofori-Acquah SF, Stevens T, Al-Mehdi AB, Fodstad O, Jiang WG. Activated leukocyte cell adhesion molecule in breast cancer: Prognostic indicator. Breast Cancer Res 2004;6(5):R478-87.

200. Kristiansen G, Pilarsky C, Wissmann C, Stephan C, Weissbach L, Loy V, Loening S, Dietel M, Rosenthal A. ALCAM/CD166 is up-regulated in low-grade prostate cancer and progressively lost in high-grade lesions.

Prostate 2003 Jan 1;54(1):34-43.

201. Mezzanzanica D, Fabbi M, Bagnoli M, Staurengo S, Losa M, Balladore E, Alberti P, Lusa L, Ditto A, Ferrini S, Pierotti MA, Barbareschi M, et al. Subcellular localization of activated leukocyte cell adhesion molecule is a molecular predictor of survival in ovarian carcinoma patients. Clin Cancer Res 2008 Mar 15;14(6):1726-33.

202. King JA, Tan F, Mbeunkui F, Chambers Z, Cantrell S, Chen H, Alvarez D, Shevde LA, Ofori-Acquah SF. Mechanisms of transcriptional regulation and prognostic significance of activated leukocyte cell adhesion molecule in cancer. Mol Cancer 2010 Oct 7;9:266.

203. Burkhardt M, Mayordomo E, Winzer KJ, Fritzsche F, Gansukh T, Pahl S, Weichert W, Denkert C, Guski H, Dietel M, Kristiansen G. Cytoplasmic overexpression of ALCAM is prognostic of disease progression in breast cancer. J Clin Pathol 2006 Apr;59(4):403-9.

204. van Kempen LC, van den Oord JJ, van Muijen GN, Weidle UH, Bloemers HP, Swart GW. Activated leukocyte cell adhesion molecule/CD166, a marker of tumor progression in primary malignant melanoma of the skin. Am J Pathol 2000 Mar;156(3):769-74.

205. Tachezy M, Effenberger K, Zander H, Minner S, Gebauer F, Vashist YK, Sauter G, Pantel K, Izbicki JR, Bockhorn M. ALCAM (CD166) expression and serum levels are markers for poor survival of esophageal cancer patients. Int J Cancer 2011 Aug 19.

206. van den Brand M, Takes RP, Blokpoel-deRuyter M, Slootweg PJ, van Kempen LC. Activated leukocyte cell adhesion molecule expression predicts lymph node metastasis in oral squamous cell carcinoma. Oral Oncol 2010 May;46(5):393-8.

207. Kahlert C, Weber H, Mogler C, Bergmann F, Schirmacher P, Kenngott HG, Matterne U, Mollberg N, Rahbari NN, Hinz U, Koch M, Aigner M, et al. Increased expression of ALCAM/CD166 in pancreatic cancer is an independent prognostic marker for poor survival and early tumour relapse. Br J Cancer 2009 Aug 4;101(3):457-64.

208. Weichert W, Knosel T, Bellach J, Dietel M, Kristiansen G. ALCAM/CD166 is overexpressed in colorectal carcinoma and correlates with shortened patient survival. J Clin Pathol 2004 Nov;57(11):1160-4. 
209. Dalerba P, Dylla SJ, Park IK, Liu R, Wang X, Cho RW, Hoey T, Gurney A, Huang EH, Simeone DM, Shelton AA, Parmiani G, et al. Phenotypic characterization of human colorectal cancer stem cells. Proc Natl Acad Sci U S A 2007 Jun 12;104(24):10158-63.

210. Corrias MV, Gambini C, Gregorio A, Croce M, Barisione G, Cossu C, Rossello A, Ferrini S, Fabbi M. Different subcellular localization of ALCAM molecules in neuroblastoma: Association with relapse. Cell Oncol 2010;32(1-2):77-86.

211. Ihnen M, Kress K, Kersten JF, Kilic E, Choschzick M, Zander H, Muller V, Mahner S, Janicke F, Woelber L, Milde-Langosch K. Relevance of activated leukocyte cell adhesion molecule (ALCAM) in tumor tissue and sera of cervical cancer patients. BMC Cancer 2012 Apr 4;12:140.

212. Ihnen M, Muller V, Wirtz RM, Schroder C, Krenkel S, Witzel I, Lisboa BW, Janicke F, Milde-Langosch K. Predictive impact of activated leukocyte cell adhesion molecule (ALCAM/CD166) in breast cancer. Breast Cancer Res Treat 2008 Dec;112(3):419-27.

213. Hein S, Muller V, Kohler N, Wikman H, Krenkel S, Streichert T, Schweizer M, Riethdorf S, Assmann V, Ihnen M, Beck K, Issa R, et al. Biologic role of activated leukocyte cell adhesion molecule overexpression in breast cancer cell lines and clinical tumor tissue. Breast Cancer Res Treat 2011 Sep;129(2):347-60.

214. Rosso O, Piazza T, Bongarzone I, Rossello A, Mezzanzanica D, Canevari S, Orengo AM, Puppo A, Ferrini S, Fabbi M. The ALCAM shedding by the metalloprotease ADAM17/TACE is involved in motility of ovarian carcinoma cells. Mol Cancer Res 2007 Dec;5(12):1246-53. 


\section{Appendices}

\section{Appendix I}

Supplementary Table S1 - Summary of high-confidence proteins in BCPAP, C643, and SW1736 thyroid cancer cell lines identified by mass spectrometry at York University

\begin{tabular}{|c|c|c|c|c|c|c|c|c|}
\hline Accession \# & Protein & $\begin{array}{c}\text { Protein- } \\
\text { pilot } \\
\text { Unused } \\
\text { Score }\end{array}$ & $\begin{array}{l}\text { \# Unique } \\
\text { peptides }\end{array}$ & Sample & Peptide sequence & $\begin{array}{l}\text { Precursor } \\
\mathbf{m} / \mathbf{z}\end{array}$ & Charge & $\begin{array}{c}\text { Peptide } \\
\text { confidence }\end{array}$ \\
\hline spt|P63104 & $14-3-3$ & 2.42 & 1 & ВCPAP-SFM 17/05 & DSTLIMQLLR & 595.3297 & 2 & 99 \\
\hline spt|P63104 & $14-3-3$ & 4 & & C643-SFM & DSTLIMQLLR & 595.2571 & 2 & 99 \\
\hline spt|P63104 & $14-3-3$ & 3.15 & & SW-SFM 04/27 & DSTLIMQLLR & 595.3312 & 2 & 99 \\
\hline spt|Q06481 & APLP2 & 6.02 & 3 & SW-SFM 04/27 & $\begin{array}{l}\text { C[Cam]LVGEFVSDVL } \\
\text { LVPEK }\end{array}$ & 902.4816 & 2 & 99 \\
\hline spt|Q06481 & APLP2 & & & SW-SFM 04/27 & $\begin{array}{l}\text { M[Oxi]ALE[Dhy]NYL } \\
\text { AALQSDPPRPHR }\end{array}$ & 545.0292 & 4 & 99 \\
\hline spt|Q06481 & APLP2 & & & SW-SFM 04/27 & $\begin{array}{l}\text { VPYVAQEIQEEIDEL } \\
\text { LQEQR }\end{array}$ & 810.4114 & 3 & 99 \\
\hline spt|Q06481 & APLP2 & 3.52 & & SW-SFM 05/13 & $\begin{array}{l}\text { VPYVAQEIQEEIDEL } \\
\text { LQEQR }\end{array}$ & 811.0769 & 3 & 99 \\
\hline spt|P05067 & APP & 2.16 & 2 & SW-SFM 04/27 & $\begin{array}{l}\text { LEVPTDGNAGLLAE } \\
\text { PQIAMFC[Cam]GR }\end{array}$ & 820.4079 & 3 & 99 \\
\hline spt|P05067 & APP & 3.7 & & SW-SFM 05/13 & $\begin{array}{l}\text { C[Cam]LVGEFVSDAL } \\
\text { LVPDK }\end{array}$ & 881.4588 & 2 & 99 \\
\hline spt|P30530 & AXL & 1.7 & 2 & BCPAP-SFM 05/17 & APLQGTLLGYR & 594.8381 & 2 & 98 \\
\hline spt|P30530 & AXL & 2.35 & & SW-SFM $05 / 13$ & APLQGTLLGYR & 594.8384 & 2 & 99 \\
\hline spt|P30530 & $\mathrm{AXL}$ & 2.01 & & SW-SFM 04/27 & $\begin{array}{l}\text { LAYQGQDTPEVLMD } \\
\text { IGLR }\end{array}$ & 1010.015 & 2 & 99 \\
\hline spt|P61978 & hnRNP K & 2 & 2 & C643-SFM & IILDLISESPIK & 670.824 & 2 & 99 \\
\hline spt|P61978 & hnRNP K & 2 & & SW-SFM 04/27 & ILSISADIETIGEILK & 857.9958 & 2 & 99 \\
\hline spt|P00558 & PGK1 & 1.7 & 1 & C643-SFM & VLPGVDALSNI & 549.2493 & 2 & 97 \\
\hline spt|P14618 & PKM2 & 2.64 & 2 & C643-SFM & APIIAVTR & 420.7204 & 2 & 97 \\
\hline spt|P14618 & PKM2 & 2.01 & & SW-SFM 04/27 & $\begin{array}{l}\text { FGVEQDVDMVFASF } \\
\text { IR }\end{array}$ & 620.6364 & 3 & 99 \\
\hline spt|Q01105 & SET & 2 & 2 & SW-SFM 04/27 & $\begin{array}{l}\text { IPNFWVTTFVNHPQV } \\
\text { SALLGEEDEEALHYL } \\
\text { TR }\end{array}$ & 932.2211 & 4 & 99 \\
\hline spt|Q01105 & SET & 2.77 & & SW-SFM 05/13 & IDFYFDENPYFENK & 920.9081 & 2 & 99 \\
\hline spt|Q6PEY4 & ALCAM & 2 & 1 & ВСРАР $04 / 22$ & VLHPLEGAVVIIFKK & 555.0458 & 3 & 99 \\
\hline
\end{tabular}

Proteinpilot Unused score: a score $\geq 1.3$ corresponds to a confidence score $\geq 95 \%$

Legend of amino-acid modifications: $\mathrm{C}[\mathrm{Cam}]=$ Carbamidomethyl-Cystein; $\mathrm{M}[\mathrm{Oxi}]=$ Oxidized Methionine; $\mathrm{E}[\mathrm{Dhy}]=$ Dehydrated Glutamic acid. 


\section{Appendix II}

Supplementary Tables and Figures S2 - MS/MS spectra of the identified peptides at York University

Protein: 14-3-3; Sample: BCPAP-SFM 17/05

\begin{tabular}{|l|l|l|l|l|}
\hline Residue & $\mathrm{b}$ & $\mathrm{b}+2$ & $\mathrm{y}$ & $\mathrm{y}+2$ \\
\hline $\mathrm{D}$ & 116.034 & 58.5207 & 1189.66 & 595.334 \\
\hline $\mathrm{S}$ & 203.066 & 102.037 & 1074.63 & 537.821 \\
\hline $\mathrm{T}$ & 304.114 & 152.561 & 987.602 & 494.305 \\
\hline $\mathrm{L}$ & 417.198 & 209.103 & 886.554 & 443.781 \\
\hline $\mathrm{I}$ & 530.282 & 265.645 & 773.47 & 387.239 \\
\hline $\mathrm{M}$ & 661.323 & 331.165 & 660.386 & 330.697 \\
\hline $\mathrm{Q}$ & 789.381 & 395.194 & 529.346 & 265.177 \\
\hline $\mathrm{L}$ & 902.465 & 451.736 & 401.287 & 201.147 \\
\hline $\mathrm{L}$ & 1015.55 & 508.278 & 288.203 & 144.605 \\
\hline $\mathrm{R}$ & 1171.65 & 586.329 & 175.119 & 88.0631 \\
\hline
\end{tabular}

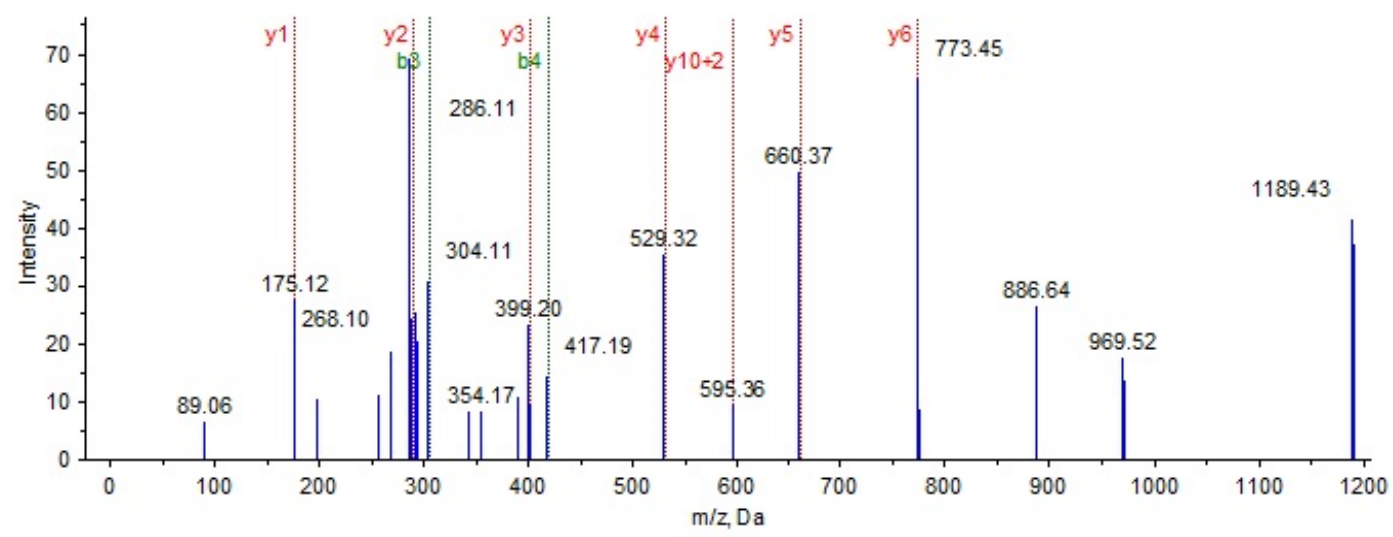


Protein: 14-3-3; Sample: C643-SFM

\begin{tabular}{|l|l|r|r|r|}
\hline Residue & $\mathrm{b}$ & $\mathrm{b}+2$ & \multicolumn{1}{l|}{$\mathrm{y}$} & $\mathrm{y}+2$ \\
\hline $\mathrm{D}$ & 116.034 & 58.5207 & 1418.72 & 709.863 \\
\hline $\mathrm{I}$ & 229.118 & 115.063 & 1303.69 & 652.35 \\
\hline C [CAM] & 389.149 & 195.078 & 1190.61 & 595.808 \\
\hline $\mathrm{N}$ & 503.192 & 252.1 & 1030.58 & 515.793 \\
\hline $\mathrm{D}$ & 618.219 & 309.613 & 916.535 & 458.771 \\
\hline $\mathrm{V}$ & 717.287 & 359.147 & 801.508 & 401.258 \\
\hline $\mathrm{L}$ & 830.371 & 415.689 & 702.44 & 351.723 \\
\hline $\mathrm{S}$ & 917.403 & 459.205 & 589.356 & 295.181 \\
\hline L & 1030.49 & 515.747 & 502.324 & 251.665 \\
\hline L & 1143.57 & 572.289 & 389.24 & 195.123 \\
\hline E & 1272.61 & 636.811 & 276.155 & 138.581 \\
\hline K & 1400.71 & 700.858 & 147.113 & 74.06 \\
\hline
\end{tabular}

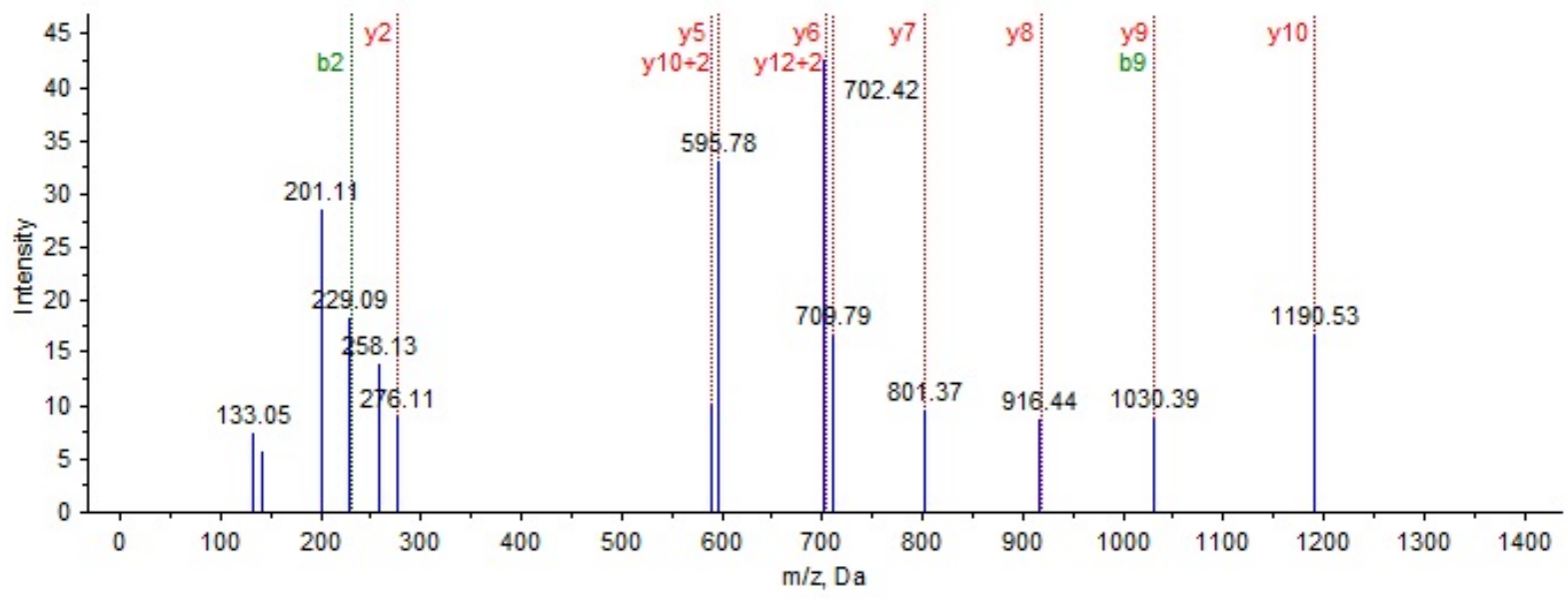

Protein: 14-3-3; Sample: SW-SFM 04/27

\begin{tabular}{|l|r|r|r|r|}
\hline Residue & \multicolumn{1}{l|}{$\mathrm{r}$} & $\mathrm{b}+2$ & $\mathrm{y}$ & $\mathrm{y}+2$ \\
\hline $\mathrm{D}$ & 116.0342 & 58.5207 & 1189.6609 & 595.3341 \\
\hline $\mathrm{S}$ & 203.0662 & 102.0368 & 1074.634 & 537.8206 \\
\hline $\mathrm{T}$ & 304.1139 & 152.5606 & 987.6019 & 494.3046 \\
\hline $\mathrm{L}$ & 417.198 & 209.1026 & 886.5543 & 443.7808 \\
\hline $\mathrm{I}$ & 530.2821 & 265.6447 & 773.4702 & 387.2387 \\
\hline $\mathrm{M}$ & 661.3225 & 331.1649 & 660.3861 & 330.6967 \\
\hline $\mathrm{Q}$ & 789.3811 & 395.1942 & 529.3457 & 265.1765 \\
\hline $\mathrm{L}$ & 902.4652 & 451.7362 & 401.2871 & 201.1472 \\
\hline $\mathrm{L}$ & 1015.5492 & 508.2783 & 288.203 & 144.6051 \\
\hline $\mathrm{R}$ & 1171.6504 & 586.3288 & 175.119 & 88.0631 \\
\hline
\end{tabular}




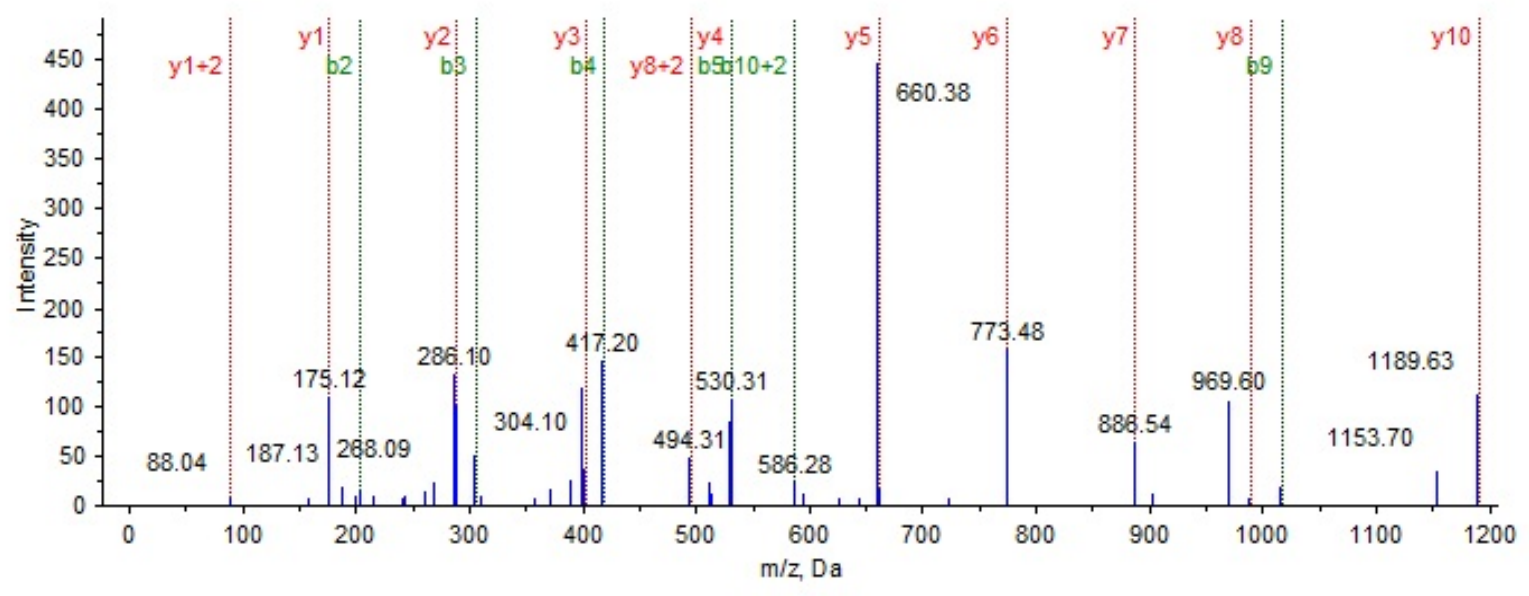

Protein: APLP2; Sample: SW-SFM 04/27

\begin{tabular}{|l|r|r|l|r|}
\hline Residue & $\mathrm{b}$ & $\mathrm{b}+2$ & $\mathrm{y}$ & $\mathrm{y}+2$ \\
\hline C [CAM] & 161.0379 & 81.0226 & 1803.956 & 902.4817 \\
\hline L & 274.122 & 137.5646 & 1643.926 & 822.4664 \\
\hline V & 373.1904 & 187.0988 & 1530.841 & 765.9243 \\
\hline G & 430.2119 & 215.6096 & 1431.773 & 716.3901 \\
\hline E & 559.2545 & 280.1309 & 1374.752 & 687.8794 \\
\hline F & 706.3229 & 353.6651 & 1245.709 & 623.3581 \\
\hline V & 805.3913 & 403.1993 & 1098.641 & 549.8239 \\
\hline S & 892.4233 & 446.7153 & 999.5721 & 500.2897 \\
\hline D & 1007.45 & 504.2288 & 912.5401 & 456.7737 \\
\hline V & 1106.519 & 553.763 & 797.5131 & 399.2602 \\
\hline L & 1219.603 & 610.305 & 698.4447 & 349.726 \\
\hline L & 1332.687 & 666.847 & 585.3606 & 293.184 \\
\hline V & 1431.755 & 716.3812 & 472.2766 & 236.6419 \\
\hline P & 1528.808 & 764.9076 & 373.2082 & 187.1077 \\
\hline E & 1657.851 & 829.4289 & 276.1554 & 138.5813 \\
\hline K & 1785.946 & 893.4764 & 147.1128 & 74.06 \\
\hline
\end{tabular}




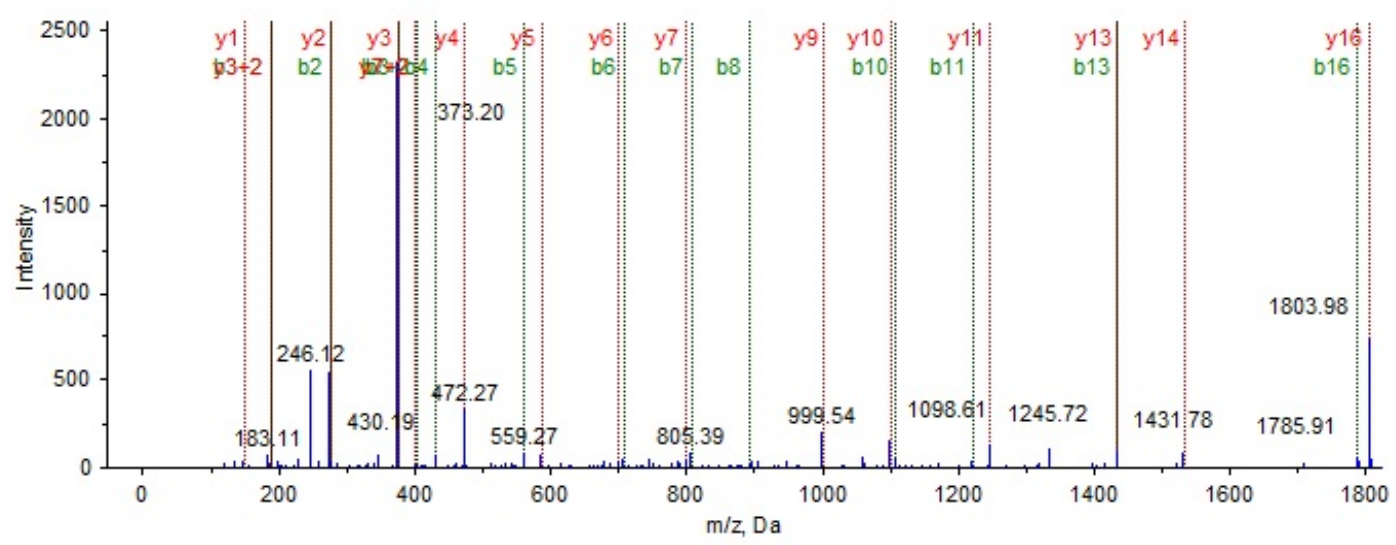

Protein: APLP2; Sample: SW-SFM 04/27

\begin{tabular}{|l|r|r|r|r|}
\hline Residue & b & \multicolumn{1}{l|}{$\mathrm{b}+2$} & $\mathrm{y}$ & $\mathrm{y}+2$ \\
\hline $\mathrm{M}[$ Oxi] & 148.0427 & 74.525 & 2177.092 & 1089.05 \\
\hline $\mathrm{A}$ & 219.0798 & 110.0435 & 2030.057 & 1015.532 \\
\hline $\mathrm{L}$ & 332.1639 & 166.5856 & 1959.02 & 980.0134 \\
\hline E[Dhy] & 443.1959 & 222.1016 & 1845.936 & 923.4714 \\
\hline $\mathrm{N}$ & 557.2388 & 279.123 & 1734.903 & 867.9554 \\
\hline $\mathrm{Y}$ & 720.3021 & 360.6547 & 1620.861 & 810.9339 \\
\hline $\mathrm{L}$ & 833.3862 & 417.1967 & 1457.797 & 729.4022 \\
\hline $\mathrm{A}$ & 904.4233 & 452.7153 & 1344.713 & 672.8602 \\
\hline $\mathrm{A}$ & 975.4604 & 488.2339 & 1273.676 & 637.3416 \\
\hline $\mathrm{L}$ & 1088.545 & 544.7759 & 1202.639 & 601.8231 \\
\hline $\mathrm{Q}$ & 1216.603 & 608.8052 & 1089.555 & 545.281 \\
\hline $\mathrm{S}$ & 1303.635 & 652.3212 & 961.4962 & 481.2518 \\
\hline $\mathrm{D}$ & 1418.662 & 709.8347 & 874.4642 & 437.7357 \\
\hline $\mathrm{P}$ & 1515.715 & 758.361 & 759.4373 & 380.2223 \\
\hline $\mathrm{P}$ & 1612.768 & 806.8874 & 662.3845 & 331.6959 \\
\hline $\mathrm{R}$ & 1768.869 & 884.938 & 565.3317 & 283.1695 \\
\hline $\mathrm{P}$ & 1865.921 & 933.4644 & 409.2306 & 205.119 \\
\hline $\mathrm{H}$ & 2002.98 & 1001.994 & 312.1779 & 156.5926 \\
\hline $\mathrm{R}$ & 2159.082 & 1080.044 & 175.119 & 88.0631 \\
\hline
\end{tabular}






Protein: APLP2; Sample: SW-SFM 04/27

\begin{tabular}{|l|r|r|r|r|}
\hline Residue & $\mathrm{b}$ & $\mathrm{b}+2$ & $\mathrm{y}$ & $\mathrm{y}+2$ \\
\hline $\mathrm{V}$ & 100.0757 & 50.5415 & 2429.22 & 1215.113 \\
\hline $\mathrm{P}$ & 197.1285 & 99.0679 & 2330.151 & 1165.579 \\
\hline $\mathrm{Y}$ & 360.1918 & 180.5995 & 2233.098 & 1117.053 \\
\hline $\mathrm{V}$ & 459.2602 & 230.1337 & 2070.035 & 1035.521 \\
\hline $\mathrm{A}$ & 530.2973 & 265.6523 & 1970.967 & 985.9869 \\
\hline Q & 658.3559 & 329.6816 & 1899.929 & 950.4684 \\
\hline $\mathrm{E}$ & 787.3985 & 394.2029 & 1771.871 & 886.4391 \\
\hline $\mathrm{I}$ & 900.4825 & 450.7449 & 1642.828 & 821.9178 \\
\hline $\mathrm{Q}$ & 1028.541 & 514.7742 & 1529.744 & 765.3757 \\
\hline $\mathrm{E}$ & 1157.584 & 579.2955 & 1401.686 & 701.3464 \\
\hline $\mathrm{E}$ & 1286.626 & 643.8168 & 1272.643 & 636.8251 \\
\hline $\mathrm{I}$ & 1399.71 & 700.3588 & 1143.6 & 572.3039 \\
\hline $\mathrm{D}$ & 1514.737 & 757.8723 & 1030.516 & 515.7618 \\
\hline $\mathrm{E}$ & 1643.78 & 822.3936 & 915.4894 & 458.2483 \\
\hline $\mathrm{L}$ & 1756.864 & 878.9356 & 786.4468 & 393.7271 \\
\hline $\mathrm{L}$ & 1869.948 & 935.4777 & 673.3628 & 337.185 \\
\hline Q & 1998.007 & 999.5069 & 560.2787 & 280.643 \\
\hline E & 2127.049 & 1064.028 & 432.2201 & 216.6137 \\
\hline Q & 2255.108 & 1128.058 & 303.1775 & 152.0924 \\
\hline $\mathrm{R}$ & 2411.209 & 1206.108 & 175.119 & 88.0631 \\
\hline
\end{tabular}




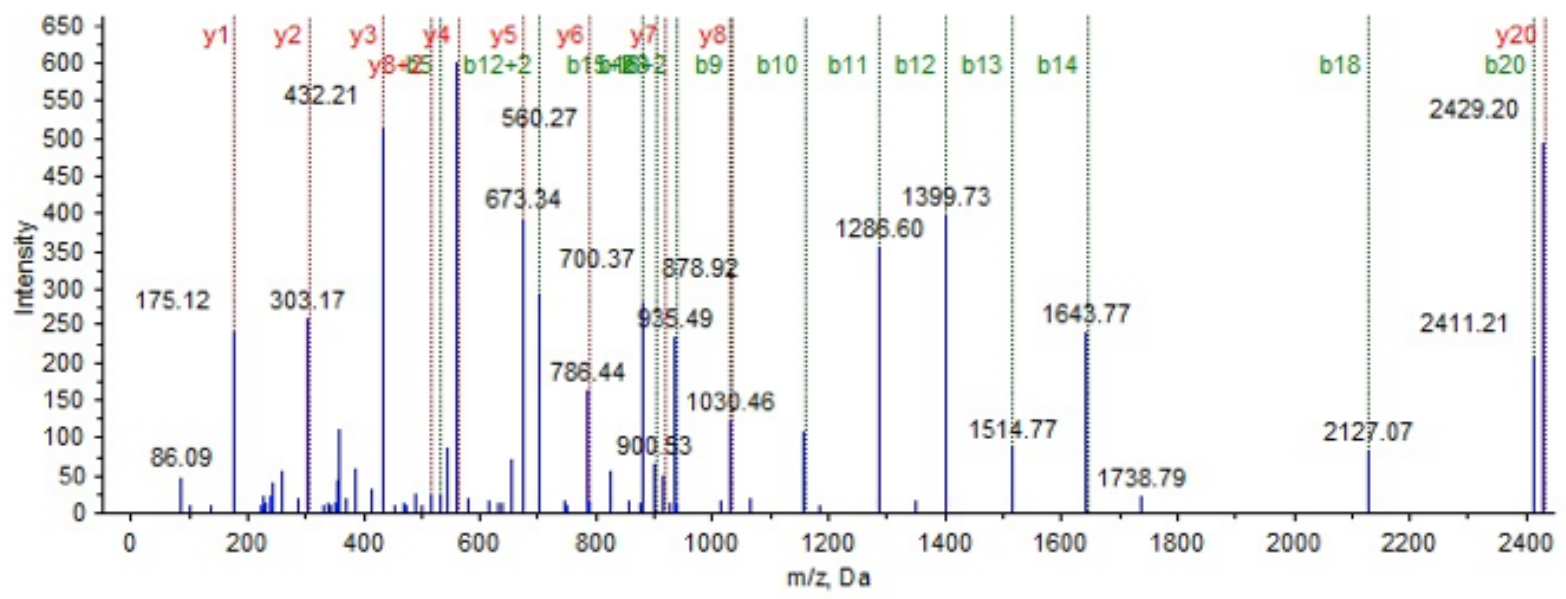

Protein: APLP2; Sample: SW-SFM 05/13

\begin{tabular}{|l|l|l|l|l|}
\hline Residue & $\mathrm{b}$ & $\mathrm{b}+2$ & $\mathrm{y}$ & $\mathrm{y}+2$ \\
\hline $\mathrm{V}$ & 100.076 & 50.5415 & 2429.22 & 1215.11 \\
\hline $\mathrm{P}$ & 197.129 & 99.0679 & 2330.15 & 1165.58 \\
\hline $\mathrm{Y}$ & 360.192 & 180.6 & 2233.1 & 1117.05 \\
\hline $\mathrm{V}$ & 459.26 & 230.134 & 2070.04 & 1035.52 \\
\hline $\mathrm{A}$ & 530.297 & 265.652 & 1970.97 & 985.987 \\
\hline Q & 658.356 & 329.682 & 1899.93 & 950.468 \\
\hline E & 787.399 & 394.203 & 1771.87 & 886.439 \\
\hline $\mathrm{I}$ & 900.483 & 450.745 & 1642.83 & 821.918 \\
\hline $\mathrm{Q}$ & 1028.54 & 514.774 & 1529.74 & 765.376 \\
\hline $\mathrm{E}$ & 1157.58 & 579.296 & 1401.69 & 701.346 \\
\hline E & 1286.63 & 643.817 & 1272.64 & 636.825 \\
\hline $\mathrm{I}$ & 1399.71 & 700.359 & 1143.6 & 572.304 \\
\hline $\mathrm{D}$ & 1514.74 & 757.872 & 1030.52 & 515.762 \\
\hline E & 1643.78 & 822.394 & 915.489 & 458.248 \\
\hline L & 1756.86 & 878.936 & 786.447 & 393.727 \\
\hline L & 1869.95 & 935.478 & 673.363 & 337.185 \\
\hline $\mathrm{Q}$ & 1998.01 & 999.507 & 560.279 & 280.643 \\
\hline E & 2127.05 & 1064.03 & 432.22 & 216.614 \\
\hline $\mathrm{Q}$ & 2255.11 & 1128.06 & 303.178 & 152.092 \\
\hline $\mathrm{R}$ & 2411.21 & 1206.11 & 175.119 & 88.0631 \\
\hline & & & &
\end{tabular}




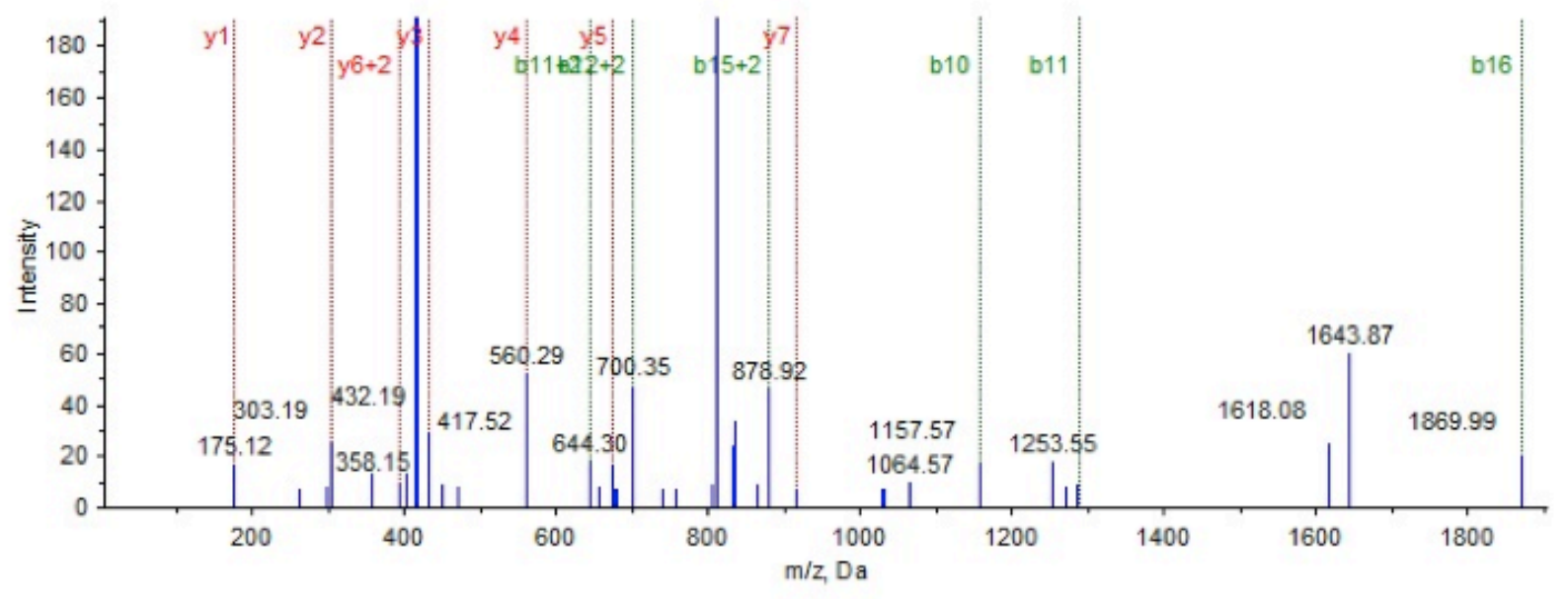

Protein: APP; Sample: SW-SFM 04/27

\begin{tabular}{|l|r|r|r|r|}
\hline Residue & \multicolumn{1}{l|}{$\mathrm{b}$} & $\mathrm{b}+2$ & $\mathrm{y}$ & $\mathrm{y}+2$ \\
\hline L & 114.091 & 57.5493 & 2459.21 & 1230.11 \\
\hline E & 243.134 & 122.071 & 2346.12 & 1173.56 \\
\hline V & 342.202 & 171.605 & 2217.08 & 1109.04 \\
\hline P & 439.255 & 220.131 & 2118.01 & 1059.51 \\
\hline T & 540.303 & 270.655 & 2020.96 & 1010.98 \\
\hline D & 655.33 & 328.169 & 1919.91 & 960.459 \\
\hline G & 712.351 & 356.679 & 1804.88 & 902.945 \\
\hline N & 826.394 & 413.701 & 1747.86 & 874.435 \\
\hline A & 897.431 & 449.219 & 1633.82 & 817.413 \\
\hline G & 954.453 & 477.73 & 1562.78 & 781.895 \\
\hline L & 1067.54 & 534.272 & 1505.76 & 753.384 \\
\hline L & 1180.62 & 590.814 & 1392.68 & 696.842 \\
\hline A & 1251.66 & 626.333 & 1279.59 & 640.3 \\
\hline E & 1380.7 & 690.854 & 1208.56 & 604.781 \\
\hline P & 1477.75 & 739.38 & 1079.51 & 540.26 \\
\hline Q & 1605.81 & 803.41 & 982.46 & 491.734 \\
\hline I & 1718.9 & 859.952 & 854.401 & 427.704 \\
\hline A & 1789.93 & 895.47 & 741.317 & 371.162 \\
\hline M & 1920.97 & 960.99 & 670.28 & 335.644 \\
\hline F & 2068.04 & 1034.52 & 539.24 & 270.123 \\
\hline C[CAM] & 2228.07 & 1114.54 & 392.171 & 196.589 \\
\hline G & 2285.09 & 1143.05 & 232.14 & 116.574 \\
\hline R & 2441.2 & 1221.1 & 175.119 & 88.0631 \\
\hline & & & &
\end{tabular}




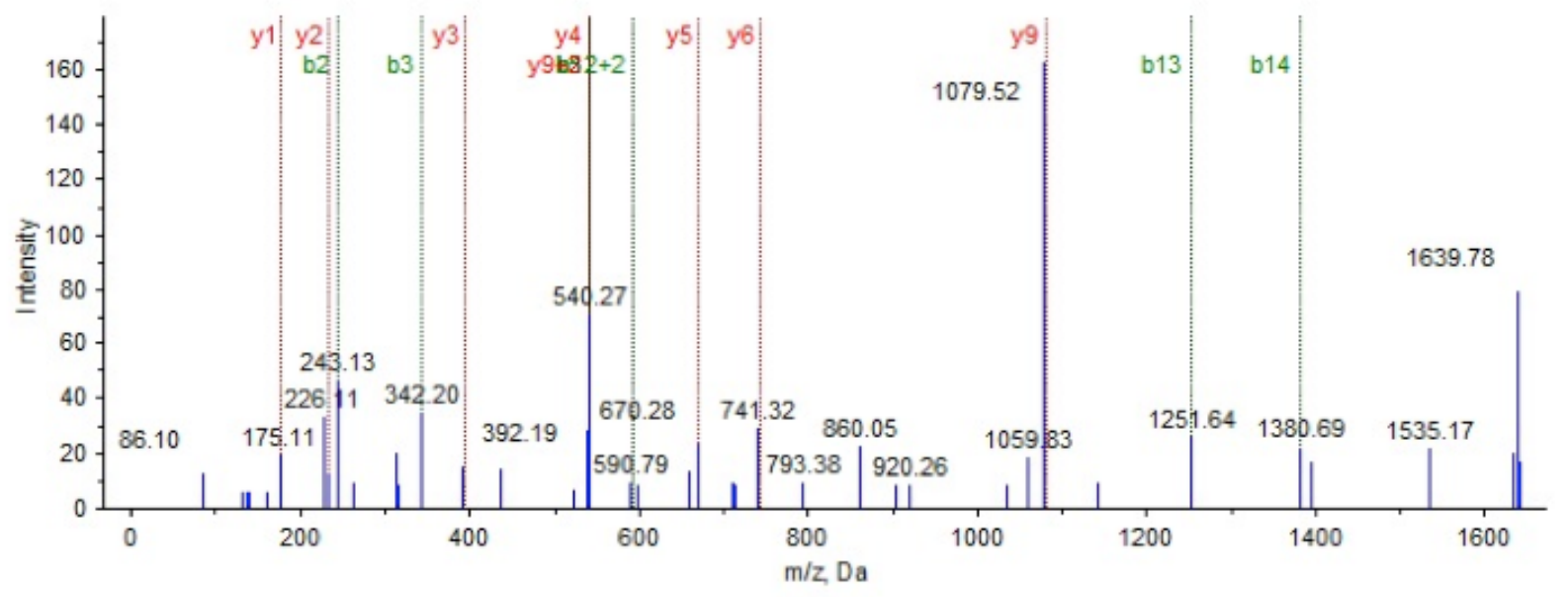

Protein: APP; Sample: SW-SFM 05/13

\begin{tabular}{|l|r|l|l|r|}
\hline Residue & \multicolumn{1}{l|}{$\mathrm{b}$} & $\mathrm{b}+2$ & $\mathrm{y}$ & $\mathrm{y}+2$ \\
\hline $\mathrm{C}[\mathrm{CAM}]$ & 161.038 & 81.0226 & 1761.91 & 881.458 \\
\hline $\mathrm{L}$ & 274.122 & 137.565 & 1601.88 & 801.443 \\
\hline V & 373.19 & 187.099 & 1488.79 & 744.901 \\
\hline $\mathrm{G}$ & 430.212 & 215.61 & 1389.73 & 695.367 \\
\hline $\mathrm{E}$ & 559.255 & 280.131 & 1332.7 & 666.856 \\
\hline F & 706.323 & 353.665 & 1203.66 & 602.335 \\
\hline $\mathrm{V}$ & 805.391 & 403.199 & 1056.59 & 528.8 \\
\hline S & 892.423 & 446.715 & 957.525 & 479.266 \\
\hline $\mathrm{D}$ & 1007.45 & 504.229 & 870.493 & 435.75 \\
\hline A & 1078.49 & 539.747 & 755.466 & 378.237 \\
\hline L & 1191.57 & 596.289 & 684.429 & 342.718 \\
\hline L & 1304.66 & 652.831 & 571.345 & 286.176 \\
\hline V & 1403.72 & 702.366 & 458.261 & 229.634 \\
\hline P & 1500.78 & 750.892 & 359.193 & 180.1 \\
\hline D & 1615.8 & 808.405 & 262.14 & 131.574 \\
\hline K & 1743.9 & 872.453 & 147.113 & 74.06 \\
\hline
\end{tabular}




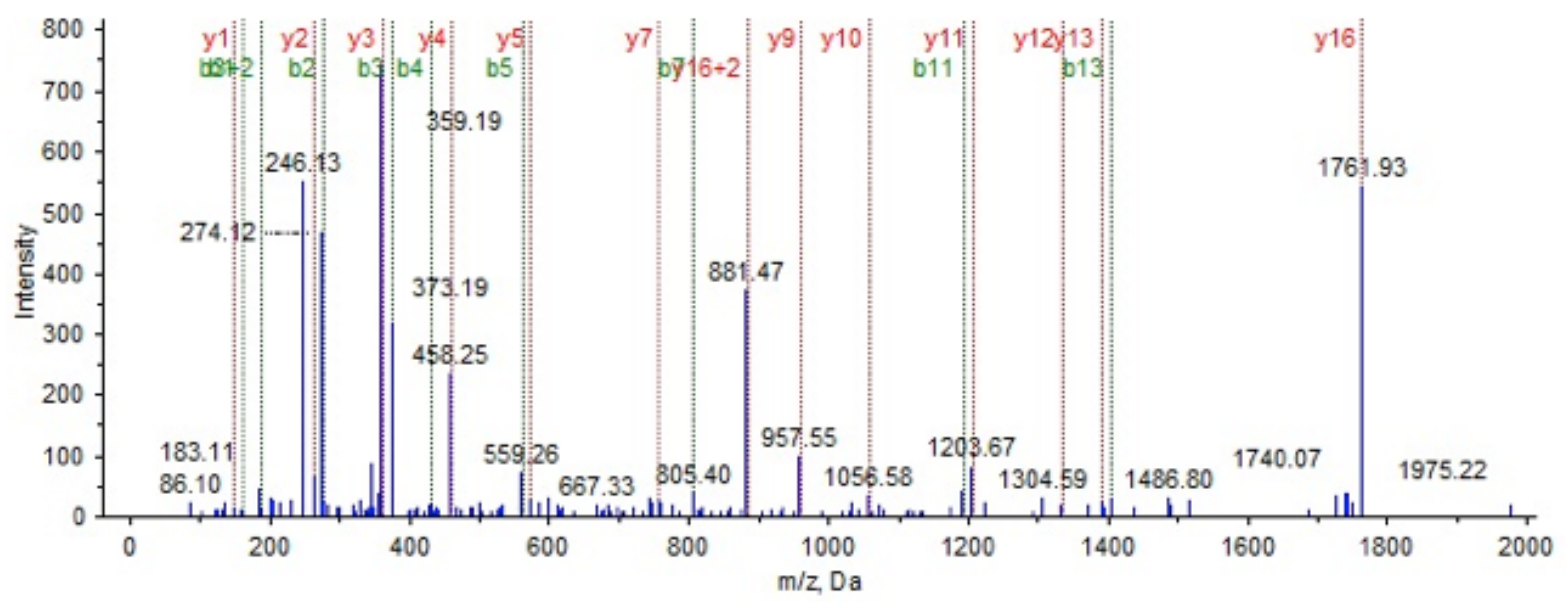

Protein: AXL; Sample: BCPAP-SFM 05/17

\begin{tabular}{|l|r|r|r|r|}
\hline Residue & \multicolumn{1}{l|}{$\mathrm{b}$} & $\mathrm{b}+2$ & $\mathrm{y}$ & $\mathrm{y}+2$ \\
\hline A & 72.0444 & 36.5258 & 1188.67 & 594.84 \\
\hline P & 169.097 & 85.0522 & 1117.64 & 559.322 \\
\hline L & 282.181 & 141.594 & 1020.58 & 510.796 \\
\hline Q & 410.24 & 205.624 & 907.5 & 454.253 \\
\hline G & 467.261 & 234.134 & 779.441 & 390.224 \\
\hline T & 568.309 & 284.658 & 722.42 & 361.713 \\
\hline L & 681.393 & 341.2 & 621.372 & 311.19 \\
\hline L & 794.477 & 397.742 & 508.288 & 254.648 \\
\hline G & 851.499 & 426.253 & 395.204 & 198.106 \\
\hline Y & 1014.56 & 507.785 & 338.182 & 169.595 \\
\hline R & 1170.66 & 585.835 & 175.119 & 88.0631 \\
\hline
\end{tabular}




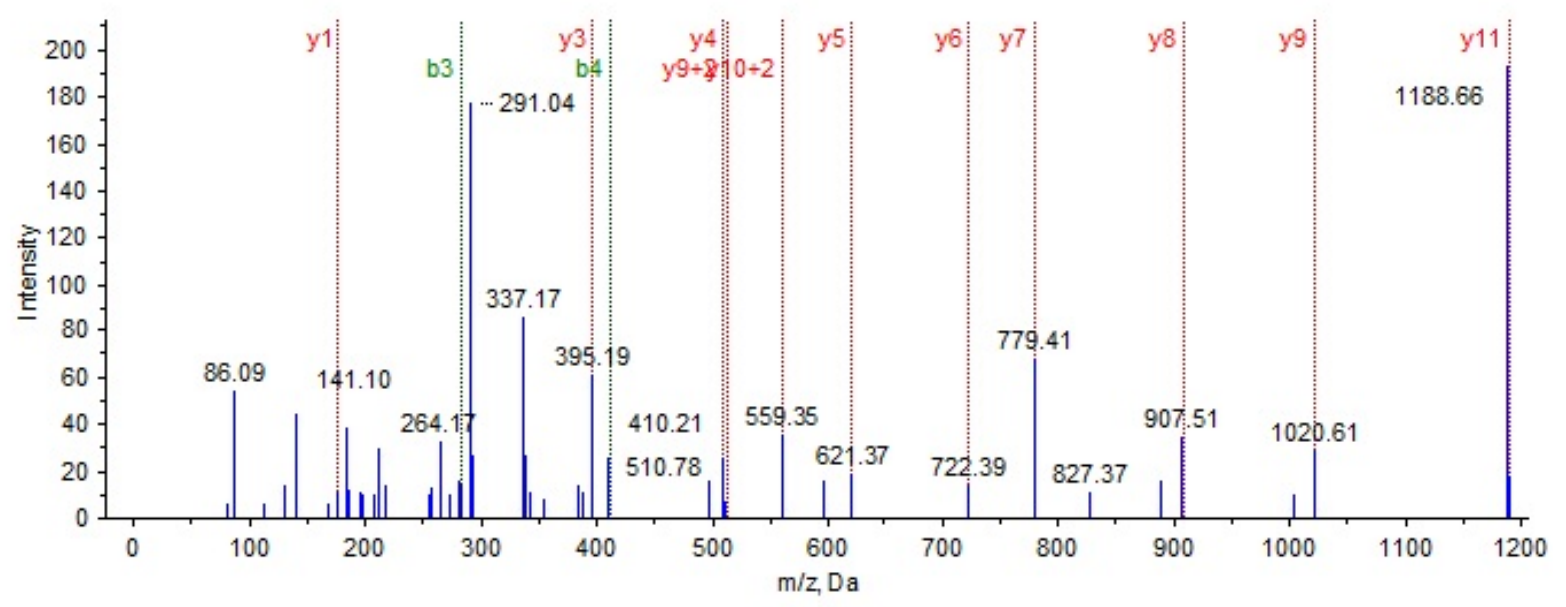

Protein: AXL; Sample: SW-SFM 04/27

\begin{tabular}{|l|r|r|r|l|}
\hline Residue & \multicolumn{1}{l|}{$\mathrm{b}$} & $\mathrm{b}+2$ & $\mathrm{y}$ & $\mathrm{y}+2$ \\
\hline L & 114.091 & 57.5493 & 2019.02 & 1010.01 \\
\hline $\mathrm{A}$ & 185.129 & 93.0679 & 1905.94 & 953.472 \\
\hline Y & 348.192 & 174.6 & 1834.9 & 917.954 \\
\hline Q & 476.25 & 238.629 & 1671.84 & 836.422 \\
\hline G & 533.272 & 267.14 & 1543.78 & 772.393 \\
\hline Q & 661.33 & 331.169 & 1486.76 & 743.882 \\
\hline D & 776.357 & 388.682 & 1358.7 & 679.853 \\
\hline T & 877.405 & 439.206 & 1243.67 & 622.339 \\
\hline P & 974.458 & 487.733 & 1142.62 & 571.816 \\
\hline E & 1103.5 & 552.254 & 1045.57 & 523.289 \\
\hline V & 1202.57 & 601.788 & 916.528 & 458.768 \\
\hline L & 1315.65 & 658.33 & 817.46 & 409.234 \\
\hline M & 1446.69 & 723.85 & 704.376 & 352.692 \\
\hline D & 1561.72 & 781.364 & 573.336 & 287.171 \\
\hline I & 1674.8 & 837.906 & 458.309 & 229.658 \\
\hline G & 1731.83 & 866.417 & 345.225 & 173.116 \\
\hline L & 1844.91 & 922.959 & 288.203 & 144.605 \\
\hline R & 2001.01 & 1001.01 & 175.119 & 88.0631 \\
\hline
\end{tabular}






Protein: AXL; Sample: SW-SFM 05/13

\begin{tabular}{|l|r|r|r|r|}
\hline Residue & \multicolumn{1}{l|}{$\mathrm{b}$} & $\mathrm{b}+2$ & $\mathrm{y}$ & $\mathrm{y}+2$ \\
\hline $\mathrm{A}$ & 72.0444 & 36.5258 & 1188.67 & 594.84 \\
\hline $\mathrm{P}$ & 169.097 & 85.0522 & 1117.64 & 559.322 \\
\hline L & 282.181 & 141.594 & 1020.58 & 510.796 \\
\hline Q & 410.24 & 205.624 & 907.5 & 454.253 \\
\hline G & 467.261 & 234.134 & 779.441 & 390.224 \\
\hline T & 568.309 & 284.658 & 722.42 & 361.713 \\
\hline L & 681.393 & 341.2 & 621.372 & 311.19 \\
\hline L & 794.477 & 397.742 & 508.288 & 254.648 \\
\hline G & 851.499 & 426.253 & 395.204 & 198.106 \\
\hline Y & 1014.56 & 507.785 & 338.182 & 169.595 \\
\hline R & 1170.66 & 585.835 & 175.119 & 88.0631 \\
\hline
\end{tabular}

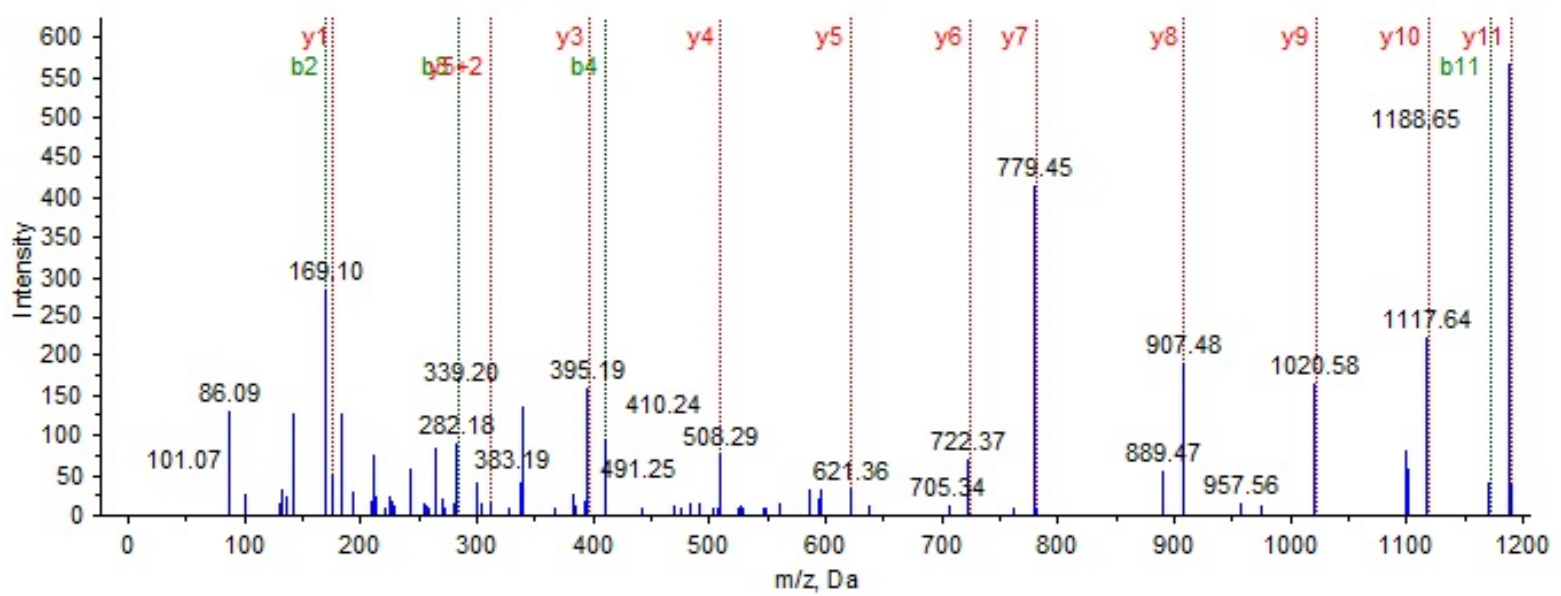


Protein: hnRNPK; Sample: C643-SFM

\begin{tabular}{|l|r|r|r|r|}
\hline Residue & \multicolumn{1}{l|}{$\mathrm{b}$} & $\mathrm{l}+2$ & $\mathrm{y}$ & $\mathrm{y}+2$ \\
\hline $\mathrm{I}$ & 114.091 & 57.5493 & 1340.8 & 670.905 \\
\hline $\mathrm{I}$ & 227.175 & 114.091 & 1227.72 & 614.363 \\
\hline L & 340.26 & 170.633 & 1114.64 & 557.821 \\
\hline $\mathrm{D}$ & 455.286 & 228.147 & 1001.55 & 501.279 \\
\hline $\mathrm{L}$ & 568.371 & 284.689 & 886.524 & 443.766 \\
\hline $\mathrm{I}$ & 681.455 & 341.231 & 773.44 & 387.224 \\
\hline S & 768.487 & 384.747 & 660.356 & 330.682 \\
\hline E & 897.529 & 449.268 & 573.324 & 287.166 \\
\hline S & 984.561 & 492.784 & 444.282 & 222.645 \\
\hline P & 1081.61 & 541.311 & 357.25 & 179.129 \\
\hline $\mathrm{I}$ & 1194.7 & 597.853 & 260.197 & 130.602 \\
\hline K & 1322.79 & 661.9 & 147.113 & 74.06 \\
\hline
\end{tabular}

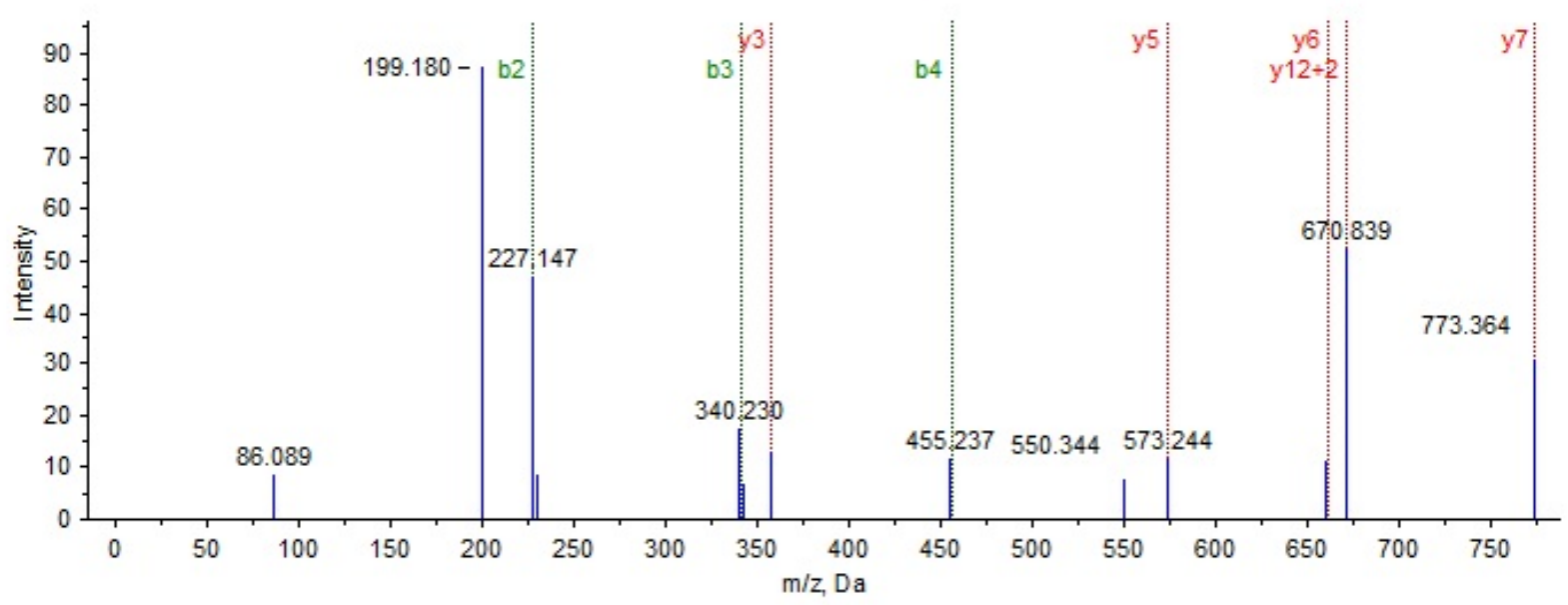


Protein: hnRNPK; Sample: SW-SFM 04/27

\begin{tabular}{|l|l|r|r|r|}
\hline Residue & $\mathrm{b}$ & $\mathrm{b}+2$ & $\mathrm{y}$ & $\mathrm{y}+2$ \\
\hline $\mathrm{I}$ & 114.091 & 57.5493 & 1714.98 & 857.996 \\
\hline $\mathrm{L}$ & 227.175 & 114.091 & 1601.9 & 801.454 \\
\hline $\mathrm{S}$ & 314.207 & 157.607 & 1488.82 & 744.911 \\
\hline $\mathrm{I}$ & 427.292 & 214.149 & 1401.78 & 701.395 \\
\hline $\mathrm{S}$ & 514.324 & 257.665 & 1288.7 & 644.853 \\
\hline $\mathrm{A}$ & 585.361 & 293.184 & 1201.67 & 601.337 \\
\hline $\mathrm{D}$ & 700.388 & 350.697 & 1130.63 & 565.819 \\
\hline $\mathrm{I}$ & 813.472 & 407.24 & 1015.6 & 508.305 \\
\hline $\mathrm{E}$ & 942.514 & 471.761 & 902.519 & 451.763 \\
\hline $\mathrm{T}$ & 1043.56 & 522.285 & 773.477 & 387.242 \\
\hline $\mathrm{I}$ & 1156.65 & 578.827 & 672.429 & 336.718 \\
\hline $\mathrm{G}$ & 1213.67 & 607.337 & 559.345 & 280.176 \\
\hline $\mathrm{E}$ & 1342.71 & 671.859 & 502.324 & 251.665 \\
\hline $\mathrm{I}$ & 1455.79 & 728.401 & 373.281 & 187.144 \\
\hline L & 1568.88 & 784.943 & 260.197 & 130.602 \\
\hline $\mathrm{K}$ & 1696.97 & 848.99 & 147.113 & 74.06 \\
\hline
\end{tabular}




Protein: PGK1; Sample: C643-SFM

\begin{tabular}{|l|r|r|l|r|}
\hline Residue & \multicolumn{1}{l|}{$\mathrm{b}$} & $\mathrm{b}+2$ & $\mathrm{y}$ & $\mathrm{y}+2$ \\
\hline $\mathrm{V}$ & 100.076 & 50.5415 & 1097.62 & 549.314 \\
\hline L & 213.16 & 107.084 & 998.552 & 499.78 \\
\hline $\mathrm{P}$ & 310.213 & 155.61 & 885.468 & 443.237 \\
\hline $\mathrm{G}$ & 367.234 & 184.121 & 788.415 & 394.711 \\
\hline $\mathrm{V}$ & 466.302 & 233.655 & 731.393 & 366.2 \\
\hline $\mathrm{D}$ & 581.329 & 291.168 & 632.325 & 316.666 \\
\hline $\mathrm{A}$ & 652.367 & 326.687 & 517.298 & 259.153 \\
\hline L & 765.451 & 383.229 & 446.261 & 223.634 \\
\hline S & 852.483 & 426.745 & 333.177 & 167.092 \\
\hline $\mathrm{N}$ & 966.526 & 483.766 & 246.145 & 123.576 \\
\hline $\mathrm{I}$ & 1079.61 & 540.308 & 132.102 & 66.5546 \\
\hline
\end{tabular}




Protein: PKM2; Sample: C643-SFM

\begin{tabular}{|l|l|l|r|r|}
\hline Residue & $\mathrm{b}$ & $\mathrm{b}+2$ & $\mathrm{y}$ & $\mathrm{y}+2$ \\
\hline A & 72.0444 & 36.5258 & 840.53 & 420.769 \\
\hline $\mathrm{P}$ & 169.097 & 85.0522 & 769.493 & 385.25 \\
\hline $\mathrm{I}$ & 282.181 & 141.594 & 672.44 & 336.724 \\
\hline $\mathrm{I}$ & 395.265 & 198.136 & 559.356 & 280.182 \\
\hline A & 466.302 & 233.655 & 446.272 & 223.64 \\
\hline V & 565.371 & 283.189 & 375.235 & 188.121 \\
\hline T & 666.419 & 333.713 & 276.167 & 138.587 \\
\hline R & 822.52 & 411.763 & 175.119 & 88.0631 \\
\hline
\end{tabular}




Protein: PKM2; Sample: SW-SFM 04/27

\begin{tabular}{|l|r|l|r|r|}
\hline Residue & \multicolumn{1}{|l|}{$\mathrm{b}$} & $\mathrm{b}+2$ & $\mathrm{y}$ & $\mathrm{y}+2$ \\
\hline $\mathrm{F}$ & 148.076 & 74.5415 & 1859.9 & 930.454 \\
\hline $\mathrm{G}$ & 205.097 & 103.052 & 1712.83 & 856.919 \\
\hline V & 304.166 & 152.586 & 1655.81 & 828.409 \\
\hline $\mathrm{E}$ & 433.208 & 217.108 & 1556.74 & 778.874 \\
\hline $\mathrm{Q}$ & 561.267 & 281.137 & 1427.7 & 714.353 \\
\hline $\mathrm{D}$ & 676.294 & 338.651 & 1299.64 & 650.324 \\
\hline V & 775.362 & 388.185 & 1184.61 & 592.81 \\
\hline $\mathrm{D}$ & 890.389 & 445.698 & 1085.54 & 543.276 \\
\hline $\mathrm{M}$ & 1021.43 & 511.218 & 970.518 & 485.763 \\
\hline V & 1120.5 & 560.753 & 839.477 & 420.242 \\
\hline F & 1267.57 & 634.287 & 740.409 & 370.708 \\
\hline $\mathrm{A}$ & 1338.6 & 669.805 & 593.341 & 297.174 \\
\hline $\mathrm{S}$ & 1425.64 & 713.321 & 522.304 & 261.655 \\
\hline F & 1572.7 & 786.856 & 435.271 & 218.139 \\
\hline $\mathrm{I}$ & 1685.79 & 843.398 & 288.203 & 144.605 \\
\hline $\mathrm{R}$ & 1841.89 & 921.448 & 175.119 & 88.0631 \\
\hline
\end{tabular}

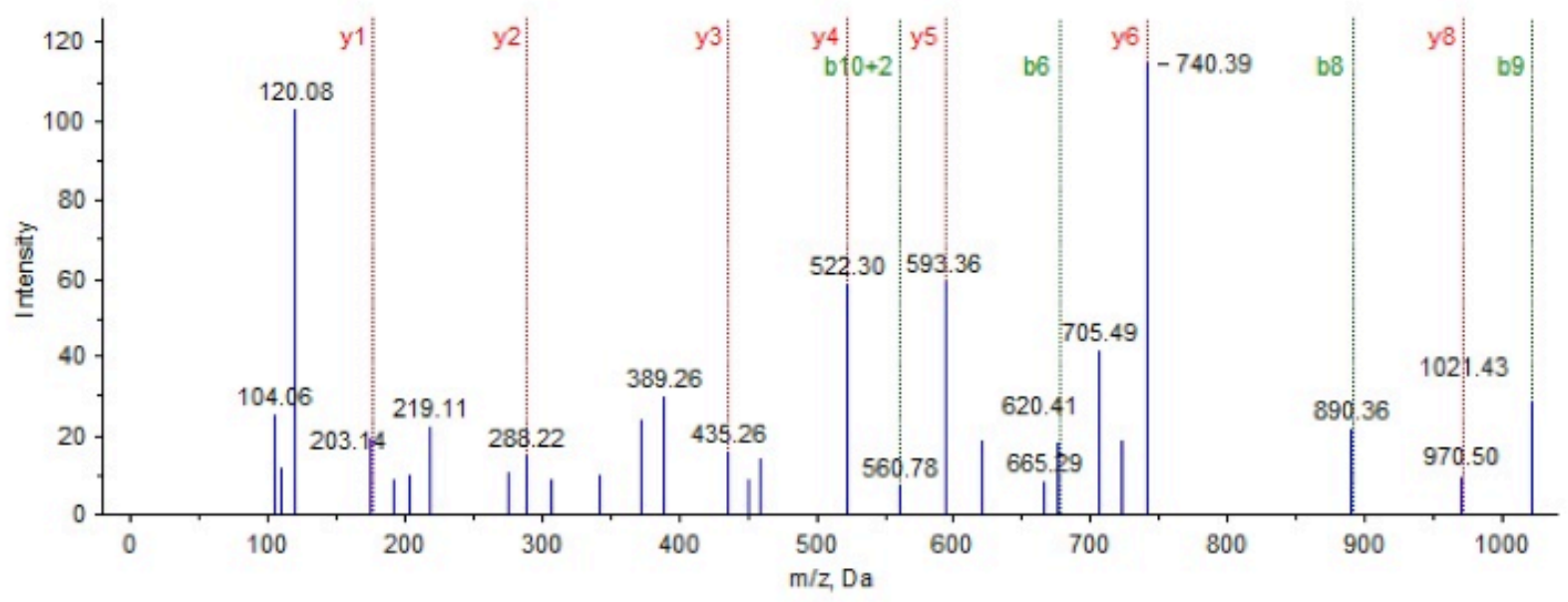


Protein: SET; Sample: SW-SFM 04/27

\begin{tabular}{|l|r|r|r|r|}
\hline Residue & \multicolumn{1}{l|}{$\mathrm{b}$} & $\mathrm{b}+2$ & $\mathrm{y}$ & $\mathrm{y}+2$ \\
\hline I & 114.091 & 57.5493 & 3725.86 & 1863.43 \\
\hline P & 211.144 & 106.076 & 3612.78 & 1806.89 \\
\hline N & 325.187 & 163.097 & 3515.72 & 1758.37 \\
\hline F & 472.255 & 236.631 & 3401.68 & 1701.34 \\
\hline W & 658.335 & 329.671 & 3254.61 & 1627.81 \\
\hline V & 757.403 & 379.205 & 3068.53 & 1534.77 \\
\hline T & 858.451 & 429.729 & 2969.46 & 1485.24 \\
\hline T & 959.499 & 480.253 & 2868.42 & 1434.71 \\
\hline F & 1106.57 & 553.787 & 2767.37 & 1384.19 \\
\hline V & 1205.64 & 603.321 & 2620.3 & 1310.65 \\
\hline N & 1319.68 & 660.343 & 2521.23 & 1261.12 \\
\hline H & 1456.74 & 728.872 & 2407.19 & 1204.1 \\
\hline P & 1553.79 & 777.399 & 2270.13 & 1135.57 \\
\hline Q & 1681.85 & 841.428 & 2173.08 & 1087.04 \\
\hline V & 1780.92 & 890.962 & 2045.02 & 1023.01 \\
\hline S & 1867.95 & 934.478 & 1945.95 & 973.479 \\
\hline A & 1938.99 & 969.997 & 1858.92 & 929.963 \\
\hline L & 2052.07 & 1026.54 & 1787.88 & 894.444 \\
\hline L & 2165.15 & 1083.08 & 1674.8 & 837.902 \\
\hline G & 2222.18 & 1111.59 & 1561.71 & 781.36 \\
\hline E & 2351.22 & 1176.11 & 1504.69 & 752.849 \\
\hline E & 2480.26 & 1240.63 & 1375.65 & 688.328 \\
\hline D & 2595.29 & 1298.15 & 1246.61 & 623.807 \\
\hline E & 2724.33 & 1362.67 & 1131.58 & 566.293 \\
\hline E & 2853.37 & 1427.19 & 1002.54 & 501.772 \\
\hline A & 2924.41 & 1462.71 & 873.494 & 437.251 \\
\hline L & 3037.49 & 1519.25 & 802.457 & 401.732 \\
\hline H & 3174.55 & 1587.78 & 689.373 & 345.19 \\
\hline Y & 3337.62 & 1669.31 & 552.314 & 276.661 \\
\hline L & 3450.7 & 1725.85 & 389.251 & 195.129 \\
\hline T & 3551.75 & 1776.38 & 276.167 & 138.587 \\
\hline R & 3707.85 & 1854.43 & 175.119 & 88.0631 \\
\hline & & & & \\
\hline
\end{tabular}




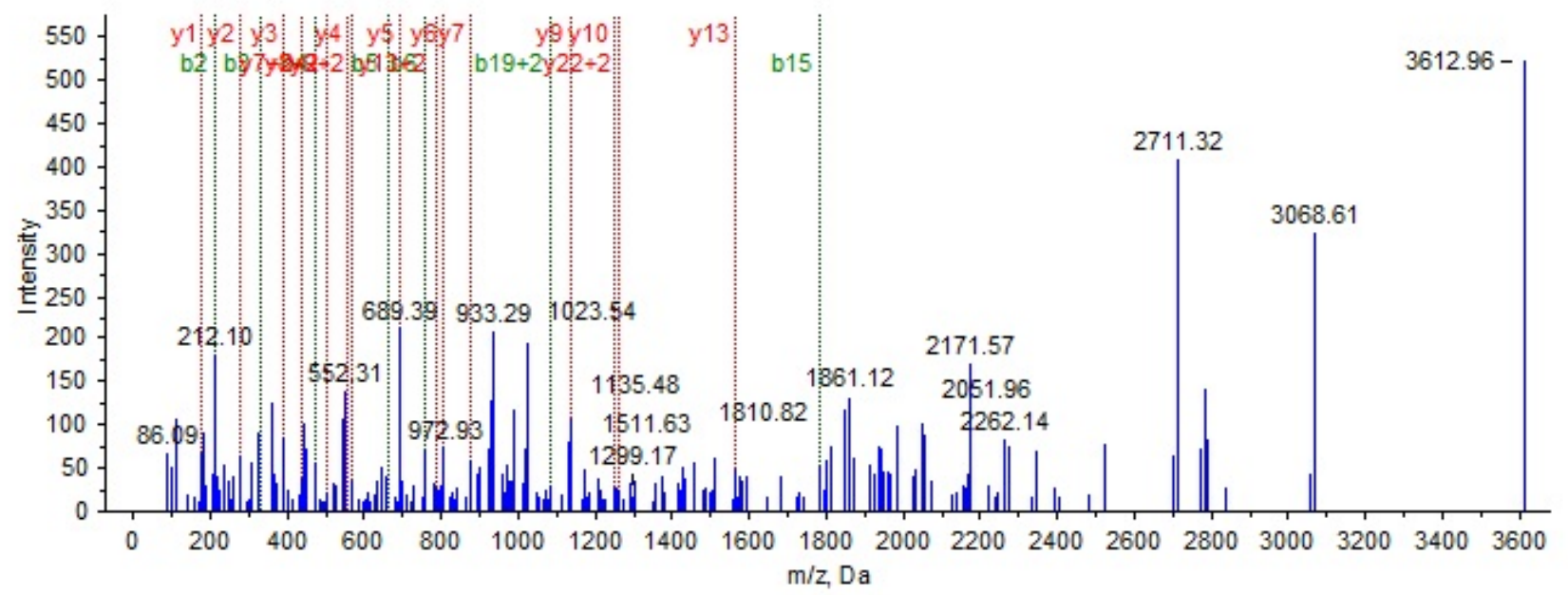

Protein: SET; Sample: SW-SFM 05/13

\begin{tabular}{|l|r|l|r|l|}
\hline Residue & $\mathrm{b}$ & $\mathrm{b}+2$ & $\mathrm{y}$ & $\mathrm{y}+2$ \\
\hline $\mathrm{I}$ & 114.091 & 57.5493 & 1840.81 & 920.907 \\
\hline $\mathrm{D}$ & 229.118 & 115.063 & 1727.72 & 864.365 \\
\hline $\mathrm{F}$ & 376.187 & 188.597 & 1612.7 & 806.851 \\
\hline $\mathrm{Y}$ & 539.25 & 270.129 & 1465.63 & 733.317 \\
\hline $\mathrm{F}$ & 686.318 & 343.663 & 1302.56 & 651.786 \\
\hline $\mathrm{D}$ & 801.345 & 401.176 & 1155.5 & 578.251 \\
\hline $\mathrm{E}$ & 930.388 & 465.698 & 1040.47 & 520.738 \\
\hline $\mathrm{N}$ & 1044.43 & 522.719 & 911.426 & 456.217 \\
\hline $\mathrm{P}$ & 1141.48 & 571.246 & 797.383 & 399.195 \\
\hline $\mathrm{Y}$ & 1304.55 & 652.777 & 700.33 & 350.669 \\
\hline $\mathrm{F}$ & 1451.62 & 726.311 & 537.267 & 269.137 \\
\hline $\mathrm{E}$ & 1580.66 & 790.833 & 390.198 & 195.603 \\
\hline $\mathrm{N}$ & 1694.7 & 847.854 & 261.156 & 131.082 \\
\hline $\mathrm{K}$ & 1822.8 & 911.902 & 147.113 & 74.06 \\
\hline
\end{tabular}






Protein: ALCAM; Sample: BCPAP 04/22

\begin{tabular}{|l|r|r|l|r|}
\hline Residue & $\mathrm{b}$ & $\mathrm{b}+2$ & $\mathrm{y}$ & $\mathrm{y}+2$ \\
\hline $\mathrm{V}$ & 100.0757 & 50.5415 & 1663.031 & 832.0189 \\
\hline $\mathrm{L}$ & 213.1598 & 107.0835 & 1563.962 & 782.4847 \\
\hline $\mathrm{H}$ & 350.2187 & 175.613 & 1450.878 & 725.9427 \\
\hline $\mathrm{P}$ & 447.2714 & 224.1394 & 1313.819 & 657.4132 \\
\hline $\mathrm{L}$ & 560.3555 & 280.6814 & 1216.766 & 608.8868 \\
\hline $\mathrm{E}$ & 689.3981 & 345.2027 & 1103.682 & 552.3448 \\
\hline $\mathrm{G}$ & 746.4196 & 373.7134 & 974.6397 & 487.8235 \\
\hline $\mathrm{A}$ & 817.4567 & 409.232 & 917.6183 & 459.3128 \\
\hline $\mathrm{V}$ & 916.5251 & 458.7662 & 846.5811 & 423.7942 \\
\hline $\mathrm{V}$ & 1015.594 & 508.3004 & 747.5127 & 374.26 \\
\hline $\mathrm{I}$ & 1128.678 & 564.8424 & 648.4443 & 324.7258 \\
\hline $\mathrm{I}$ & 1241.762 & 621.3844 & 535.3602 & 268.1838 \\
\hline $\mathrm{F}$ & 1388.83 & 694.9187 & 422.2762 & 211.6417 \\
\hline $\mathrm{K}$ & 1516.925 & 758.9661 & 275.2078 & 138.1075 \\
\hline $\mathrm{K}$ & 1645.02 & 823.0136 & 147.1128 & 74.06 \\
\hline
\end{tabular}




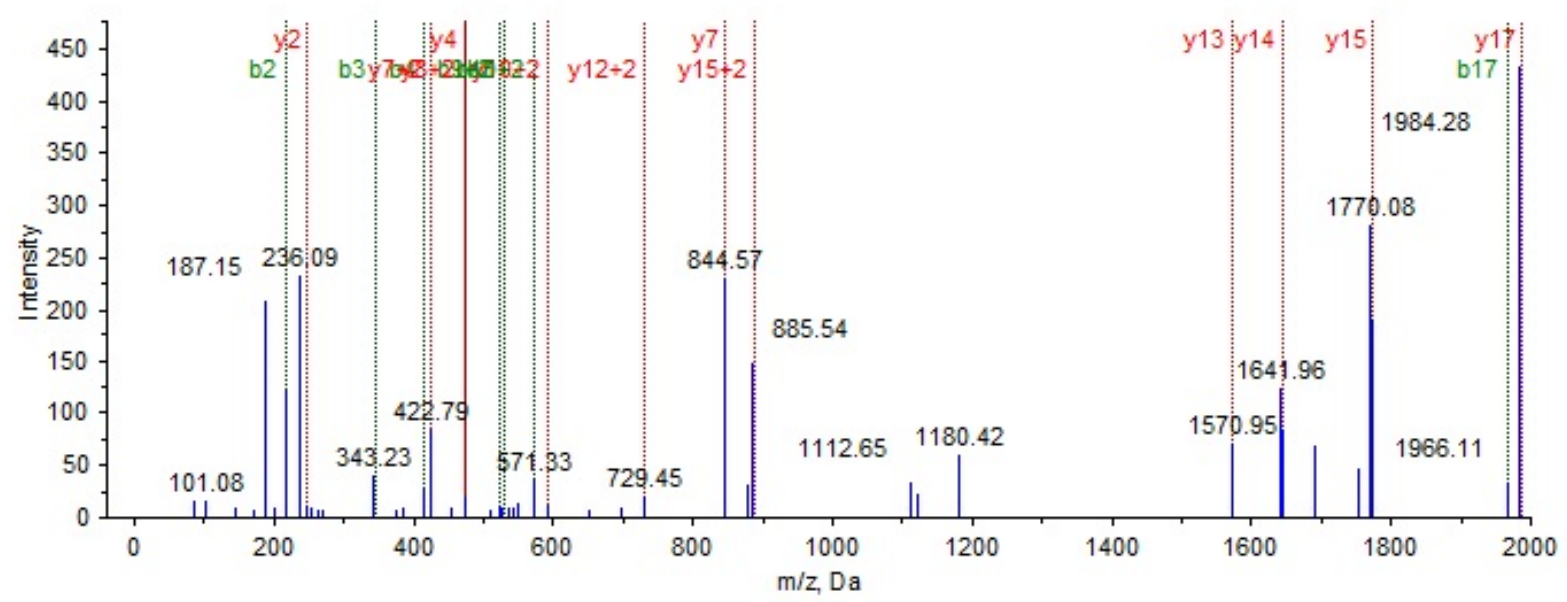




\section{Appendix III}

Supplementary Figure S3 - Representative control Ponceau S stained immunoblot

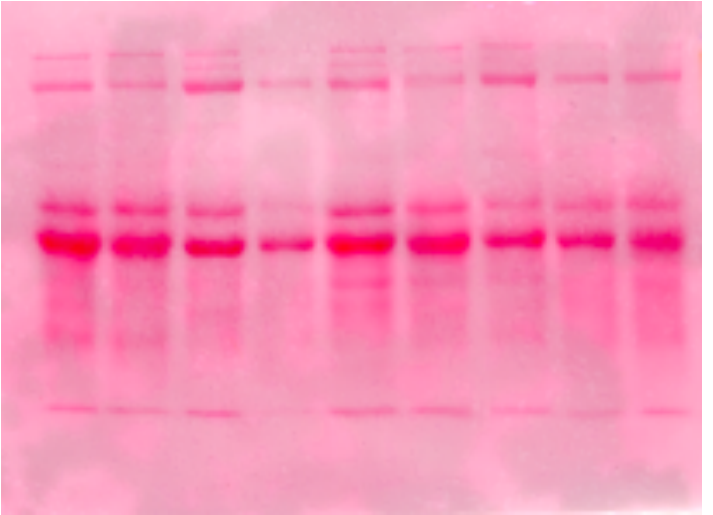




\section{Appendix IV}

Supplementary Table S4 - Outline of patient clinical information for tissues used for immunohistochemistry*

\begin{tabular}{|c|c|c|c|c|c|c|c|c|c|}
\hline $\begin{array}{c}\text { Patient } \\
\#\end{array}$ & Gender & $\begin{array}{c}\text { Age at } \\
\text { Surgery }\end{array}$ & Pathology & $\begin{array}{c}\text { Histological } \\
\text { Variant }\end{array}$ & Grade & $\begin{array}{c}\text { TNM } \\
\text { T }\end{array}$ & $\begin{array}{c}\text { TNM } \\
\text { N }\end{array}$ & $\begin{array}{c}\text { TNM } \\
\text { M }\end{array}$ & $\begin{array}{l}\text { TNM } \\
\text { Stage }\end{array}$ \\
\hline 1 & M & 67 & ATC & $\begin{array}{l}\text { Large cell } \\
\text { undifferentiated } \\
\text { carcinoma }\end{array}$ & PD & 4 & 0 & 1 & IVc \\
\hline 2 & M & 29 & Benign & Multinodular goitre & WD & & & & \\
\hline 3 & $\mathrm{~F}$ & 55 & Benign & Multinodular goitre & WD & & & & \\
\hline 4 & F & 54 & Benign & Hyperplastic nodule & WD & & & & \\
\hline 5 & $\mathrm{~F}$ & 27 & Benign & $\begin{array}{l}\text { Hashimoto's } \\
\text { thyroiditis }\end{array}$ & WD & & & & \\
\hline 6 & $\mathrm{~F}$ & 16 & Benign & Dominant nodule & WD & & & & \\
\hline 7 & $M$ & 56 & Benign & Dominant nodule & WD & & & & \\
\hline 8 & $\mathrm{~F}$ & 34 & Benign & Multinodular goitre & WD & & & & \\
\hline 9 & M & 37 & Benign & Follicular adenoma & WD & & & & \\
\hline 10 & $\mathrm{~F}$ & 76 & Benign & Multinodular goitre & WD & & & & \\
\hline 11 & M & 47 & Benign & $\begin{array}{c}\text { Multiple } \\
\text { colloid/hyperplastic } \\
\text { nodules }\end{array}$ & WD & & & & \\
\hline 12 & $\mathrm{~F}$ & 34 & Benign & $\begin{array}{c}\text { Multiple } \\
\text { colloid/hyperplastic } \\
\text { nodules }\end{array}$ & WD & & & & \\
\hline 13 & F & 65 & Benign & $\begin{array}{c}\text { Hashimoto's } \\
\text { thyroiditis, } \\
\text { Multinodular } \\
\text { hyperplasia }\end{array}$ & WD & & & & \\
\hline 14 & $\mathrm{~F}$ & 53 & Benign & $\begin{array}{c}\text { Multiple } \\
\text { colloid/hyperplastic } \\
\text { nodules }\end{array}$ & WD & & & & \\
\hline 15 & M & 44 & Benign & Colloid nodule & WD & & & & \\
\hline 16 & $\mathrm{~F}$ & 62 & Benign & Grave's Disease & WD & & & & \\
\hline 17 & $\mathrm{~F}$ & 61 & Benign & Multinodular goitre & WD & & & & \\
\hline 18 & M & 61 & Benign & $\begin{array}{c}\text { Multiple } \\
\text { colloid/hyperplastic } \\
\text { nodules }\end{array}$ & WD & & & & \\
\hline 19 & $\mathrm{~F}$ & 38 & Benign & $\begin{array}{c}\text { Hashimoto's } \\
\text { thyroiditis }\end{array}$ & WD & & & & \\
\hline 20 & $\mathrm{~F}$ & 63 & Benign & Nodular hyperplasia & WD & & & & \\
\hline 21 & $\mathrm{~F}$ & 34 & Benign & Multinodular goitre & WD & & & & \\
\hline 22 & $\mathrm{~F}$ & 47 & Benign & Follicular lesion & WD & & & & \\
\hline 23 & $\mathrm{~F}$ & 53 & Benign & Multinodular goitre & WD & & & & \\
\hline 24 & $\mathrm{~F}$ & 45 & Benign & Follicular adenoma & WD & & & & \\
\hline 25 & $\mathrm{M}$ & 76 & Benign & Multinodular goitre & WD & & & & \\
\hline 26 & $\mathrm{~F}$ & 61 & PTC & Classic variant & WD & 4 & $1 \mathrm{~b}$ & 1 & IVc \\
\hline
\end{tabular}




\begin{tabular}{|c|c|c|c|c|c|c|c|c|c|}
\hline 27 & $\mathrm{M}$ & 82 & PTC & Classic variant & WD & 4 & $1 \mathrm{~b}$ & 1 & $\mathrm{IVc}$ \\
\hline 28 & $\mathrm{M}$ & 22 & PTC & Classic variant & WD & 4 & $1 \mathrm{~b}$ & 1 & II \\
\hline 29 & $\mathrm{~F}$ & 56 & PTC & Classic variant & WD & 1 & 0 & 0 & I \\
\hline 30 & $\mathrm{~F}$ & 43 & PTC & Classic variant & WD & 2 & $1 \mathrm{a}$ & 0 & $\mathrm{I}$ \\
\hline 31 & $\mathrm{M}$ & 71 & PTC & Classic variant & WD & & & & \\
\hline 32 & $\mathrm{M}$ & 53 & PTC & Classic variant & WD & 4 & $1 b$ & 1 & $\mathrm{IVc}$ \\
\hline 33 & $\mathrm{~F}$ & 33 & PTC & Classic variant & WD & 1 & $1 \mathrm{a}$ & 0 & $\mathrm{I}$ \\
\hline 34 & $\mathrm{~F}$ & 75 & PTC & Tall Cell & WD & 1 & $1 \mathrm{~b}$ & 0 & $\mathrm{IVa}$ \\
\hline 35 & $\mathrm{~F}$ & 26 & PTC & Classic variant & WD & 4 & $1 \mathrm{~b}$ & 0 & I \\
\hline 36 & $\mathrm{M}$ & 45 & PTC & Classic variant & WD & 4 & $1 \mathrm{a}$ & 0 & IVc \\
\hline 37 & $\mathrm{~F}$ & 44 & PTC & Follicular variant & WD & 1 & $1 \mathrm{a}$ & 0 & I \\
\hline 38 & $\mathrm{~F}$ & 68 & PTC & Follicular variant & WD & 3 & 0 & 0 & III \\
\hline 39 & $\mathrm{~F}$ & 39 & PTC & Classic variant & WD & 1 & 0 & 0 & $\mathrm{I}$ \\
\hline 40 & $\mathrm{~F}$ & 66 & PTC & Classic variant & WD & 3 & $1 \mathrm{~b}$ & 0 & $\mathrm{IVc}$ \\
\hline 41 & $\mathrm{~F}$ & 47 & PTC & Classic variant & WD & 3 & $1 \mathrm{a}$ & 0 & IVc \\
\hline 42 & $\mathrm{~F}$ & 53 & PTC & Follicular Variant & WD & 1 & 0 & 0 & 1 \\
\hline 43 & $\mathrm{M}$ & 55 & PTC & Follicular Variant & WD & 1 & 0 & 0 & $\mathrm{I}$ \\
\hline 44 & $\mathrm{~F}$ & 82 & PTC & Insular & PD & 4 & 0 & 1 & IVc \\
\hline 45 & $\mathrm{~F}$ & 35 & PTC & $\begin{array}{c}\text { Follicular variant, } \\
\text { micro }\end{array}$ & WD & 1 & $1 \mathrm{~b}$ & 0 & I \\
\hline 46 & $\mathrm{~F}$ & 43 & PTC & Oncocytic & WD & 1 & $1 \mathrm{a}$ & 0 & I \\
\hline 47 & $\mathrm{~F}$ & 63 & PTC & $\begin{array}{c}\text { follicular and } \\
\text { insular }\end{array}$ & WD & 2 & 0 & 0 & II \\
\hline 48 & $\mathrm{~F}$ & 66 & PTC & Follicular Variant & WD & 1 & 0 & 0 & $\mathrm{I}$ \\
\hline 49 & $\mathrm{~F}$ & 37 & PTC & Follicular Variant & WD & 2 & 0 & 0 & $\mathrm{I}$ \\
\hline 50 & $\mathrm{M}$ & 28 & PTC & Follicular Variant & WD & 3 & 0 & 0 & $\mathrm{I}$ \\
\hline 51 & $\mathrm{M}$ & 52 & PTC & Classic variant & WD & 3 & $1 \mathrm{~b}$ & 0 & $\mathrm{IVc}$ \\
\hline 52 & $\mathrm{~F}$ & 36 & PTC & Follicular variant & WD & 1 & 0 & 0 & I \\
\hline 53 & $\mathrm{~F}$ & 64 & PTC & Follicular variant & WD & 1 & 0 & 0 & $\mathrm{I}$ \\
\hline 54 & $\mathrm{~F}$ & 38 & PTC & Classic variant & WD & 1 & $1 \mathrm{a}$ & 0 & I \\
\hline
\end{tabular}

UD: undifferentiated , PD: poorly-differentiated, WD: well-differentiated

* ALCAM patient information provided in table in main thesis text 


\section{Appendix V}

Supplementary Figure S5 - Receiver operating curve analyses of protein expression in benign versus malignant thyroid tissues. Green diagonal lines represent reference lines.




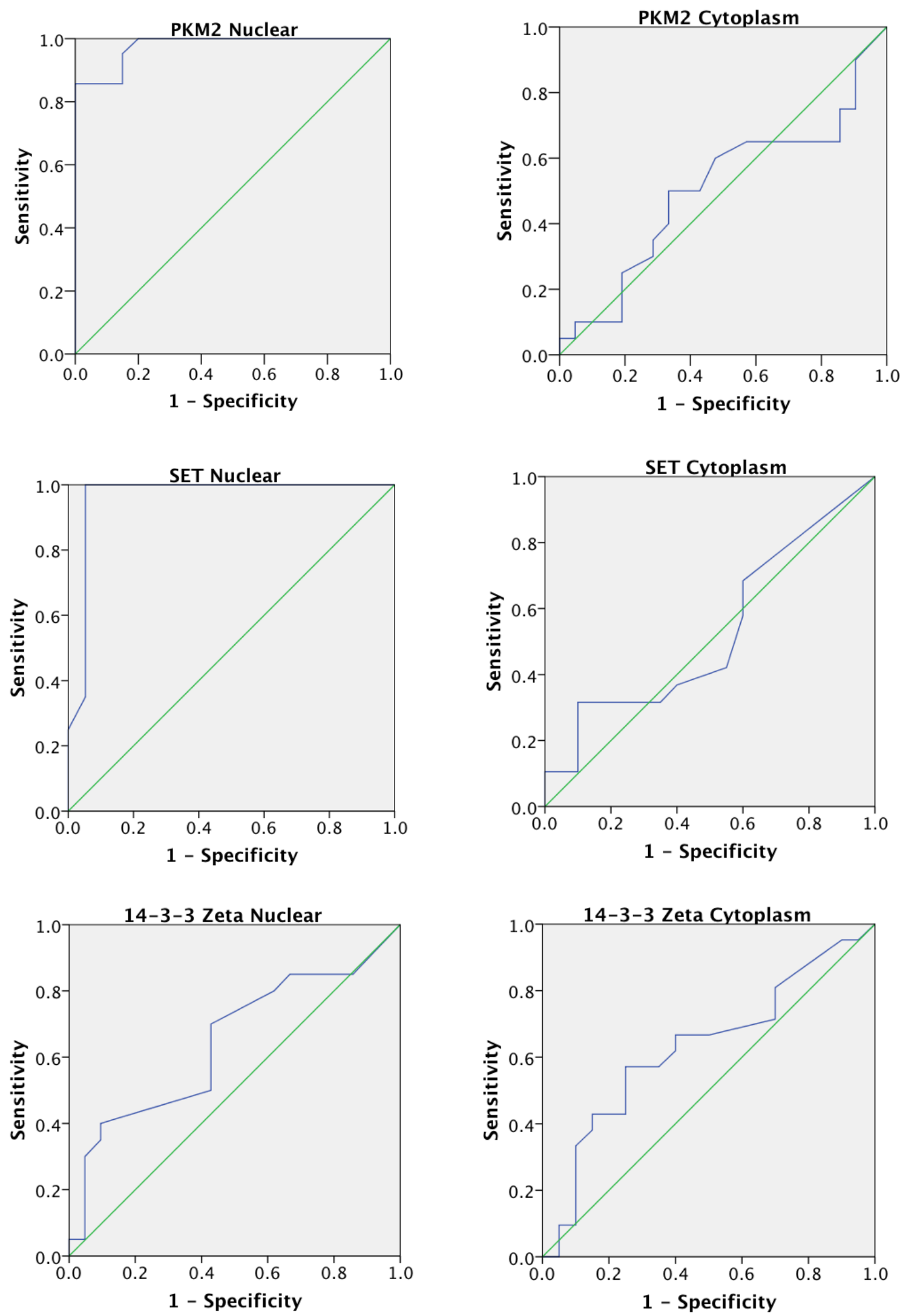


\section{Appendix VI}

Supplementary Figure S6 - Detailed analyses of protein expression in benign versus malignant thyroid tissues

\begin{tabular}{|c|c|c|c|c|c|c|c|c|c|c|c|c|}
\hline \multirow{2}{*}{ Protein } & \multicolumn{6}{|c|}{ Nuclear Expression } & \multicolumn{6}{|c|}{ Cytoplasmic Expression } \\
\hline & $\begin{array}{c}p \\
\text { value }\end{array}$ & AUC & $\begin{array}{l}\text { Sen } \\
(\%)\end{array}$ & $\begin{array}{l}\text { Spe } \\
(\%)\end{array}$ & $\begin{array}{r}\text { PPV } \\
(\%)\end{array}$ & $\begin{array}{l}\text { NPV } \\
(\%)\end{array}$ & $\begin{array}{c}p \\
\text { value }\end{array}$ & $\mathbf{A U C}$ & $\begin{array}{l}\text { Sen } \\
(\%) \\
\end{array}$ & $\begin{array}{l}\text { Spe } \\
(\%) \\
\end{array}$ & $\begin{array}{r}\text { PPV } \\
(\%) \\
\end{array}$ & $\begin{array}{l}\text { NPV } \\
(\%) \\
\end{array}$ \\
\hline$A P L P 2$ & 1.000 & 0.606 & 65 & 35 & 50 & 50 & 0.044 & 0.555 & 95 & 35 & 59.4 & 87.5 \\
\hline$A P P$ & $<0.001$ & 0.937 & 63.2 & 100 & 100 & 75 & 0.745 & 0.605 & 66.7 & 42.1 & 56 & 53.3 \\
\hline$A X L$ & $<0.001$ & 0.995 & 100 & 90 & 90.9 & 100 & 0.001 & 0.788 & 80 & 73.9 & 72.7 & 81 \\
\hline$h n R N P K$ & $<0.001$ & 0.962 & 100 & 43 & 54.2 & 80 & 0.002 & 0.816 & 75 & 69.2 & 55.6 & 84.4 \\
\hline$P G K 1$ & $<0.001$ & 0.926 & 100 & 61.9 & 71.4 & 100 & $<0.001$ & 0.950 & 100 & 57.1 & 69 & 100 \\
\hline$P K M 2$ & $<0.001$ & 0.977 & 85.7 & 100 & 100 & 87 & 0.350 & 0.507 & 50 & 33.3 & 41.2 & 41.7 \\
\hline SET & $<0.001$ & 0.963 & 100 & 73.7 & 80 & 100 & 0.480 & 0.528 & 31.6 & 80 & 60 & 55.2 \\
\hline $\begin{array}{c}\text { 14-3-3 } \\
\text { zeta }\end{array}$ & 0.067 & 0.644 & 35 & 90.5 & 77.8 & 59.4 & 0.058 & 0.630 & 57.1 & 75 & 70.6 & 62.5 \\
\hline
\end{tabular}

AUC, area-under-curve; sen, sensitivity; spe, specificity; PPV, positive predictive value; NPV, negative predictive value

IHC positivity score cut-offs are as follows:

APLP2 nuclear $=5$, cytoplasmic $=5$

APP nuclear $=2$, cytoplasmic $=4.2$

AXL nuclear $=4.7$, cytoplasmic $=3$

hnRNP K nuclear $=5.2$, cytoplasmic $=3$

PGK1 nuclear $=5.1$, cytoplasmic $=5.3$

PKM2 nuclear $=3.5$, cytoplasmic $=3.3$

SET nuclear $=5.5$, cytoplasmic $=2$

14-3-3 zeta nuclear $=1$, cytoplasmic $=2.4$ 


\section{Appendix VII}

Supplementary Figure S7 - Combined ALCAM and AXL sera expression in relation to clinico-pathological parameters using ELISA

\begin{tabular}{|l|c|c|c|c|}
\hline $\begin{array}{l}\text { Clinicopathological } \\
\text { Parameter }\end{array}$ & $\begin{array}{c}\text { Total } \\
\text { Cases }\end{array}$ & $\begin{array}{c}\text { s-AXL \& } \\
\text { ALCAM } \\
\text { positivity, N (\%) }\end{array}$ & $p$ & 95\% CI \\
\hline Pathology & & & & \\
\hline Benign & 39 & $12(31)$ & 1.000 & $0.428-2.759$ \\
\hline Cancer & 43 & $14(33)$ & & \\
\hline PTC Aggressiveness & & & & \\
\hline Non-aggressive & 28 & $7(25)$ & 0.184 & $0.696-9-895$ \\
\hline Aggressive & 15 & $7(47)$ & & \\
\hline Histotype & & & & \\
\hline Classic PTC & 20 & $5(25)$ & 0.869 & \\
\hline Follicular PTC & 16 & $6(38)$ & & \\
\hline Tall cell PTC & 2 & $1(50)$ & & \\
\hline Oncocytic PTC & 3 & $1(33)$ & & \\
\hline $\begin{array}{l}\text { Diffuse sclerosing } \\
\text { PTC }\end{array}$ & 3 & $2(67)$ & & \\
\hline AJCC Stage & & & & \\
\hline I & 34 & $10(29)$ & 0.547 & \\
\hline II & 4 & $1(25)$ & & \\
\hline III & 2 & $1(50)$ & & \\
\hline IV & 2 & $2(100)$ & & \\
\hline LN metastasis & 32 & $7(22)$ & $\mathbf{0 . 0 2 2}$ & $1.413-27.653$ \\
\hline Absent & 11 & $7(64)$ & & \\
\hline Present & & & & \\
\hline Extrathyroidal \\
Extension
\end{tabular}

